Florida International University FIU Digital Commons

10-23-1995

\title{
The effects of an augmented art curriculum on the attitudes of high school art students toward diversity in art
}

Azalea Aluija Alvarez

Florida International University

DOI: $10.25148 /$ etd.FI13101614

Follow this and additional works at: https://digitalcommons.fiu.edu/etd

Part of the Education Commons

\section{Recommended Citation}

Alvarez, Azalea Aluija, "The effects of an augmented art curriculum on the attitudes of high school art students toward diversity in art" (1995). FIU Electronic Theses and Dissertations. 1118.

https://digitalcommons.fiu.edu/etd/1118

This work is brought to you for free and open access by the University Graduate School at FIU Digital Commons. It has been accepted for inclusion in FIU Electronic Theses and Dissertations by an authorized administrator of FIU Digital Commons. For more information, please contact dcc@fiu.edu. 


\title{
FLORIDA INTERNATIONAL UNIVERSITY
}

\author{
Miami, Florida
}

\section{EFFECTS OF AN AUGMENTED ART CURRICULUM ON THE ATTITUDES OF HIGH SCHOOL ART STUDENTS TOWARD DIVERSITY IN ART}

\begin{abstract}
A dissertation submitted in partial satisfaction of the requirements for the degree Doctor of Education in Curriculum and Instruction

by

Azalea Aluija Alvarez
\end{abstract}

1995 
To: Dean Ira Goldenberg

College of Education

This dissertation, written by Azalea Aluija Alvarez, and entitled EFFECTS OF AN AUGMENTED ART CURRICULUM ON THE ATTITUDES OF HIGH SCHOOL ART STUDENTS TOWARD DIVERSITY IN ART, having been approved in respect to style and intellectual content, is referred to you for judgment.

We have read this dissertation and recommend that it be approved.

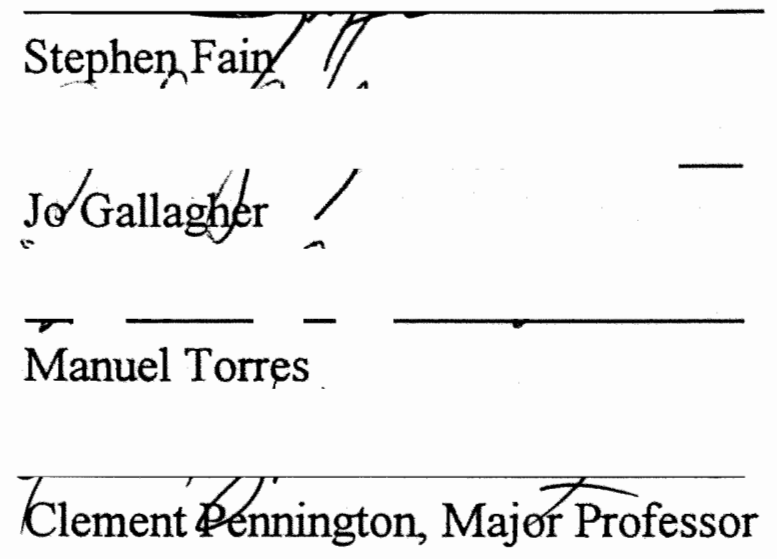

Date of Defense: October 23, 1995

The dissertation of Azalea Aluija Alvare

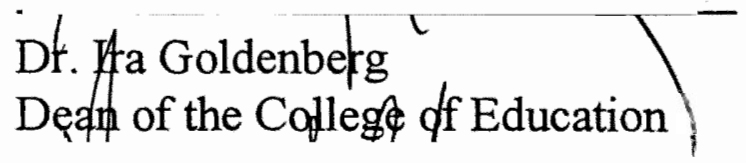

Dr. Richard Campbell

Dean of Graduate Studies

Florida International University, 1995 
(C)OPYRIGHT 1995 by Azalea Aluija Alvarez

All rights reserved 


\section{DEDICATION}

I dedicate this dissertation to my family, for their understanding and patience. To my parents, Emilio and Amada Aluija who taught me to value education and instilled in me a love of learning that enabled me to persevere on the road to achieving this goal. To my husband who was supportive and attentive even when I was not at my most coherent. To my daughter Monica, adventurous and wise beyond her years, who showed me by her example that you can be anything you want to be, if you really want it badly enough. To my daughter Leticia whose curiosity about other cultures helped to remind me why this work was important. And finally, to my son Carlos who put up with having a mother who was at times as busy with her own school work as he was with his. 


\section{ACKNOWLEDGMENTS}

I wish to thank the members of my committee for their invaluable assistance during the dissertation process. I would also like to thank Dr. Lorraine Gay for being my 'voice in the wilderness'. When I was lost, hers was the reassuring and confident voice that would show me the way. Thanks are also extended to Dr. Paulette Johnson and Dr. Paul Rendulic who helped me to navigate through a sea of statistics and enabled me to present my results in a coherent fashion. Special thanks to Leticia for keeping things running smoothly at home during the dissertation process.

I would especially like to thank (though words hardly suffice to express my gratitude) my major professor, Dr. Clem Pennington. Without his support, encouragement, and good cheer throughout the years, I would not even have undertaken this task. 


\section{ABSTRACT OF THE DISSERTATION \\ EFFECTS OF AN AUGMENTED ART CURRICULUM ON THE \\ ATTITUDES OF HIGH SCHOOL ART STUDENTS TOWARD \\ DIVERSITY IN ART}

by

Azalea Aluija Alvarez

Florida International University, 1995

Miami, Florida

Dr. Clement Pennington, Major Professor

The purpose of this study was to investigate the effects of an augmented art curriculum on high school art students to determine if those receiving it had more positive attitudes toward diversity in art and used diversity in their art more than students receiving traditional instruction. This study was conducted in a South Florida public high school, with beginning art students. Using a posttest-only control group design and ANOVA $(\alpha=.05)$, it was found that students $(\underline{\mathrm{n}}=54)$ receiving an augmented art curriculum did not have significantly higher scores on the Attitudes About Art questionnaire than students $(\underline{\mathrm{n}}=57)$ receiving traditional instruction $\underline{\mathrm{F}}(1,91)=.00, \underline{\mathrm{p}}>.05$. However, using the Checklist of Cultural References in Student Art to evaluate student work it was found that there was a significant teacher effect $\underline{F}(1,30)=14.14, \underline{p}<.05$, curriculum effect $\underline{F}(1,30)=48.59, \underline{p}<.05$, and teacher by curriculum effect $\underline{F}(1,30)=8.09, \underline{p}<.05$ for assignment one, and a significant teacher effect $\underline{\mathrm{F}}(1,32)=8.04, \underline{\mathrm{p}}<.05$ for assignment two. For most of the other assignments the differences though favoring the augmented 
curriculum group, were not statistically significant. It was concluded that an augmented art curriculum did not seem to foster more positive attitudes toward diversity, but in some cases did seem to move students toward incorporating diversity in their own work. 
Chapter

I. Introduction

Background 1

Rationale 4

Statement of the Problem 6

Definitions $\quad 6$

Assumptions and Limitations $\quad 8$

II. Review of Related Literature

$\begin{array}{ll}\text { Cognitive Theories of Learning } & 10\end{array}$

Paradigms for Art Education $\quad 11$

Pedagogical Implications of Diversity in Art Education $\quad 13$

Issues of Aesthetics and Valuing 15

Statement of the Hypotheses 18

III. Method

$\begin{array}{lr}\text { Subjects } & 19\end{array}$

Instruments 20

Experimental Design $\quad 23$

Procedure 25

IV. Results

Hypothesis 1

$\begin{array}{ll}\text { Hypothesis } 2 & 40\end{array}$ 
V. Discussion

Research hypotheses $\quad 51$

Comments on Student and Teacher Performance $\quad 54$

$\begin{array}{ll}\text { VI. Conclusions } & 60\end{array}$

Recommendations $\quad 61$

Research Alternatives 63

References $\quad 65$

Visual References $\quad 71$

Appendixes

A. Instruments

A1. Attitudes About Art Questionnaire 73

A2. Checklist of Cultural References in Student Art 75

B. Sample Teacher Enrichment Materials and

Visual Aids for Culturally Augmented Curriculum

B1. Transparency Master

B2. Transparency Master 78

B3. Transparency Master 79

B4. Transparency Master 80

B5. Handout 81

B6. Transparency depicting Maya art and glyphs $\quad 82$

B7. Handout for lesson on hieroglyphics 83

B8. Handout of Maya calendar glyphs 84

B9. Parthenon handout 85

B10. Handout for lesson two 86 
B11. Handout for lesson two 87

B12. Color tranparency of terra-cotta warrior figures 88

B13. Color transparency of Islamic mosaic 89

B14. Color transparency of Inca textile 90

B15. Laminated visual aid of a Benin warrior figure 91

B16. Laminated visual aid of Chinese art 92

B17. Visual aid showing Edward VI by Hans Holbein 93

B18. Laminated visual aid showing Takami Senseki by Watanabe Kazan 94

C. List of Cultures Used to Augment Art Curriculum and Sample Lesson Plans

C1. Cultures used in augmenting the art curriculum 96

C2. Lesson plans $\quad 97$

D. Samples of Student Art Work

D1. Sample of lesson one elements of traditional art $\quad 100$

D2. Sample lesson one elements of culturally augmented art instruction $\quad 101$

D3. Sample lesson seven culturally augmented instruction 102

D4. Sample lesson seven culturally augmented instruction 103

D5. Sample lesson nine synthesis of traditional and culturally diverse art elements

D6. Sample lesson nine synthesis traditional and culturally diverse art elements

D7. Sample lesson nine synthesis traditional and culturally diverse art elements 
D8. Sample lesson nine synthesis traditional and culturally diverse art elements

D9. Sample lesson 11 showing both western and culturally diverse portrait images

D10. Sample lesson 11 showing both western and culturally diverse portrait images 
List of Tables and Figures

Table

Page

1. Distribution of Students by Racial/Ethnic Group 20

2. Experimental Design 24

3. Means, Standard Deviations, and ns for the Augmented Art Curriculum Group and the Traditional Art Curriculum Group 35

4. Analysis of Variance for Augmented Curriculum by Teacher 36

5. Means, Standard Deviations, and ns for Teacher by Curriculum 38

6. Scheffé Test Showing Pairs of Groups Significantly Different at the .05 Level

7. Means, Standard Deviations, and nي for Assignment by Teacher by Group

8. Scheffé Test Showing Pairs of Groups

Significantly Different at the .05 Level

Figure

1. Mean Cultural Evidence Score by Art Assignment 42

2. Cultural Evidence Score by Treatment 43

3. Comparison of Rater Means For Each Assignment 49 


\section{Chapter 1}

\section{Introduction}

This study was done to investigate the effects of an augmented art curriculum on high school art students. The idea was first, to determine if students who received this augmented art curriculum had more positive attitudes towards diversity in art and second, to see if those same students used references to that diversity when they created their own art forms.

\section{Background}

There is much interest in revamping curriculum to reflect the push toward excellence in education. Reformers feel it is essential that our students receive a first-class education if our nation is to take its place among the world leaders. Every discipline taught in our schools is scrambling to develop and implement standards for excellence in its particular field. Art education is no different. The National Art Education Association in a series of briefing papers on excellence in art education proposes that excellence in art education should entail teaching the students not only about art production, but also about the history of art, aesthetics, and art criticism.

Aware that our classrooms reflect a variety of cultural heritage, and that in the past what was taught in the art classrooms was tied to the dominant culture, ignoring the contributions of other cultures within the nation, some educators have been proposing that when working on excellence in the art curriculum art educators recognize this and adapt accordingly (Smith, 1993). In fact, in a 1994 article Smith states that art education had in the past been guilty of what he called "surface multiculturalism," with teachers "...'doing 
African art for the next two weeks' or ice cream container totem poles, milk carton kachinas" (Smith, 1994, pp. 15-16). The result of this cursory encounter with cultural diversity in art is not only that it trivializes images that are visual expressions of beliefs within these cultures, but that it also unknowingly communicates to students that these art forms are from far away places and somehow peculiar (Smith, 1994). Increasing awareness and study of cultural diversity according to Lankford (1992), has lead to increased recognition, understanding, and appreciation for the richness of other artistic and aesthetic traditions. Smith (1994) states that an approach where the teacher presents the cultural heritage of the various students represented in the class in a positive light, if one avoids trivialization, helps to strengthen a student's self-image through self-identification with the culture presented. This approach dating back to Lowenfeld's practice at the Hampton Institute, has an extra-art goal, a psychological goal that some have called repair multiculturalism. But Smith (1994) states that parallel goals are possible, and they include increasing knowledge about various cultures' art productions, art history, and aesthetics. Hart (1992/93) states that unless we seriously consider the fundamental differences in the art of different cultures, the specific social and cultural contexts in which the art is produced, and then act on our conclusions, any multicultural art content would remain an "add-on" (quotations in the original) to the basic curriculum. Issues about curriculum content and whether to teach about art in context of the culture that has creates it are basic to the debate on what constitutes an excellent art education curriculum. An important first step according to Wolff, (cited in Hart, 1992/93) is for those who work in the art field (critics, art historians, and art teachers), to realize that our understanding and appreciation of 
western art itself requires a great deal of information about the social and cultural context in which this art is created. Non-western as well as western art would benefit says Hart (1992/93) if viewers could "dis-illusion" (quotations in the original) themselves of the mistaken belief that looking at and responding to images requires no more than the minimum of contextual information.

A point is made by Smith (1994) when he states that art educators need to worry about more than just avoiding trivialization when presenting art from diverse cultures to students. He mentions that students might find it difficult and in fact might "...refuse to identify with a heritage whose origin was in an environment different from modern America" (Smith, 1994, p. 17). Even if a student's heritage is African, Asian, or Native American, they might considered that heritage strange, far away (either in a geographic sense or in the sense of time elapsed since contact), and not related to their daily lives. In many instances Americanization either forced or voluntary, might cause students whose heritage is culturally different to feel alienated from this diversity. Though it is also possible that some cultures to avoid forced Americanization, choose to perpetuate some cultural heritage (as is evident in South Florida's Hispanic community). Smith (1994) states that to avoid a monoculture that might arise through technology, media, and extra-school pressures, art educators would do well to concern themselves with fostering diversity of expression in the art classrooms.

Questions about what to include in an expanded curriculum whose aim is excellence in art education invariably lead to issues about aesthetic evaluation of visual art products from diverse cultures. Neperud and Stuhr (1993) point to the fact that investigations on how people value diverse visual 
art products not only have potential for use in instructional practice, but may help to provide information on questions about whether cross-cultural valuing reveals variations on a universal aesthetic or a more culturally determined one.

Would an augmented curriculum that includes examples of the visual art production of diverse cultures have any effect on students' valuing of this diversity in art? Would students accept works of art that typified this diversity as examples of excellence in art, and would they be used as a source of inspiration for student art work? Or, would this non-familiar art be considered a curiosity not on a par with traditional art?

\section{$\underline{\text { Rationale }}$}

Since it seems that most art educators and researchers in the field of art education advocate an art curriculum that includes the study of diverse artistic forms of expression in art history, art production, aesthetics, and art criticism, it is puzzling to see that in current practice, there is very little being done by teachers that includes this diversity of art expression in their lessons. This current practice in art education was observed during a pilot qualitative study with beginning art students and their teachers. The purpose of that pilot study was to investigate whether the attitude of teachers and students toward diversity in art played any part in the lack of emphasis the art curriculum places on exploring a wider range of art works typical of the diversity of expression possible in art. Three teachers and four students from two middle class high schools in Broward County, Florida with ethnically diverse populations were the participants of this study. During interviews (using a semi-structured interview guide developed for this study) they were asked to 
respond to open-ended questions that would show how they felt about diversity in art, and whether they felt it was important to include it in their art classes. Field observations of art classes with those teachers and students revealed that though they stated positive attitudes toward diversity in art during interviews, and were for inclusion of diversity in the art classes, there was little evidence of it in the classes observed. An analysis of the data in this qualitative pilot study provides some information on possible reasons for the disparity between responses in the interviews, and actual practice. Most teachers during interviews stated that they themselves have received little exposure to or training in art that deals with diversity, "Certainly you would not mind teaching multicultural art if you felt you had a clue about it and knew more than enough to just keep a few paces ahead of your students" (teacher cited in Alvarez, 1994). They felt ill-prepared to teach diversity in art without doing significant research in the field (Alvarez, 1994). They mentioned the very real lack of time to conduct said research as a stumbling block to providing an augmented art curriculum for their students.

Students in their interview responses quite often stated that they feel learning about the art of other cultures could help them understand those cultures better. Paco (pseudonym used) said, "...it could like influence a person's idea about the country," and Penny (also a pseudonym) said,"...it's visual [by it she means the art of other cultures], and this way you can see how it differs from your own culture." Paco also addressed the issue of crosscultural aesthetics when he said that through art, you could "...see how like a the different people from other countries react to their art compared to our art" (students cited in Alvarez, 1994). Though students could state in their 
own words that they value exposure to diversity in art, they are hardly ever exposed to this diversity on a regular basis in their art classes.

The responses of teachers and students during the pilot qualitative study, led to the development of this experimental study to investigate whether providing students with an augmented art curriculum that exposes them to art representative of diverse art producing cultures affects their attitudes toward diversity in art, and whether students receiving an augmented art curriculum choose to use the diversity of art presented to them, and incorporate references to it in their own art products.

\section{Statement of the Problem}

The purpose of this study is to compare the effects of two types of art curricula -- an augmented art curriculum and a traditional art curriculum -- to determine if high school art students who are taught using an augmented art curriculum 1) have more favorable attitudes toward diversity in art and 2) whether they use that diversity as a source of inspiration for their own art work more often than high school art students who are taught using the traditional art curriculum .

\section{Definitions}

Since this study focuses on how beginning high school art students are affected when the art curriculum is augmented to include art examples from diverse artistic communities, it is important to define the terms diversity in art, and the art of other cultures. These terms serve as the fulcrum upon which the construction of the augmented curriculum balances, so how the curriculum developer and the implementing teachers define these terms is of 
importance. It is also important to know how the terms augmented art curriculum and traditional art curriculum are defined for the purposes of this study. Therefore, the following definitions are submitted as the ones which defined these crucial terms throughout the study.

\section{Diversity in art}

For the purposes of this study diversity in art is defined as the inclusion in what one considers as art, of a wide range of visual art expressions from a variety of artistic communities around the world. It is emphasized that this diversity includes works that perhaps are traditionally considered functional or craft by western art standards, but which clearly have expressive artistic qualities and therefore would be considered works of art.

\section{$\underline{\text { Art of other cultures }}$}

Throughout this study when teachers or curriculum developers refer to the art of other cultures they mean the art produced by cultures other than mainstream American or Western-European cultures. This means that for the purposes of this study the art of Native American peoples, is considered nonwestern although they live in North America which is geographically part of the western hemisphere. This somewhat arbitrary assignment of art producing cultures into categories of "traditional western" and "other" is done because in the art history curriculum students are exposed to this dichotomy by art history texts (Janson \& Janson, 1969, and Preble \& Preble, 1989), and since in a pilot study (Alvarez, 1994) students themselves seem to make this distinction.

\section{Augmented art curriculum}

For the purposes of this study an augmented art curriculum is defined as one that begins with the traditional art curriculum currently taught in the 
school and is supplemented with relevant lessons on art historical and technical art knowledge, as well as aesthetics and socio-cultural beliefs of diverse artistic communities. This is done by using a time-line and chronologies of political and social events to organize the diversity of human artistic endeavors and correlate it to the art history lesson currently being taught by the art teacher. This newly augmented lesson is used as an advance organizer for the homework and studio lessons that follow.

\section{Traditional art curriculum}

A traditional art curriculum is defined as one that focuses mainly on the art history, art production, aesthetics, values and belief systems of the western world as presented in traditional art history texts (e.g., Janson \& Janson, 1969). This traditional art curriculum is the one used by most schools in Dade, Broward, and Palm Beach counties during the time the experimental study was conducted.

\section{Assumptions and Limitations}

One of the assumptions made in conjunction with this study was that one could generalize the results of this study only in the area of art since that is the subject area of this study. One cannot say that augmenting the social studies curriculum like the art curriculum was augmented during this study would cause similar results in that discipline. One can certainly not generalize and say that the results of one study from Broward County, Florida would be true across the nation, any more than they could be assumed to be true for the rest of the state of Florida. It was also assumed that South Florida's special ethnic mix of cultures would color the results of this study to some extent in a way that would perhaps not happen in the rest of the state. It was not the 
intent of this study to prove one art curriculum better than another or to state that treatment alone (augmenting the art curriculum) made the difference in student's attitudes and art. The limitations of this study were such that perhaps the results serve only to illustrate what was accomplished with beginning high school art students in South Florida when the curriculum was augmented to include more references to cultural diversity in art.

Despite these limitations and the narrow scope of the study, and because of the interest within the art education community for curriculum reform to reflect excellence as well as diversity, it was important to see if augmenting the art curriculum to include more art exemplars representative of cultural diversity would in fact enhance student attitudes toward diversity in art and cause them to use that diversity when they made their own art. 


\section{Chapter 2}

Review of Related Literature

When dealing with curriculum reform, student attitudes, and learning it is important to look at the literature in a variety of areas to help guide any new curriculum being implemented. Since this study was investigating the effect of an augmented art curriculum on student attitudes and on their art work, it was important to look at the literature in the areas not only of art education, aesthetics, and valuing, but also in the area of learning theories to help promote meaningful learning for students.

\section{Cognitive Theories of Learning}

Ausubel (1963), writing about the difference between rote learning and meaningful learning, stated that rote learning is the memorization of facts or associations that are essentially arbitrary, while meaningful learning is not arbitrary. Rather, it involves the relating of information or concepts to knowledge the student already has. Meaningful learning is stored in long-term memory in a series of networks of connected facts and concepts known as schemata. One of the most important principles of schema theory is that activating prior knowledge (existing schema) allows new information to be more easily understood and learned than information that does not (Ausubel, 1968). The networks of interconnected facts stored in long-term memory provide a structure for making sense of new information. This also serves not only to enhance understanding, but also retention (Pressley, Wood, Woloshyn, Martin, King, \& Menke, 1992). 
Advance organizers, are statements given before instruction to guide students to the material they are about to learn, and to help them recall related information that they can use to help them incorporate the new information (Ausubel, 1978). In Ausubel and Youssef's 1963 study where college students were given an advanced organizer comparing Christianity to Buddhism, the advanced organizer served to activate student's knowledge about a familiar subject and allowed them to use that knowledge to incorporate information about a less familiar subject. Many other studies (Corkill, 1992; Glover, Bullock, \& Dietzer, 1990; and Mayer, 1984) have established that advanced organizers are useful in increasing student understanding of certain kinds of material.

\section{Paradigms For Art Education}

The paradigm one chooses to guide curriculum making decisions has a direct relation to what and how children will be taught. Sahasrabudhe (1992) stated that we have been used to discussing art education in terms of what it does for and to our children, in other words, we talk about the functions and purposes of art. Indeed, most paradigms for art education can be seen as outcome oriented. If one is interested in one particular function of art, and then designs programs of instruction to achieve that goal, whether it be acquiring information, mastering studio skills, or learning about artists and artworks, then the approach to art education is a formalist one that Sahasrabudhe (1992) has called art as content/instruction. She believes this paradigm contributes to the lack of diversity in art education and advocates a shift in field orientation to something she calls art as experience. In Dewey's work, to have an experience means to encounter and interact with something 
of relevance to one's own life. A parallel is drawn to how the study of unfamiliar art (culturally diverse art), the thing "out there," can be linked to what is "in here" (familiar visual images and student's own concerns). In the art as experience curriculum, art work from unfamiliar cultures (out there) with specific human issues and meanings will be used to bring students to involvement with their own concerns with the aim of creating their own unique symbolic forms (Sahasrabudhe, 1992). This more complete art experience that requires the student's total involvement in the art of diverse cultures, is interesting considering what Eisner (1985) stated about empowering children to have access into major sources of culture. He said that if this is a goal for art education, it will come about by providing an allinclusive visual art experience, not by merely learning about other cultures.

Freedman (1994) advocated a position he called teaching visual culture. He uses the phrase visual culture to refer to forms of human production that function as images. Teaching visual culture entails having a curriculum that "...encompasses the peculiar sociopolitical, as well as sensory, formal, and material characteristics and effects of fine art, and goes beyond fine art to include the expressive foundations and implications of multicultural and mainstream artifacts..." (Freedman, 1994, p.158). Two problems that need to be addressed when teaching visual culture are the fact that visual culture like general culture (whether it is familiar or from an ethnically diverse population) is continuously in a state of flux, and the incongruous notion of teaching a common culture in a discipline like art that is rooted in the idea of individualism. According to Freedman (1994) it is an illusion to assume that students can at the same time adopt a universal model 
of aesthetics when they are viewing a work of art, and then go on to conceive unique ideas when producing art.

\section{Pedagogical Implications of Diversity in Art Education}

If one focuses on the idea of integration, one is bringing to the center of the art curriculum for inclusion, elements from a variety of cultural sources. According to Amdur (1993) more is gained when interrelationships are promoted than when lessons are kept isolated. He goes on to say that formal qualities of an art work are given more attention by students when they are seen as clues to the lived experience of the people who made and used the art object. Galbraith (1992/93) stated that across grade levels art teaching is more than the mere transmission of art curricular knowledge to students. As a first step toward inclusion of diversity in an art curriculum Dilger (1994) proposed learning about world traditions through reading, listening, viewing original art and artifacts, interviewing artist, and perhaps trying out in the studio materials and techniques that are indigenous to various societies. The idea of inclusion and integration is, "... not to abandon an existing curriculum based on Western culture, but to expand it to accommodate cultural plurality" (Dilger, 1994, p.52).

One needs to explore a variety of pedagogical implications that include but are not exclusive to, how the knowledge is transmitted, what the relationship is between the teacher and those being taught, the ability to listen to what others have to say, examining the choices that teachers make, and how other viewpoints are presented. According to Dufrene (1994) art educators need to shed old definitions of race and culture to challenge the outdated categories of cultural inclusion or exclusion for certain periods and 
peoples. It is time to see that while Egyptian art is discussed in traditional western art history texts, a glance at any map will tell you it is on the African continent, and that while the Native American artists are not white or descended from Europeans, they are indigenous Americans and inhabit the western hemisphere. Accuracy is important when striving for an art curriculum that is ethnically diverse. "If art educators want to include Art history into the curriculum, it is imperative that Art history examples be accurately portrayed, defined and classified without racial/cultural biases"(Dufrene, 1991, p.253). According to Grisby (cited in Kellman, 1992/93) art is the means of teaching the pleasure of differences between cultures. He goes on to say, that without this ability to delight in the unfamiliar and unimagined, life is reduced to a repetition of the most limited local daily patterns.

Maxine Greene (1981) has pointed out that art can bring into view dimensions which are inaccessible through other experiences and that it is the obligation of the teacher to open minds to be perceptive and free enough to see forms never imagined before. Perceptual and imaginative awareness has to be cultivated in a deliberate way, says Greene, through a cognitive understanding of the symbol systems and the conscious style involved in works of art. "To perceive, to imagine new possibilities of being and action is to enlarge the scope of freedom for the individual; and, when people work to open new perspectives together, they may even discover ways of transforming their lived worlds" (Greene, 1981 p. 158).

Agard (cited in Kellman, 1992/93) wrote, that art can be a medium for understanding different cultural values and reinforcing racial and cultural pride. "After all, art does not exist for art's sake, it exists for our sake because 
it is a human statement" (Agard, 1981 p.3). According to Newman (1970) if one operates on the assumption that schools can facilitate student empathy, one of the pedagogical strategies that might be employed toward this end is student interaction with the art of the culturally different. Blandy and Congdon (1988) stated that exposure to multicultural art broadened students' perspectives.

An appropriate goal for art education in a pluralistic society according to Armstrong (cited in Young, 1990) is to contribute to student's comprehensive knowledge and valuing of the diversity and aesthetic qualities of visual arts as seen through the contributions of cultures and ethnic groups present in the United States. Taught this way Armstrong says, that art education can help students to value their own heritage, understand the heritage of other persons, and appreciate the diversity of art forms and interpretations that communicate about common concerns of life (cited in Young, 1990).

\section{Issues of Aesthetics and Valuing}

Feldman (1992) has proposed that our liking or not liking of certain works of art (our aesthetic response) need not be considered inevitably culture-bound, since art is made by flesh and blood men and women very much like ourselves. He goes on to say that "... the act of seeing is personal, not collective... the capacity of 'strong' images to break through cultural constraints should not be underestimated...good art is more about sharing than excluding...great art tends to build bonds among dissimilar peoples and personalities" (Feldman, 1992, p.264). Students says Amdur, will at times prejudge an art work as ugly, until "...they are encouraged to 'read' the work's 
stylistic characteristic to discover the human value and ideas that informed its making... Better understanding of formal qualities and greater aesthetic appreciation follow" (Amdur, 1993, p. 13).

When including a variety of cultural expressions, Greene (1993) cautioned that it is essential to avoid fixed notions and stereotypes. She goes on to say that to view something as "representative" of a culture is to presume an objective reality called "culture," which is homogeneous, fixed, and that can be represented by existing subjects. When in reality, while cultural background plays a role in shaping identity, it does not determine identity.

Clifford (1988) has discussed the issue of individuality and the historically and culturally determined nature of what is accepted as art in the western world today. He has stated that the western art system divides aesthetic objects into four categories that he labels "art", "culture", "not-art", and "not-culture" (Clifford, 1988). Fine "art" is seen as anything considered unique, or a masterpiece in the realm of connoisseurs, art museums, and galleries. "Culture" includes traditional objects, material culture and craft objects that are in the realm of folklore or history. In the "not-art" category, are the reproductions or fakes that also include tourist art. "Not-culture" includes fakes, ready-made objects, and things considered in the realm of technology. One can go down the line and question these strict divisions of aesthetic objects. Where would one place a one-of-a-kind painting that is boring and poorly executed? Is it art? What about a pair of silver serving spoons with ebony handles made by a contemporary smith. Are they art objects because of their elegant balance, symmetry and design excellence? Are they objects of culture since they relate to material culture and craft? Are they not art at all, since they are commercial products, made to be sold to 
consumers and used in daily life? According to Hart (1991) this classification leads to considering non-western art forms not as art, but as something else, something not worth serious attention by connoisseurs of art, and by extension, something not worth teaching our children.

Cappetta (1993) speaking in the context of changes in general education has stated that art educators have to assess what students are taught to do with art-related content in terms of their lives, families, careers, and the world. She sees an augmented curriculum that helps students identify humanity's cultural diversity as well as commonalities as greatly needed.

In art education, a socio-cultural approach sees art as having multiple meanings connected to social, cultural, economic and political forces (Bersson, 1981, 1986, 1987; Blandy \& Congdon, 1987; Lanier, 1976,1983). Thus the things people make and their associated practices are perceived as contextually grounded. Because artworks are expressive products of their original social contexts, Amdur (1993) has proposed that they can be used to bring students to empathic connection with a foreign or historical culture, and to make more explicit connections between an artwork's stylistic characteristics, and the defining characteristics of its original culture.

Others have espoused the universal aesthetic approach (Broudy, 1972; Feldman, 1973; Smith, 1981, 1982, 1985) which sees art as having only one transcendental meaning and believes art to be relatively autonomous and non contextual. The lesson we can take from art history according to Feldman (1992) is that some works of art easily transcend group preferences while other works can be understood outside their original geographic area and society only with difficulty. The variations in aesthetic response Feldman 
feels have more to do with the difference between good, mediocre, and bad art than with any failure of the viewer.

\section{Statement of the Hypotheses}

A review of the literature suggests that teaching about the diversity in art would broaden students' perspectives. Research also suggests that, inclusion of the art of diverse cultures in the high school art curriculum might help to increase tolerance to diversity of art expression. Data from a previous qualitative study suggests that students and teachers feel it is important to include a wide range of visual art expression in the high school art curriculum. On the basis of this, it was hypothesized that : high school art students who receive an augmented art curriculum will 1) have more positive attitudes toward diversity in art and will 2) choose to use this diversity in art as inspiration for their own art work more often than students who receive the traditional art curriculum. 
Chapter 3

Method

This chapter discusses the subjects of the study, the instruments used to gather the data, the experimental design chosen for the study, and the procedure followed in the implementation of the study. In each instance the choices that were made had direct implications to any assumptions that could be made on generalizability and to any limitations of the study.

\section{Subjects}

The subjects for this study were the entire population of beginning art students $(\underline{\mathrm{N}}=182)$ at a middle class high school in Broward County, Florida. These students were in six beginning art classes taught by two art teachers in the school. The general student population of this school appears culturally diverse to any person visiting the campus, being composed of African American, Asian, Hispanic, Native American, and Caucasian Non-Hispanic students. It is interesting to note, however, that according to data provided to teachers in January of 1994 and made available to the researcher, a large percentage $(69.50 \%)$ of the student body is reportedly composed of Caucasian Non-Hispanic students. This school population percentage $(69.50 \%)$ however displays less than a $9 \%$ difference from the state population percentage of Caucasian Non-Hispanic students $(60.60 \%)$ as can be seen in Table 1. One can also see in Table 1 that this school has fewer African American and Asian students than the average at the state level, yet it has more Native American students. The proportionately greater Native 
American population can perhaps be explained by the presence of an Indian Reservation nearby.

Students at the study site are randomly assigned by computer to any one of the six possible beginning art classes taught at this school when they sign up to take art during scheduling week. Thus the students ultimately taking part in this study were randomly formed into groups without taking into concern the racial and ethnic composition of the groups.

Table 1

Distribution of Students by Racial/Ethnic Group

\begin{tabular}{lrr}
\hline & School \% & State $\%$ \\
\cline { 2 - 3 } Caucasian & $69.5 \%$ & $60.6 \%$ \\
African American & $14.5 \%$ & $23.2 \%$ \\
Hispanic & $12.9 \%$ & $13.9 \%$ \\
Asian & $1.8 \%$ & $2.2 \%$ \\
Native American & $1.3 \%$ & $.2 \%$ \\
\end{tabular}

Note. Figures for this table come from a report prepared by the Florida Department of Education (1994) from data provided by local school districts for the school year 1992-93.

\section{Instruments}

Since this study dealt with beginning art students, there were no previous art tests or portfolios to serve as pre-tests measuring ability in the 
area of art. There were also no attitudinal test scores available that would help to determine student attitudes toward art prior to treatment.

There were no published or unpublished tests identified that could be used to measure specifically attitudes toward diversity in art, so the Attitudes About Art questionnaire was developed by the researcher to be used as the instrument to measure attitudes about diversity in art. The questionnaire was designed for high school art students in grades 9-12. An initial field test was done for a first version of this questionnaire with a class of beginning high school art students $(\underline{\underline{n}}=24)$ in Broward County, Florida, three weeks prior to the beginning of this study. This version of the questionnaire consisted of 10 items, most of which had some reference to a specific art-producing culture. This initial field test revealed some problems with certain items (lack of correlation between questions since each one dealt with culture specific items) that lead to unacceptable reliability for the instrument. The Attitudes About Art questionnaire was revised (by including more generic questions about diversity in art) to arrive at the form that was used in this study (see Appendix A1). This revised form of the instrument consisted of 20 questions -- 14 general questions about diversity in art -- 6 are culture-specific questions. A five point Likert-like scale was used to score student responses. Students could respond to the questions on the questionnaire as follows: strongly disagree; disagree; undecided; agree; strongly agree. Their responses were then coded numerically for later scoring and statistical evaluation in the following manner: strongly disagree $=1$; disagree $=2$; undecided $=3$; agree $=4$; strongly agree $=5$.

The revised version of the Attitudes About Art questionnaire was then field-tested with a different population of high school beginning art students 
$(\underline{n}=34)$ in Broward County before being administered to the subjects of this study. The art teacher at the site where the revised version of the questionnaire was field-tested (a teacher with over 14 years experience teaching art) judged the questions to be age-appropriate for use with high school students, and felt that beginning art students would be able to answer these questions. Students responding to the questionnaire during the field test of the instrument did not seem to have serious problems answering any of the questions and there was variability in their responses. An alpha reliability (Cronbach, 1951) was computed for this group of respondents to the attitudinal questionnaire. This yielded an $\alpha$ of .95 , suggesting that this attitudinal questionnaire was acceptable for measuring student attitudes in the area of diversity in art.

This revised version of the Attitudes About Art questionnaire was administered at the end of the study to students in both the control groups and the experimental groups (as a posttest) in one session and took approximately 20 minutes to complete. Student responses were compared to see if those who received an augmented art curriculum had more positive attitudes toward diversity in art.

The actual art works that students produced were also examined (when students turned in their portfolios at the end of the semester), to see if as a result of treatment, students in the experimental group used this diversity in art as a source of inspiration for their own work more often than students in the control group. A Checklist of Cultural References in Student Art (see Appendix A2) was developed by the researcher for use by evaluators to examine student art work and note the presence of references to diversity in art in student art work. The checklist could be marked with either an " $\mathrm{x}$ " or a 
$" \checkmark "$ in the appropriate row and column to indicate if 1) there was evidence of traditional art elements, 2) evidence of elements indicative of diversity, and 3) a synthesis of traditional and culturally diverse art elements. If there was no evidence, the raters' mark stood for a zero. If there was a missing assignment, their mark indicating that was coded 99. The two teachers implementing this study and two independent, non-involved art specialists chosen for their experience teaching beginning art classes and their knowledge of diverse cultural art elements, evaluated student art productions using the checklists. A reliability coefficient was computed for the checklist which yielded an $\alpha$ of .71 .

Experimental Design

The design for this study was the posttest-only control group design (see Table 2). This design was chosen because it controls for many sources of invalidity and because random assignment of subjects to groups was possible. The independent variable was type of curriculum -- augmented (labeled $\underline{b}$ in Table 2) versus traditional (labeled $\underline{a}$ in Table 2 ). There were six randomly formed beginning art classes, with each teacher at the site teaching three. One of each teacher's beginning art classes was randomly designated control and one was randomly designated experimental. The posttests were an attitudinal questionnaire that measured attitudes toward the art of other cultures, and a checklist to see whether students exposed to an augmented art curriculum used the diversity of art presented to them as a source or point of departure for their own art work. Mortality which can be a threat to validity cannot be controlled in this design due to an absence of pretest scores. Despite this fact, the posttest-only control group design was chosen since the pretest would 
have to be an attitude scale and the treatment is designed to change attitudes.

Due to the possibility that there might be pretest-treatment interaction, no pretest was administered. Keeping the study relatively short in duration (18 weeks) was an attempt to control for mortality and keep group sizes relatively stable.

Table 2

Experimental Design

\begin{tabular}{lllll}
\hline Group & Assignment & $\underline{\mathrm{n}}$ & Treatment & Posttests \\
\hline $1 \mathrm{a} / 2 \mathrm{a}^{\mathrm{a}}$ & Random & $26 / 31^{*}$ & $\begin{array}{l}\text { Traditional Art } \\
\text { Curriculum }\end{array}$ & $\begin{array}{l}\text { Questionnaire } \\
\text { \& Checklist } \\
\end{array}$ \\
$1 \mathrm{~b} / 2 \mathrm{~b}^{\mathrm{a}}$ & Random & $24 / 31^{*}$ & $\begin{array}{l}\text { Augmented Art } \\
\text { Curriculum }\end{array}$ & Questionnaire \\
& & & \& Checklist
\end{tabular}

${ }^{\text {a }}$ On this table $1 \mathrm{a} / 2 \mathrm{a}$ refers to teacher one control/teacher two control and $1 \mathrm{~b} / 2 \mathrm{~b}$ refers to teacher one augmented/teacher two augmented.

* The numbers 26 / 31 refer to number of students from teacher one and teacher two control group. The numbers 24 / 31 refer to number of students in teacher one and teacher two experimental group. 


\section{Procedure}

This study was conducted for one semester (18 weeks) at a public high school in Broward County, Florida. This site offered a variety of art classes from beginning art to graphic design, sculpture, and animation. In this study only the beginning art classes were involved.

Before the opening of the school year, students were assigned to one of the six beginning art classes at random by a computer, according to how the class fit in with the rest of their schedule. Each of the two art teachers was to teach three of the beginning art classes. No attempt was made to assign students to a particular art teacher, and no attempt was made to assign students according to grade point average, conduct, age, or ethnicity. This method thus yielded randomly formed groups where any lack of heterogeneity was due to chance alone, and not due to systematic bias on the part of the researcher. From each teacher's classes, one of the three was randomly designated control (group labeled a in Table 2 ), or experimental (group labeled $\underline{b}$ in Table 2). In this way, teachers (the difference in teacher is denoted by the number $\underline{1}$ or $\underline{2}$ under group in Table 2) taught both a control group and an experimental group, in an attempt to control for between teacher difference. Each teacher's remaining class, though not initially included in the experimental study, received instruction parallel to that received by the control group.

Permission was acquired from the principal to conduct the study with the beginning art classes at this site. Both art teachers at the site also expressed their willingness to be involved in the study. The two teachers who participated in this study, one male and one female, were quite similar with respect to education and experience. Each teacher had 14 years of experience 
teaching art, and both received their Master of Education degree in Art Education from the same institution. Each teacher had three classes of beginning art students. Since during a pilot study conducted earlier at the site (Alvarez, 1994) both teachers had expressed a lack of adequate background in culturally diverse art and a lack of time to conduct appropriate research in the area, and since both teachers would be teaching experimental groups, brief training sessions were provided to help them present the culturally diverse material. The training sessions were conducted just prior to the teachers at the site introducing each new art history lesson (from a week prior to a few days prior, depending on the free time the teacher's had at their disposal). They were held in the teachers' own classroom and lasted anywhere from one half hour to an hour and a half. In these brief training sessions the new cultural material was explained from anthropological and art historical perspectives and appropriate linkage was made to the western art form that the teachers usually used to teach a particular topic. Background information in the form of notes for teacher use and student handouts as well as appropriate visual aids representing a range of visual art production from diverse ethnic populations were also provided to each teacher (see Appendix B).

Treatment began at the end of the second week of school. The two classrooms were self-contained units, as identical as possible, and were located across the hall from each other. Both groups followed the same rotator school schedule (7:40 - 3:00) of seven classes a day, with one class skipped each day in rotation so that teachers taught a total of six classes each day. 
For the duration of the study, each teacher taught an experimental group and a control group of beginning art students. The problem of keeping groups separate since the same teacher had both a control group and an experimental group was kept to a minimum due to the fact that when the classes were randomly assigned to be control or experimental, they happened to occur at quite different times of the day. The experimental class for teacher one was fifth period and the control class was first period. Teacher two had the experimental class second period and the control class sixth period. One would think that this would counterbalance the effect of time of day since both teachers taught an early class and a class later in the day. Students in the experimental and control groups did not come into contact with one another as they went in for classes due to this time spread between the classes. Student interaction between groups outside of class time did not appear to be a problem during on-site observation despite the fact that all students were at the same school and had equal access to the art rooms. Beginning art students did not come in to the art rooms with any frequency during lunch or teacher planning, and did not make any comment about any perceived difference in the content of other students' art work. The only comments made or interest expressed in the different beginning art assignments were made by advanced students who were using the room for independent work.

Experimental and control classes were the same length and received the same amount of homework as determined by the art teachers at the site. They used the same texts and art materials, and had in-class assignments that allowed the same time for completion. Only the subject matter used was different. It should be noted that all students paid an art fee at this site which 
entitled them to art materials to take home and use in the production of their homework assignments.

The teachers implementing the treatment in this study use formalism, which according to Lankford (1992) is a particularly potent theory in Western Art of the 20th century that emphasizes the composition and structural arrangement of works of art, to organize their art lessons. The fact that the teachers in this study are dealing with beginning art students that possess the most rudimentary knowledge of the principles and elements of art, that they need to teach the "basics" in order to enable interested students to advance to the next level in the art curriculum at this site, and that most art texts and visual aid materials available to them on site emphasize the formal or structural aspects of a work of art, perhaps explains their formalist approach to teaching art. This formalist perspective to curriculum at the site was kept in mind when designing the treatment.

Treatment consisted of having the experimental group receive the traditional art curriculum customarily used at the site, and supplementing it with the addition of art historical exemplars (in the form of $81 / 2$ by 11 inch color transparencies for lessons $1-7$, and $81 / 2$ by 14 inch laminated visual aids for lessons 8 to 11) from diverse art-producing groups around the world. This augmented art history lesson was given once a week (usually on Friday) and served as an advance organizer for the following week's studio homework assignment and for the in-class studio assignment (see Appendix C). In the studio homework assigned for the experimental group, the students were asked to reflect on the art works they saw during their art history lessons, and remember the examples of the art elements in those works. They were told they could use the art historical works as references while they worked on 
their studio assignment, emphasizing that they had a choice of art historical works that they could look at. The experimental group's augmented curriculum used a time line and chronologies of political and social events to help organize and make sense of information. The augmented curriculum consisted of lessons that included the art history, art techniques, and aesthetics of diverse artistic populations (e.g., Japanese, Maya, and Inca) around the world (see Appendix $\mathrm{C} 1$ ) as they were relevant to the art element or principle taught by the teacher at the time. Topics for lessons included the following: hieroglyphics, columns, mosaics, line designs, geometry in art and so on (see Appendix C2).

The control group received the traditional art curriculum that was provided to all students in beginning art classes at the site. This included art history once a week (usually on Friday and based on western art history) as an advance organizer for the following week's assignments, a weekly studio homework assignment, and in-class studio assignments that ranged from straight drawing to painting and paper mosaics. The lesson topics were the same ones used in the experimental group except for the fact that they included only exemplars of western art.

Both the control and experimental group classes were of the same length (50 minutes). Both groups were required to complete all 11 studio homework assignments and place them in a portfolio (for the beginning art classes a folder was used as a portfolio) when they turned them in. In the control group, when the teacher finished presenting the art history lesson, the written art history homework, the studio homework for the week (which is linked to the art history), and the related in-class studio assignment, the students were free to begin their studio homework assignment in class. 
In the experimental group, the teacher presented the usual western art history lesson and then using the time line and chronology of world events, presented a parallel to another artistic community from around the world whose art work presented similar elements to those present in the work of art considered an example of western art. The teacher then presented the written art history homework, the weekly studio homework assignment, and the related in-class studio assignment that would be based on the art history lesson presented. If there was any time left before the bell rang the students were allowed to begin work on their studio homework assignment.

At the end of the study all groups were administered the Attitudes About Art questionnaire (see Appendix A1) to see which group showed more positive attitudes toward diversity in art. All student portfolios turned in by students in the experimental and control groups from both teachers were evaluated using the Checklist of Cultural References in Student Art (see Appendix A2) both by the teachers in the study and by two independent art experts who were selected for their experience teaching beginning art students in South Florida and their knowledge of diverse cultural art elements, to see if students exposed to cultural diversity in art included references to such diversity in their art work.

Prior to portfolio review a training session was conducted with the teachers and the independent art experts who would be rating student art work. It was not possible for all four people to attend training the same day. A training session was first held with one of the independent art experts. The rater was shown the art history visual aids that students saw as advance organizers for the studio assignments. She was instructed to make only one mark in each row (i.e., not evident, evident traditional, evident diverse, and 
synthesis of traditional and diverse) for each assignment turned in, or to mark the column for missing assignment when marking the checklist. The lesson plans for each assignment were available to help clarify any studio assignment. The first rater had many questions and asked for clarification of both the instrument and the student assignments. Her questions and the clarification given along with ideas generated by this training session were written down and used to script the second training session to be attended by the remaining raters which was held two days later. Due to personal problems, the second independent art expert was unable to attend this scheduled training session. His training took place two weeks later using the same scripted instructions.

During portfolio evaluation the teachers and independent art experts were shown unidentified student portfolios containing black and white photocopies of student art work. Color copies were not provided since color was not an essential factor in any assignment. They were given a Checklist For Cultural References in Student Art for each portfolio to mark whether in each assignment student art work showed references to traditional art, diversity in art, a synthesis of traditional and diverse, or if the assignment was missing. They each had complete sets of student portfolios and conducted their evaluation of student work independent of one another. During portfolio evaluation they were allowed access to visual aids that the students had seen in conjunction with each assignment and to lesson plans for each art assignment.

Student art work from the control group was compared to that of the experimental group to see if there was more reference to diversity in the work of the experimental group than in the work of the control group. This should 
indicate if treatment (exposure to the art of diverse artistic groups from around the world) had any influence in a student's creative process -- whether the student moved from just merely valuing diversity in art to using that diversity when creating art.

In summarizing this chapter, it is important to note that students were randomly assigned by computer to any one of six beginning art classes at the study site. There was no attempt to assign students to a given art teacher, nor was there any attempt to use gender, ethnicity, or grade point average when assigning students to beginning art classes. The classes that were randomly formed by computer were then used to randomly select from each teacher's three classes, one to be experimental and one to be control. The choice to use the posttest only control group design was made even though mortality cannot be controlled for because of the danger of pretest-treatment interaction since the pretest would have been an attitudinal questionnaire. Another point introduced in this chapter is that two different posttests were used to evaluate the data from this study, an attitudinal questionnaire and a checklist, since this study looked both at a student's attitude and his or her art work. 
Chapter 4

Results

This chapter presents the results of the experimental study conducted to see if augmenting the art curriculum of beginning art students would cause them to have more favorable attitudes toward diversity in art and to use that diversity in their own art. It presents the statistical analysis of the data from the study and reports any changes that occurred in the study.

At the end of the first semester of school (which coincided with the end of the 18 week study), students completed the posttest phase of the study. They answered the questions on the Attitudes About Art questionnaire and they turned in their portfolios for an evaluation of their art production. At this point, of the original 138 students that had been randomly selected to be in either the experimental group or the control group and participate in the study, only 111 actually participated. One student was found to appear on both teacher's class rolls so he had been counted twice in the study yet only attended one class. Twenty six had been lost during the course of the study. Some had withdrawn from the art class, some were habitual absentees, and others just refused to participate (they were physically present, but would not do any work). Of the 26 students lost (one can't consider the student who was on both rolls as a missing participant since he did attend one of the art classes in the study), 11 were in the class designated as experimental and 15 were in the class designated as the control. If one looks at the available ethnic and gender breakdown of the students that were lost one sees that most students were Caucasian non-Hispanic $(\underline{n}=19)$ and that overall there were more male students ( $\underline{n}=16)$ lost to the study than females (10). So, despite this 
loss of students, the ethnic proportions of the student population in this study was not significantly altered.

\section{Hypothesis 1}

Since student responses on the attitudinal questionnaire were on a five point Likert scale, (1 for strongly disagree; 2 for disagree; 3 for undecided; 4 for agree; 5 for strongly agree) their responses to each question were scored accordingly. Those numbers were added and then divided by the number of questions answered by the student to arrive at a mean response score for each student questionnaire ( "mean attitude score"). This mean substitution procedure was done because some students did not answer all questions on the questionnaire. The questionnaires answered by both teacher 's experimental groups were put together $(24+31=\underline{\mathrm{n}}=54)$ as were the questionnaires answered by both teacher's control groups $(26+31=\underline{\mathrm{n}}=57)$. Mean response scores were calculated for the experimental group and the control group (see Table 3). A glance at the mean response score for the experimental group and the control group shows that there is no difference in the mean response scores on the attitudinal questionnaire between the groups after treatment (see Table 3). 
Table 3

Means, Standard Deviations, and ns for the Augmented Art Curriculum Group and the Traditional Curriculum Group

Group

Test

Augmented Traditional

$\underline{\mathrm{M}}$

3.27

3.27

$\underline{\mathrm{SD}}$

.78

.71

$\underline{\mathrm{n}}$

54

57

An ANOVA $(\alpha=.05)$ was computed on the data from the attitudinal questionnaire. It should be noted that, at first glance, Chi square may appear to be the appropriate statistic. However, since these data deal with frequencies in existing groups rather than proportions of a pre-determined total, ANOVA was chosen as the appropriate test of significance. The results confirmed that there was no significant difference in attitude as measured by the questionnaire between the groups after treatment, $\underline{F}(1,91)=.00, \underline{p}=>$ .05. Therefore the original hypothesis that high school art students who receive an augmented art curriculum will have more positive attitudes toward diversity in art was not supported by the data from the questionnaires used in this study. 
In the process of calculating mean response scores for each teacher's experimental and control group prior to performing any statistical analysis, it became obvious that there was a difference between the scores of teacher one and teacher two. Since students had been randomly assigned to groups and there seemed to be a difference between teacher one and teacher two in both experimental and control groups, further statistical analysis was done.

The two groups (experimental and control) were separated into four (teacher one experimental, teacher one control, teacher two experimental and teacher two control) and a two-way ANOVA was computed with these data (see Table 4).

Table 4

Analysis of Variance for Augmented Art Curriculum by Teacher

\begin{tabular}{lcc}
\hline Source & $\underline{\mathrm{df}}$ & $\underline{\mathrm{F}}$ \\
\hline Teacher & 1,91 & $8.50 *$ \\
Group & 1,91 & .00 \\
2-way Interaction & 1,91 & 1.51 \\
\hline
\end{tabular}

$* \mathrm{p}<.05$.

The results of this analysis of variance confirm that there was no overall treatment effect. The results also indicate that there was no significant interaction between treatment and teacher. However, there was a significant teacher effect. Despite the fact that teachers were matched as closely as 
possible in education and experience, and that they were given identical materials to work with, teacher two had better mean results with both the experimental and control groups (see Table 5). Another fact that is interesting to note is that teacher one had better mean results with the control group which were the students receiving the traditional art instruction that has routinely been offered at this site. When one considers that students were randomly assigned (by computer) to each teacher's art class, and that they were again randomly assigned by the researcher to treatment, any apparent difference between students taught by teacher one and teacher two (higher GPA, more motivation, and so forth) should have been due to chance.

Interestingly, Scheffé post hoc analysis done after breaking down the two groups (experimental and control) into four groups (teacher one experimental, teacher one control, teacher two control, and teacher two experimental) revealed (see Table 6 ) that while teacher two had higher mean results $(\underline{M}=3.38)$ in the control group than teacher one $(\underline{M}=3.13)$, the control group means (traditional curriculum) were not significantly different $(\alpha=.05)$ for teacher one and teacher two. It was only the experimental group means (augmented curriculum) on the attitudinal questionnaire that were significantly different $(\alpha=.05)$ for teacher one $(\underline{M}=2.93)$ and teacher two $(\underline{M}=3.56)$. 
Table 5

Means, Standard Deviations, and ns For Teacher by Curriculum

Curriculum

Teacher

1

2

Traditional

$\underline{\mathrm{M}}$

$\underline{\mathrm{SD}}$

$\underline{\mathrm{n}}$

Augmented

$\underline{\mathrm{M}}$

$\underline{\mathrm{SD}}$

$\underline{\mathrm{n}}$
3.13

.80

26

2.93

.91

24
3.38

.61

31

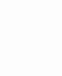


Table 6

Post-hoc Scheffé Test Showing Pairs of Groups Significantly Different at the .05 Level

Group

$\begin{array}{llll}1 & 2 & 3 & 4\end{array}$

Mean $\quad$ Group

$2.93 \quad 1$

3.132

$3.38 \quad 4$

$3.56 \quad 3 \quad *$

Note. The groups in the table are identified as follows: group 1 is teacher one experimental, group 2 is teacher one control, group 3 is teacher two experimental, and group 4 is teacher two control.

$* \underline{p}<.05$.

In an effort to try to understand whether time of day was a factor in the results obtained in the experimental study, the Attitudes About Art questionnaire was administered to each teacher's remaining beginning art class. The responses given by the students to the questionnaires were scored using the same 1 - 5 Likert scale used with the responses of the students participating in the original study. These numerically scored responses were divided by the number of questions answered by each student to arrive at a 
mean response score per student as was done in the original study group. These classes can essentially be considered like the control classes in the original study, as they did not receive the augmented curriculum. Teacher one's remaining beginning art class ( $\underline{n}=22$ respondents) was fourth period (just before lunch) and teacher two's remaining beginning art class $(\underline{n}=22$ respondents) was seventh period (the last class of the day). There was no significant difference, $\underline{F}(0,1)=.08 \quad \underline{p}>.05$ between the mean response score for the students in these additional control classes ( Mean $=3.58$ vs. 3.54) on the questionnaire despite the fact that one was before lunch and the other was at the end of the day. So it appears that for the original study group one can state that teacher, not time of day, was significant.

\section{Hypothesis 2}

The second hypothesis that students would choose to use references to diversity in art in their own art work was tested by using student portfolios. These were evaluated using the Checklist of Cross-Cultural Reference in Student Art to arrive at a score for the number of art works that showed references to diversity in art. Out of the possible 54 portfolios in the experimental class, only 32 were turned in. Out of the possible 57 portfolios in the control group, only 30 were turned in. This lack of data cannot be attributed to missing cases due to attrition, since some students who completed the attitudinal questionnaire neglected or chose not to turn in a portfolio. It did, however, seem to be a problem for both the experimental and control groups so treatment did not appear to make a difference in whether a student chose to turn in his or her art work or not. 
The student portfolios were evaluated by the teachers participating in this study and two independent art experts using the Checklist of Cultural References in Student Art. The portfolios were each marked with a number used to identify the individual student and contained a similarly marked checklist. Each evaluator also included the initial of his or her last name on each checklist they scored-- for ease in coding data from individual evaluators. The checklists were marked by evaluators by putting either an " $\mathrm{x}$ " or a " $\checkmark$ " in the appropriate row and column. These marks were later coded 1 for any mark in the evident column of the first row for any given assignment (these were the traditional art forms); 2 for any mark in the evident column for the second row in any given assignment (these were the art forms representing diversity); 0 for any mark in the not evident column of either row one or two; and 99 for any missing assignment. Although not anticipated when the checklist was developed a third sort of evident score arose. There was some student art work that the evaluators felt displayed both traditional art elements and elements indicative of diversity (that had a mark in the evident column for both row one and row two). These were coded as a 3. For each assignment the rating given (0-3) by each rater was used to arrive at a mean rating per assignment which represented the average of all four rater's scores for a given assignment.

The data generated from these checklists were examined in two ways - first to look at the individual assignments and then to look at the raters. Analysis of variance $(\alpha=.05)$ on the data from the checklists shows that there was a significant difference among assignments, $\underline{F}(1,10)=4.27$, $\mathrm{p}=.00$. Reliability data on the assignments showed that if assignment 11 was deleted, the reliability coefficient $\alpha=.54$ changes to $\alpha=.73$. In Figure 1, 
one can see that the mean rating for assignment 11 was significantly higher (more evidence of diversity) than the other art assignments. Since an average of the rating given by the four people evaluating student art work was used to come up with these means, one cannot attribute the unusually high score to any individual rating the work. There was something distinctly different about this assignment that caused such a high mean score.
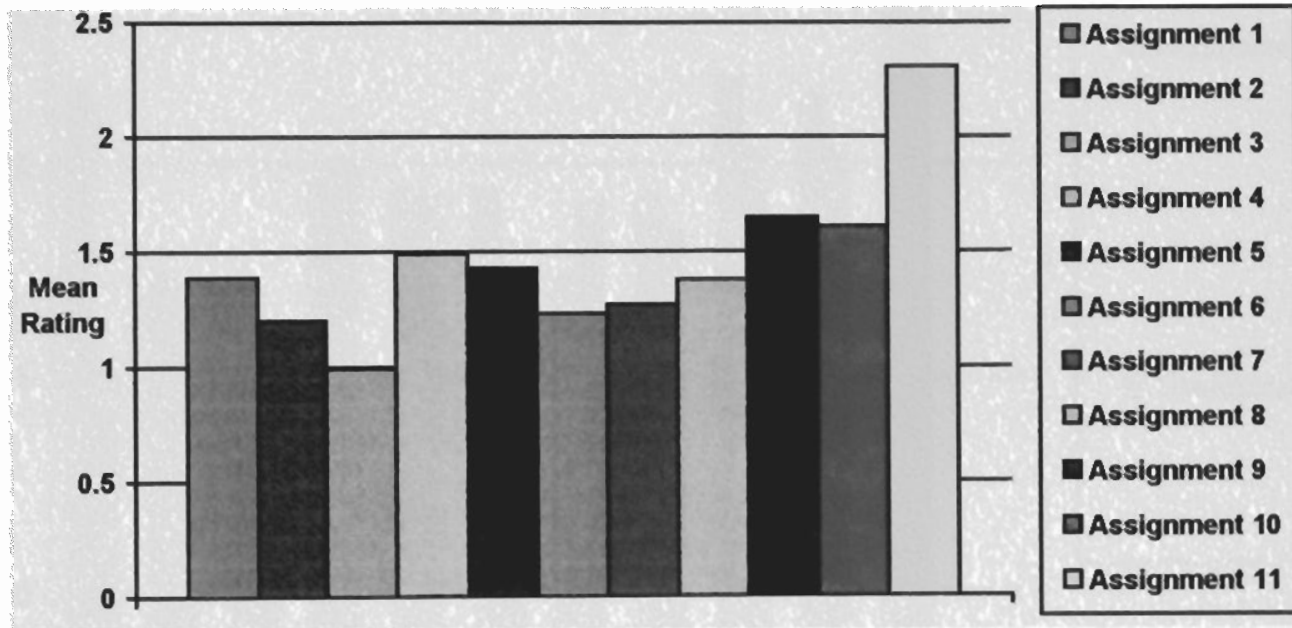

Studio Homework Assignments

Figure 1. Mean cultural evidence scores by art assignment.

If one looks at how treatment affects the mean cultural evidence score of the individual art assignments (see Figure 2) one can see that for seven of the 11 assignments $(1,2,3,6,8,9$, and 10) the experimental group had higher mean cultural evidence scores. An interesting thing to note when the 
experimental and control groups are split by teacher, is that teacher 1(despite having overall lower mean scores on the attitudinal questionnaire than teacher 2) had higher mean evidence scores in the experimental group on six of the 11 assignments (see Table 7).

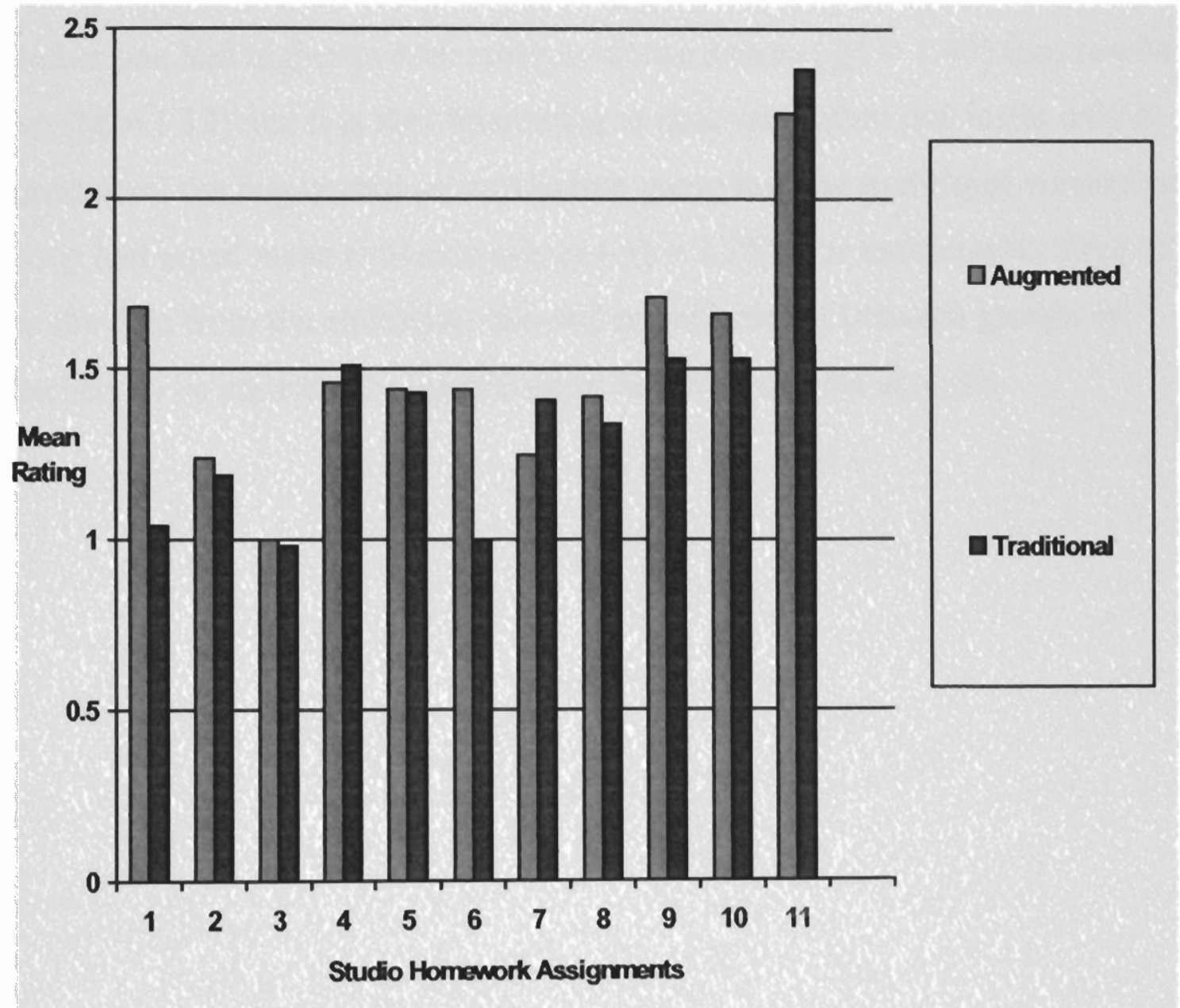

Figure 2. Cultural evidence score by treatment. 
Analysis of variance $(\alpha=.05)$ done on individual assignments also showed that for assignment one there was both a significant teacher effect, $\underline{F}(1,30)=14.14, \underline{p}<.05$, and curriculum effect, $\underline{F}(1,30)=48.59, \underline{p}<.05$ as well as a significant teacher/curriculum interaction, $\underline{F}(1,30)=8.09, \underline{p}<.05$. For assignment two analysis of variance showed a significant teacher effect, $\underline{F}(1,32)=8.04, \underline{p}<.05$. It is of interest to note that for assignment two teacher one had higher overall mean evidence scores $(\underline{M}=1.40)$ than teacher two $(\underline{M}=1.13)$ and it is also interesting to note that, when one looks only at curriculum, the augmented art curriculum group and the traditional curriculum group had equal mean evidence scores $(\underline{\mathrm{M}}=1.25)$. For assignments three to ten the data from the checklists showed no differences between groups or teachers to be statistically significant in Scheffé post hoc analysis. 
Table 7

Means, Standard Deviations, and ns For Assignment by Teacher by Group

Assignment

Teacher 1

Augmented Traditional
Teacher 2

Augmented Traditional

1

$\underline{\mathrm{M}}$

1.98

1.10

1.38

1.00

$\underline{\mathrm{SD}}$

$\underline{\mathrm{n}}$

.16

.31

.55

.00

10

5

8

9

2

$\underline{\mathrm{M}}$

1.36

1.48

1.15

1.10

$\underline{\mathrm{SD}}$

.54

.51

.58

.40

n

9

5

10

7

3

$\underline{\mathrm{M}}$

1.00

1.00

1.00

.97

$\underline{\mathrm{SD}}$

.00

.00

.00

.17

$\underline{n}$

9

5

9

8

4

M

SD

$\underline{\mathrm{n}}$

1.43

1.43

1.50

1.53

.55

.50

.59

.57

10

7

11

6 
Table 7 continued

Means, Standard Deviations, and ns for Assignment by Teacher by Group

Assignment

Teacher 1

Augmented Traditional
Teacher 2

Augmented Traditional

5

$\underline{\mathrm{M}}$

1.48

1.56

1.39

1.32

$\underline{\mathrm{SD}}$

.51

.61

.69

.81

$\underline{\mathrm{n}}$

7

9

8

10

6

M

1.20

1.00

1.39

1.00

$\underline{\mathrm{SD}}$

.45

.00

.55

.00

$\underline{\mathrm{n}}$

1

5

10

4

7

M

1.25

2.00

1.57

1.00

SD

.00

.00

.68

.41

$\underline{\mathrm{n}}$

1

1

7

3

8

M

1.50

1.27

1.36

1.39

$\underline{\mathrm{SD}}$

.67

.47

.66

69

$\underline{n}$

5

4

9

7 
Table 7 continued

Means, Standard Deviations, and ns for Assignment by Teacher by Group

$\begin{array}{lll}\text { Assignment } & \text { Teacher } 1 & \text { Teacher } 2\end{array}$

Augmented Traditional Augmented Traditional

9

$\underline{\mathrm{M}}$

1.59

1.43

1.86

1.63

$\underline{\mathrm{SD}}$

.80

.69

.57

.59

$\underline{\mathrm{n}}$

10

7

12

10

10

$\underline{\mathrm{M}}$

1.78

1.52

1.54

1.55

SD

1.19

1.12

1.13

1.01

$\underline{\mathrm{n}}$

15

7

12

10

11

$\underline{\mathrm{M}}$

2.43

2.34

2.07

2.42

$\underline{\mathrm{SD}}$

.68

.79

.93

.81

$\underline{\mathrm{n}}$

12

14

11

9

A Scheffé test (see Table 8) done for assignment 1 showed that for teacher two the control group was significantly different from the experimental group, for teacher one the control group was significantly 
different from the experimental group, and that the experimental group of teacher two was significantly different from the experimental group of teacher one.

Table 8

Scheffé Test Showing Pairs of Groups Significantly Different at the .05 Level

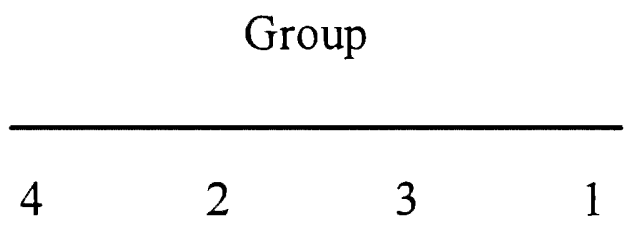

Mean $\quad$ Group

$1.00 \quad 4$

$1.08 \quad 2$

$1.38 \quad 3$

1.98

$3 \quad *$

Note. The groups in the table are identified as follows: group 1 is teacher one experimental, group 2 is teacher one control, group 3 is teacher two experimental, and group 4 is teacher two control.

$* \underline{p}<.05$.

The data were also examined to see how much agreement there was between raters on the individual rating given to student art work. Analysis of variance $(\alpha=.05)$ was used as a test of significance since there were more than two raters, and it showed that there was a significant difference between 
raters, $\underline{F}(3,183)=6.13, \underline{p}<.05$. Despite the fact that the identically scripted instructions were used in the training sessions for the raters and that all raters had equal access to art visual aids and lesson plans, rater four was significantly different from the other three. When the mean rating per assignment of each rater was placed on a multiple line graph, it was easier to see where the differences were (see Figure 3).

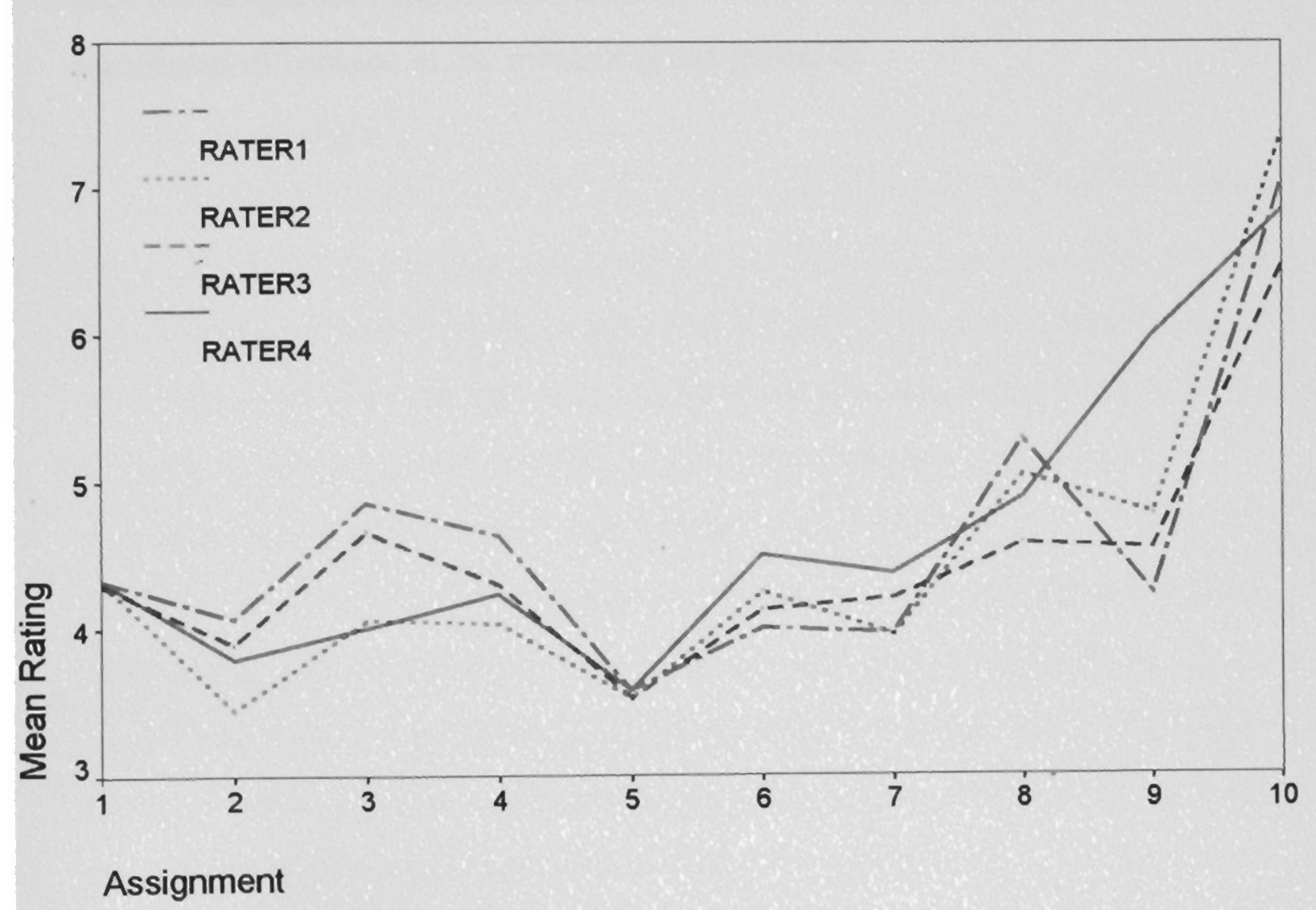

Figure 3. Comparison of Rater Means For Each Assignment 
In summary, it can be said that using ANOVA to test for a statistically significant difference between groups on the attitudinal questionnaire after treatment it was found, that the data did not support hypothesis one. Students exposed to the augmented curriculum did not have more positive attitudes toward art. It can also be said that unexpectedly teacher emerged as a significant effect when looking at the results of the attitudinal questionnaire data in this study. Also, that running individual ANOVAs on the checklist data for each assignment yielded a statistically significant treatment effect only for assignment one, and a teacher effect for assignment two, with no significant difference in the remaining assignments. 


\section{Chapter 5}

\section{Discussion}

In the previous chapter the data and the results of the statistical analysis performed on it were presented. There was no attempt to try to explain why this study netted these particular results, or what some of the implications of these results could be for the curriculum. This chapter will attempt to address these issues in an effort to illuminate the issues this study deals with as fully as possible.

\section{$\underline{\text { Research Hypotheses }}$}

The posttest results on the attitudinal questionnaire data did not support the original hypothesis that high school art students exposed to an augmented art curriculum would have more positive attitudes toward diversity in art. They were still valuable since they did indicate the importance of teacher as a variable. Even though teachers were matched as closely as possible in education and teaching experience, teacher effect emerged as a variable that might make a difference in the results attained in a study designed along the lines of this one. Some of the reasons for the importance of teacher as a variable to consider are that, short of having the researcher teach all groups (which would of course introduce the possibility of researcher bias), it is not possible at all times to control for teaching style, interest level, or a teacher's ability to communicate their enthusiasm with a project to students no matter how closely they are matched on any number of readily identifiable variables.

When an experimental study is short in duration as this was (in an attempt to control for mortality) and the teachers participating essentially 
consider themselves novices in the treatment area (Alvarez, 1994), teacher training prior to implementing the treatment might also be very important. One of the areas that future researchers might want to examine is how adequate was the short training session (discussed in Chapter 3) provided to the teachers in this study. The results on the questionnaire data seem to suggest that for one teacher ( teacher two) these brief sessions were adequate. Since teacher one had good results with the control group (traditional art curriculum), perhaps more training, more background material, and more support from someone knowledgeable in the field during the time the treatment was being implemented would have been enough to make teacher one feel as comfortable with the new material as with the traditional material. If that had been achieved, perhaps the bridge between the traditional and the new could have been made for the students in teacher one's experimental group. As the results of the Scheffé test performed on the attitudinal questionnaire data indicate, with a teacher who is either well versed in the subject or is really interested in the new curriculum materials, or can communicate and make bridges between the old material and the new for the students (make the most of the advance organizer lesson), augmenting the art curriculum to include relevant references to diversity in art can help move students to more positive attitudes toward diversity in art.

The second hypothesis in this study was that students exposed to diversity in art through the augmented art curriculum would choose to incorporate elements of diversity in their own work. Performing and evaluating statistical analysis of this data proved to be more difficult than expected given the results attained on the attitudinal questionnaire data. The first and most vexing problem encountered was student non-participation 
which translated into missing data on the Checklist For Cultural References In Student Art. Of the 111 students who participated in this study only 62 turned in portfolios so that their art work could be evaluated for elements of diversity.

At the site where this study was conducted, a student's grade is broken down into four components -- test grades, written art history homework, studio homework (which is turned in every week in a portfolio or folder), and in-class studio assignments (which are turned in directly to the teacher upon completion). The grades students receive for each component are averaged to arrive at a final grade for each quarter.

Many students who appeared not to be interested in learning any art, but rather were just there to receive a passing grade for the state required fine arts credit, did just enough work to get by. Turning in a completed portfolio did not seem to be a priority for these students. For other students there were other concerns-- poor home environment, work, or just plain laziness. In fact, it is important to state here that of the 62 portfolios turned in, there were few that contained all 11 assignments. These incomplete data (62 out of 111 portfolios) and the many missing assignments in the portfolios that were turned in, required running analysis of variance on the mean cultural evidence score for each assignment, instead of being able to look at an overall assignment mean cultural evidence score for the experimental and control groups. One was able to see that for assignment one (with 34 of the 62 students doing assignment one) there was a significant difference. Also one could see that the mean cultural evidence scores were higher for the treatment group on seven of the 11 assignments. Perhaps if more students had turned in portfolios, or more portfolios contained all 11 assignments, one might have 
been better able to judge what kind of overall treatment effect there was. Instead one had to limit the discussion to individual assignments. It is interesting to note that even though it is not statistically significant, students can be inspired to use diversity in creating their own art as was shown by the students who when exposed to the augmented curriculum were able to make a synthesis of art elements and arrive at their own personal art statement in which evaluators could clearly see both traditional art elements and elements indicative of diversity (these are the works that the raters felt had both elements of traditional art and element indicative of diversity in art).

\section{Comments on Student and Teacher Performance}

When discussing student performance one looks first to see if they performed at all. Did they do the work that was required of them? How well did they do it? If they did not do the work -- why? It has already been mentioned that student non-participation was a problem in being able to adequately evaluate whether exposure to treatment made any difference in the art work in the experimental and control groups. In this experimental study how well students did their art work, if they were neat, expressive, or creative, was not an issue. The only thing required was that the student do the assignment well enough to be able to judge if there were elements indicative of diversity in the assignment or not (see Appendix D for samples of student art work). Answers about why students did not turn in their art work would require a separate study (perhaps a qualitative study allowing the individual students to voice their reasons to the researcher) to investigate all the issues that could possibly contribute to a student's non-compliance with the portfolio requirement. However those interested in portfolio assessment as 
part of the authentic assessment movement, might want to look at the implications of this study and what they say about portfolio assessment.

Another issue that bears discussing here, along with student performance, is the perceived difference of assignment 11 . What caused it to be so different from the others in this study? Why did students perform as they did when doing assignment 11 ? Assignment 11 did not seem to be very different from the other assignments at first glance. Students in the control class were shown a portrait of Edward VI by the German artist Hans Holbein. In the experimental class after seeing the Holbein portrait they were shown a portrait of Takami Senseki by Watanabe Kazan, a Japanese artist. Both the experimental and control classes received some instruction on the art of portraiture using the portraits by famous artists that they had been shown to illustrate the discussion. The students were then told that as a studio homework assignment for that week they were to create a portrait collage from portrait images available in newspapers or magazines. They were allowed to bring images that they liked from home or they could use images that had been photocopied by the teachers for their use from the magazines available in class. After the collage of portraits was assembled, students were to either use a wash of color or some drawn lines to unify the composition.

Most students chose to use the photocopied images available in class. This could be attributed to the fact that it was easier to use those (they did not have to look for any themselves or bring then from home) or to the fact that the black and white photocopied images lent themselves especially well to a collage that would later be either drawn on or receive a color wash. In any event since there was only one box containing photocopied images in both teacher's classrooms and since this box contained both traditional western 
portrait images and images of portraits from diverse cultures, students from both the experimental and control classes were able to use portrait images representing cultural diversity. Without the researcher's knowledge the photocopied images were not separated into two boxes -- one traditional western and another culturally diverse (so that only the experimental group would have access in the art class to culturally diverse art). Rather they were put together in one box. At first this might seem to be contraindicated by the questions this study seeks to answer, given that the control group had access to materials representative of diversity in art. Actually the control group students who chose culturally diverse images from the box had access to only the images, and not to the instruction, or visual stimulation in the form of the art history lessons available to the experimental group students. That students who had no formal instruction or introduction to culturally diverse portraiture would choose to use this diversity in their own portrait collage is in itself of interest. This might suggest that students are innately interested in other cultures and their visual images. Perhaps this also suggests that a curriculum augmented to include a variety of visual cultural images is of interest to students and that future researchers might achieve significant results (acceptance and use of diversity in art) if they allow enough time (assignment 11 was the last assignment) for students to become involved and comfortable with new curriculum matter.

The other thing that assignment 11 pointed to was the fact that the teachers themselves were interested enough in this assignment to go out find and then photocopy portrait images representative of a wide range of cultures. They were actively involved in the choosing of materials (photocopied images made available to students) and comfortable enough with visual images 
representing diversity that they perhaps unconsciously made them available to all students, not just to those in the augmented curriculum group.

This leads to a discussion of teacher performance. This study used two teachers, each teaching an experimental and a control group. Informal observation of teachers during the study revealed that they were both competent art teachers able to explain the art elements and concepts of the lesson at hand to their students. Observation of the experimental classes revealed that though teacher one covered all the new material adequately and used the same visual examples and student handouts as teacher two, this teacher seemed less at ease with the new material and did not dwell on it as much as on the traditional material.

During one of the early observation visits, teacher two asked if there was any additional background material that could be made available to help clarify and assist in giving a better grasp of the new material. This teacher also asked if in addition to the visual aids that were provided them, supplementary slides could be used. This suggested that this teacher was truly interested in the new curriculum and wanted to be able to provide as much help as possible to his students with the new material. In faimess to teacher one it should be mentioned that at the same time that this study was being conducted this teacher was also teaching another totally new class for the first time at the site. This required a lot of preparation time and the generating of new materials for the students of this new class. Perhaps it was too much to hope that this teacher could give equal time to both the new art class being introduced at the site and the temporary implementation of an augmented curriculum for one beginning art class. It is also important to mention that at some point (early on with assignments one and two) teacher one was able to 
get significant results as evidenced by student art work in the augmented curriculum group. However, one must be willing to consider that there will be teachers who regardless of the additional training offered and the validity of the new subject matter, cannot or will not accept changes in the curriculum that lead to cultural diversity.

A discussion of raters is necessary to shed some light on the ANOVA results that reported a significant difference between raters. The raters were trained separately (as was previously mentioned in Chapter 3) with rater one trained in the first session, raters two and three trained together in the second session, and rater four trained in a third session two weeks after the other raters. Some might attribute the difference between rater four and the other raters to the fact that he was unable to be trained with the other raters. However, rater one was also trained separately from the other raters. In fairness, it must be remembered that although rater one was also trained separately, she was trained first, and her session served as the model or script for the subsequent training. So perhaps, it would have made no difference that she was trained separately. The fact that rater four was an independent art expert, and not intimately involved with the subjects in this study, could not be considered the source of the difference in his rating of student works, since rater one was also an independent art expert. One has to look elsewhere for an explanation to rater four's significant difference. Perhaps the personal problems that prevented him from attending the scheduled training in the first place were still a factor which preoccupied him during his involvement in the evaluation of student art work. There is a danger, however, of equating this significant difference of rater four's ratings with unacceptable rating. It could, in fact, be that rater four was the most conscientious rater and that as an 
independent art expert with no knowledge of the students in the study, their art ability and their personal problems, he was able to render the most honest evaluation. 


\section{Chapter 6}

Conclusions

The results of this study indicate that providing new curriculum material even if it is innovative, timely, and interesting is not as important as having a teacher who is open to, and embraces, the idea of diversity in the art curriculum. In this study, teacher, was more important than curriculum, in effecting change in student attitude toward diversity in art. Regardless of how great any new curriculum is, if the material is not presented to the students by teachers who themselves are open to the material, in the way that students can best use and understand it, then the new material will have no impact. Research on the importance of the teacher variable will add substantially not only to art education, but also to the area of curriculum and instruction.

Another unexpected finding in this study was the ineffectiveness of portfolios as an assessment tool for evaluating evidence of cultural diversity in student art work. Clearly for the group of students in this study, it would seem that unless there was some punitive repercussion linked to not turning in a portfolio ( thus defeating the essence of the true portfolio process which involves choice on the part of the student), students did not willingly participate in the portfolio process. Was this because these students were not really "art" students but just students required to take an art credit for graduation, or was it just the nature of students in today's classrooms? If it was neither one of these, one has to look directly at portfolios as a means of assessment, and see how valuable a tool they are for evaluating any given curriculum's effectiveness, or indeed any individual student's progress in light 
of results like these from an experimental study utilizing portfolios as an assessment tool.

The last thing that must be mentioned is the lack of interest students in this study seemed to have for the art class. This lack of interest in art should be noted by those who state that art is the universal language and can be used to communicate any number of subject matters in an inter-disciplinary curriculum. Those wishing to integrate the visual arts into a core curriculum in our nation's schools, point to art as an area where one can bring people together, since art has a symbol set that cuts across linguistic barriers and allows entry to any artist's production. Therefore, many art educators stress the importance of art as a discipline worth teaching in all our schools. Perhaps in the classes where art does succeed in totally involving students in meaningful learning, one should examine whether it is due to the subject being taught, or whether the important variable is the teacher, as was the case in this study.

\section{$\underline{\text { Recommendations }}$}

More research is necessary in the area of diversity in art, especially if it helps create a bridge between traditional western art forms and culturally diverse forms of art. Prior investigations in the field point to both teacher and student interest in the area. An interesting, if not statistically significant, item worth noting when thinking about future research, is the fact that quite a few students in this study moved beyond just using traditional visual elements or elements indicative of cultural diversity, to create a synthesis of the two elements and arrive at a visual statement that was unique to them but based on a wide range of visual symbols. The curricular implications for future 
research based of this might be to see if students remain on task longer and complete more homework or class assignments in art classes that are monocultural for the whole term (either all western European art, or all African art, or all Asian art) than they do in a class that offers a variety of cultures during the term with no emphasis on any specific culture.

Perhaps researchers would be interested in addressing how to more effectively motivate students in today's culturally diverse classrooms to encourage more active student participation. Research might also be helpful in the area of how to best present new materials to students -- Are books more helpful? Would it be better to use overhead transparencies? Should each student have a sheet with samples and instructions at his or her desk?

Certainly an area that would benefit from more research, as was found when creating the instruments for this study, is the area of evaluation in the art field. Portfolio evaluation seems to be one of the ways that art teachers believe one can assess individual student growth in art. Results of this study point to non-participation as a problem in portfolio evaluation. Researchers might wish to study whether more students turn in their work when they are made to do so weekly, as opposed to at the end of the quarter or the semester in a portfolio.

Teacher training in cross-cultural art is another area of research suggested by the results of this study. It would be interesting to study the difference in the results achieved by the students of teachers receiving preservice training in culturally diverse art forms (college courses that are an integral part of their teacher training) and the students of teachers receiving in-service training in culturally diverse art forms (on-the-job training in the 
form of day-long or week-end seminars) on measures like the attitudinal questionnaire used in this study.

Researchers wishing to replicate this study might wish to consider comments made by rater four. When commenting on the absence of work in student portfolios he suggested it might be interesting to repeat this study with a different student population -- gifted art students, advanced placement art students, or international baccalaureate art students since these are all populations that are used to having to produce a steady stream of work on a regular basis.

\section{$\underline{\text { Research Alternatives }}$}

The comment by rater four on the population used in this study raised several questions about the choices made when this study was designed.

\section{Was the right population selected to work with?}

The original intention in using beginning art students was to have as generic a population as possible with students from every ethnic and ability group represented -- random selection and assignment of students should provide for this. By using this supposedly generic population of students I hoped to be able to generalize the results of this study to other high school populations. Of course as with any study, many different populations could have been chosen -- ethnically diverse students only, language minority students only, or as rater four suggested, gifted students, advanced placement students, or international baccalaureate students. The results of this study with any of those special populations might certainly have been different. 
Were the proper things selected to measure?

The decision to measure both attitude toward diversity in art (with a questionnaire that could be measured objectively and quantitatively) and evidence of diversity in a student's art (which is necessarily a more subjective area to measure) left many other areas of interest untouched. Time on task and assignment completion rates would perhaps have been alternate variables that could have been used to measure treatment effect.

\section{Was enough done when designing the treatment?}

Surely there might be others in the field of art education who will suggest that accepting the curriculum used at the study site as is, and merely adding some art exemplars representative of diverse art producing cultures, did not go far enough. Perhaps a more radical treatment could have been designed where the experimental group received intensive instruction in only culturally diverse art while the control group received only traditional western European art instruction. This intensive curriculum would have been a radical departure from the norm at the site. It would have required intensive training of the participating teachers and a much wider variety of special materials (books, student handouts, as well as visual aids) to be used in implementing the treatment. The time available and the financial limitations of this study would not have allowed for this. I hope this study will be judged for what it was able to say about the difference between students after exposure to culturally diverse art (that in the hands of the right teacher treatment did make a difference) rather than on its limitations. 
To what extent are the results of this study limited to high school art students in South Florida?

Certainly one cannot generalize and say that what was true for one study group population in Broward County, Florida will be true for high school art students across the nation, any more than one can say it is so for all of Florida. South Florida is perhaps unique in that it possesses a rich mix of cultures that is not represented in the rest of the population of the state. Of course student populations in other locations would perhaps be more homogeneous. All of this could lead to quite different results if this study were replicated exactly somewhere else. It was never the intent of this study to prove one curriculum better than another or generalize across the board that treatment would make the difference in student's attitudes and art. All that can be said is what happened with this population of students. It remains for other researchers to see how much they can generalize these results when similar studies are conducted with other populations. 


\section{References}

Agard, N. (1981) . Art as a medium for counteracting stereotypes. Interracial books for children: Bulletin, 11 (ㅁ) , 3-5.

Alvarez, A . (1994) . Multicultural art education: Current practice in Broward county schools and perspectives of teachers and students. Unpublished manuscript.

Amdur, D. (1993) . Arts and cultural context a curriculum integrating discipline based art education with other humanities subjects at the secondary level. Art Education, 46 (3), 12-19.

Armstrong, C. (1990). Teaching art in a multicultural/multiethnic society. In B. Young (Ed.), Art, culture, and ethnicity (pp. 97-113) . Reston:

National Art Education Association.

Ausubel, D. P. (1963) . The psychology of meaningful verbal learning. New York: Grune and Stratton .

Ausubel, D. P. (1968) . Educational psychology: A cognitive view. New

York: Holt, Rinehart, \& Winston .

Ausubel, D. P. (1978) . In defense of advance organizers: A reply to the critics. Review of Educational Research, 48, 251-258 .

Ausubel, D. P., and Youssef, M. (1963) . Role of discriminability in meaningful parallel learning. Journal of Educational Psychology, 54, 331336.

Bersson, R. (1981) . Cultural democracy in art education: Elitism rebutted. Art Education, 34 (6), 35.

Bersson, R. (1986) . Why art education lacks social relevance: A contextual analysis. Art Education, (4) , 41-45. 
Bersson, R. (1987) . Why art education is neither socially relevant nor culturally democratic: A contextual analysis . In D. Blandy and $\mathrm{K}$. Congdon (Eds.), Art in a democracy. New York: Columbia Teacher's College Press, 78-90 .

Blandy, D. and Congdon, K. (1987). Art in a democracy. New York:

Columbia Teacher's College Press .

Broudy, H. (1972) . Enlightened cherishing: An essay on aesthetic education.

Urbana: University of Illinois Press.

Capetta, A. (1993) . Change: An opportunity for self-renewal . Briefing Paper Series Fall 1993, Reston: National Art Education Association.

Clifford, J. (1988) . The predicament of culture: Twentieth century ethnography literature, and art . Cambridge Harvard University Press . Corkill, A . J . (1992) . Advance organizers: Facilitators of recall .

Educational Psychology Review , 4 , 33-67.

Cronbach, L. (1951). Coefficient alpha and the internal structure of tests.

Psychometrika, 16 , 297-334.

Dilger, S . C. (1994) . Developing policy and programs for multicultural art education: Curriculum and instruction responsive to cultural diversity . Art Education, $\underline{47}(4), 49-53$.

Dufrene, P. (1994) . A response to Mary Erickson: It is time to redefine "Western" and "Non-Western" Art or when did Egypt geographically shift to Europe and Native Americans become "Non-Western". Studies in Art Education, 35 (4) , 252-253.

Eisner, E. (1985) . Why art in education and why art education? Beyond creating: the place for art in America's schools. The Getty Center for Education in the Arts. 
Feldman, E . B . (1973). The teacher as model critic . Journal of Aesthetic Education, 7 (1) , 50-57.

Feldman, E . B . (1992) . Varieties of visual experience . New York: Harry

N. Abrams . 261-266.

Florida Department of Education. (1994). Florida School Report 1992-1993.

Tallahassee, Florida.

Freedman, K. (1994). Interpreting gender and visual culture in art classrooms.

Studies in Art Education, 35 (3), 157-170.

Galbraith, L . (1992/93) . Crossing cultural boundaries: Case studies,

reflective inquiry, and a common language in the preservice classroom.

Journal of Multicultural and Cross-Cultural Research in Art Education, 10/11, 89-99.

Greene, M. (1981) . Aesthetic literacy . In R. A. Smith and A. Simpson (eds.), Aesthetics and arts education (pp. 149-161). Urbana: University of Illinois Press .

Greene, M . (1993). The passions of pluralism multiculturalism and the expanding community . Educational Researcher, 22 (1) , 13-19.

Glover, J . A., Bullock, R. G . \& Dietzer. M . L . (1990) . Advance organizers: Delay hypotheses. Journal of Educational Psychology, $\underline{82}$, 291-297.

Hart, L . M. (1991). Aesthetic pluralism and multicultural art education . Studies in Art Education, 32 (2) , 145-159 .

Hart, L. M . (1992/93) . The role of cultural context in multicultural aesthetics . Journal of Multicultural and Cross-Cultural Research in Art Education $, \underline{10 / 11}, 5-19$. 
Hicks, L . (1992/93). Designing nature: A process of cultural interpretation . Journal of Multicultural and Cross-Cultural Research in Art Education, $\underline{10 / 11}, 73-88$.

Janson, H. W., \& Janson, D. J. (1969) . History of art: A survey of the major visual arts from the dawn of history to the present day. Prentice-Hall, Inc.

New Jersey \& Harry N. Abrams, New York.

Kellman, J . (1992/93). Thread between worlds: Multiculturalism in a

Guatemalan school. Journal of Multicultural and Cross-Cultural

Research in Art Education, 10/11, 101-109.

Lanier, V . (1976). The unseeing eye: Critical consciousness and the teaching of art. In E. W. Eisner (Ed.), The arts, human development and education, (pp. 19-29). Berkeley, CA: McCutchan.

Lanier, V. (1983). Beyond aesthetic education. Studies in Art Education, $\underline{36}$ (6), $31-37$.

Lankford, E . L. (1992) . Aesthetics: Issues and inquiry . Reston: National Art Education Association .

Mayer, R . E . (1984) . Twenty years of research on advance organizers .

Instructional Science, $\underline{8}, 133-169$.

Newman, A. (1970). Promoting intercultural understanding through art . Art Education, 23 (1), $18-20$.

Neperud, R. W . and Stuhr, P . L . (1993) . Cross-cultural valuing of

Wisconsin Indian art by Indians and non-Indians . Studies in Art

Education, $\underline{34}$ (4), 244-253.

Preble, D., \& Preble, S. (1989). Artforms (4th ed.) New York : Harper \& Row. 
Pressley, M., Wood, E., Woloshyn, V.E., Martin, V., King, A., \& Menke, D. (1992). Encouraging mindful use of prior knowledge: attempting to construct explanatory answers facilitates learning. Educational Psychologist, 27, 91-109.

Sahasrabudhe, P . (1992). Multicultural art education: A proposal for curriculum content, structure and attitudinal understandings. Art Education $\underline{45}(3), 41-47$.

Smith, P. (1993). Wherever excellence is found . Briefing Paper Series Fall $\underline{1993}$, National Art Education Association .

Smith, R . (1981) . Elitism versus populism: A question of quality. Art Education, $3 \underline{4}$ (4) , 35-44.

Smith, R . (1982) . Elitism versus populism: The continuing debate. Journal of Aesthetic Education, 16 (1) , 5-10.

Smith, R . (1985) . A right to be the best: Or, once more, elitism versus populism in art education. Studies in Art Education, $\underline{26}(\underline{3}), 169-175$. 
Visual References

Chapman, L. H. (1992). A world of images teacher's edition. Worcester : Davis Publications.

Josserand, J. K. \& Hopkins, N. A. (1992). Maya hieroglyphic writing.

Tallahassee : Jaguar Tours. 
APPENDIX A

Instruments 


\section{Attitudes About Art}

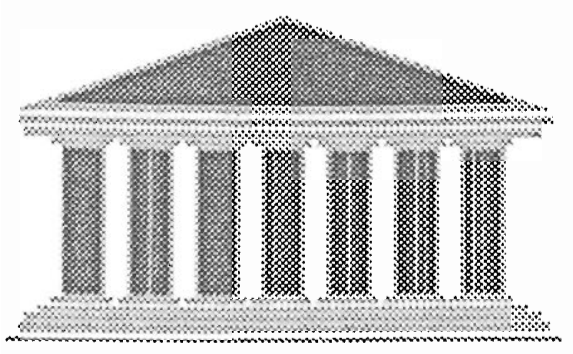

1. I would go to an exhibit of art from another country.

2. In my home, I would display art from different countries

3. I would visit an artist from another country.

4. I am inspired by the art of different cultures.

5. I would make art using designs from other cultures.

6. I would like to own African art.

7. I would buy American art.

8. I would study the art techniques of other cultures.

9. Studying the Art history of other cultures is interesting.

10. Even when created for useful purposes art on other cultures has artistic intent.
Bubble In The Answer

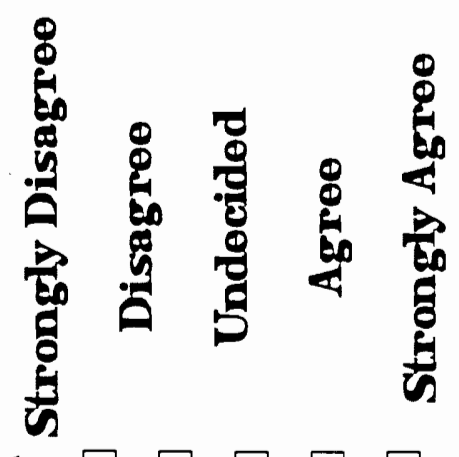

1 .

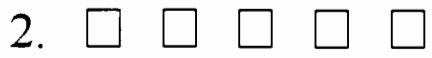

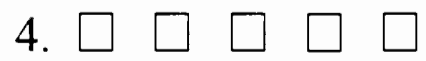

5. $\square \square \square \square \square$

6. $\square \square \square \square \square$

7. $\square \square \square \square \square$

8. $\square \square \square \square \square$

9. $\square \square \square \square \square$

10. $\square \square \square \square \square$ 
11. I would study Central

American art.

12. Native American designs are interesting.

13. Learning about the art of other cultures helps me understand those cultures.

14. Asian art is beautiful.

15. The art of South America is creative.

16. The art of other cultures should be included for study in high school art classes.

17. Learning about the art of other cultures helps me understand those cultures.

18. Studying the art of many cultures helps me see that cultures have elements in common.

19. Including culturally different art in my art has given me more choices when I make art.

20. I would like to learn more about the art of other cultures.

A1. Attitudinal Questionnaire
11. $\square \square \square \square \square$

12. $\square \square \square \square \square$

13. $\square \square \square \square \square$

14. $\square \square \square \square \square$

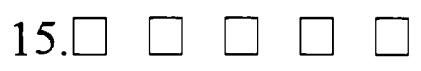

16. $\square \square \square \square \square$

17. $\square \square \square \square \square$

18. $\square \square \square \square \square$

19. $\square \square \square \square \square$

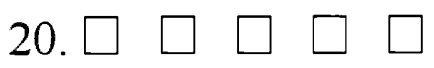




\section{Checklist of Cultural References in Student Art}
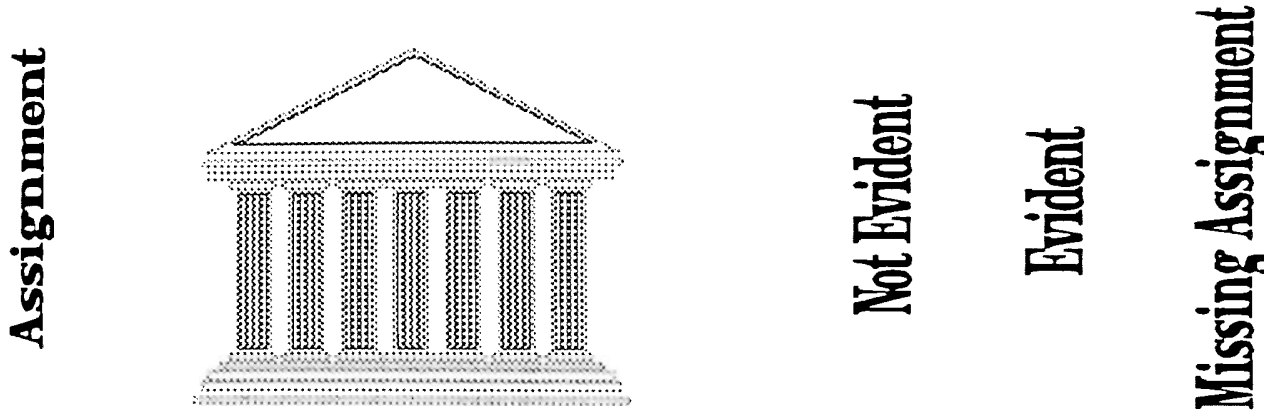

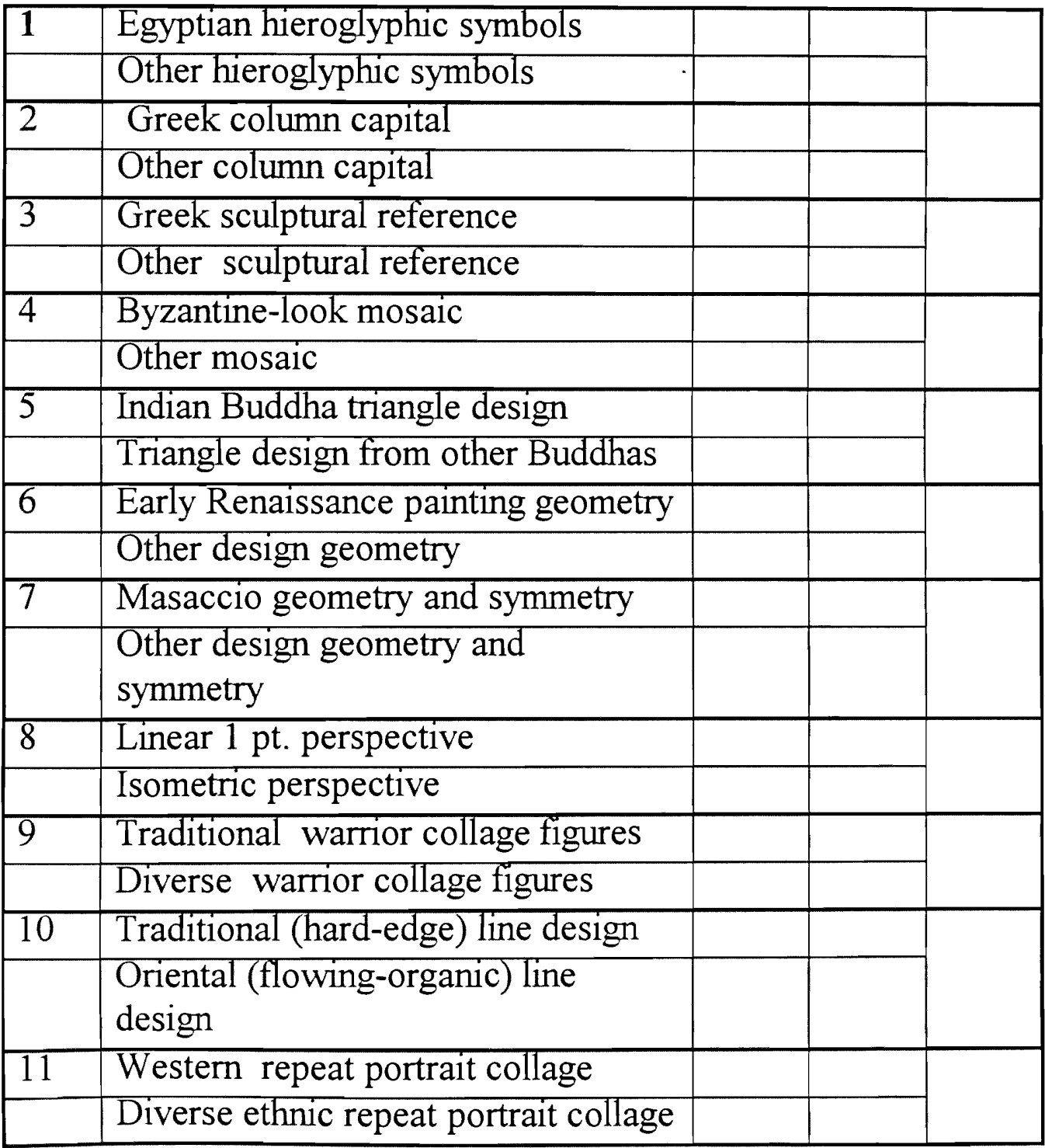

A2. Checklist of Cultural References in Student Art 
APPENDIX B

Sample Teacher Enrichment Materials and Visual Aids for Culturally Augmented Curriculum 


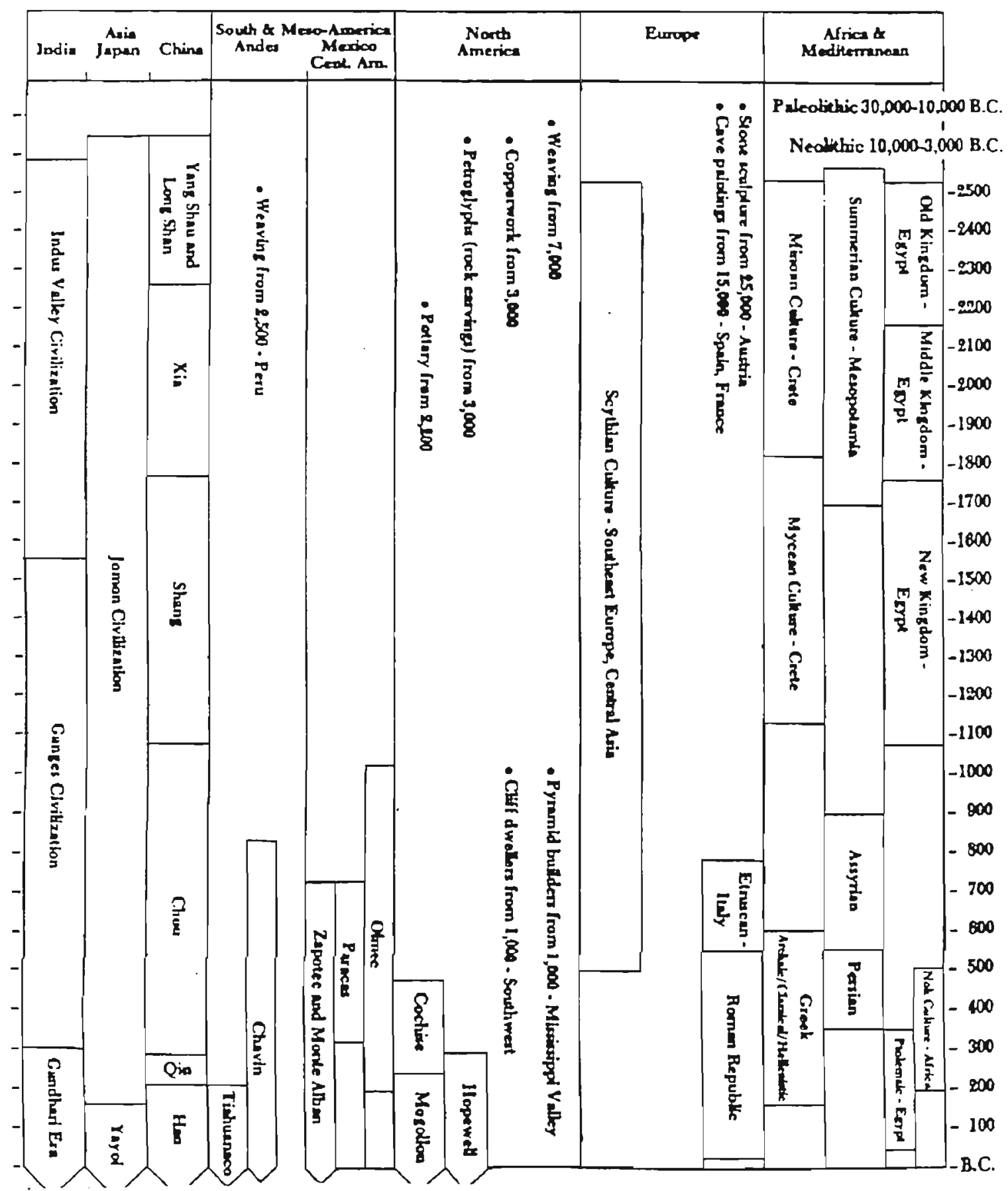

B1. Transparency master ${ }^{1}$.

${ }^{1}$ From A World of Images Teacher's Edition. by L. H. Chapman, 1992, Worcester: Davis Publications, Inc. Reprinted with permission. 


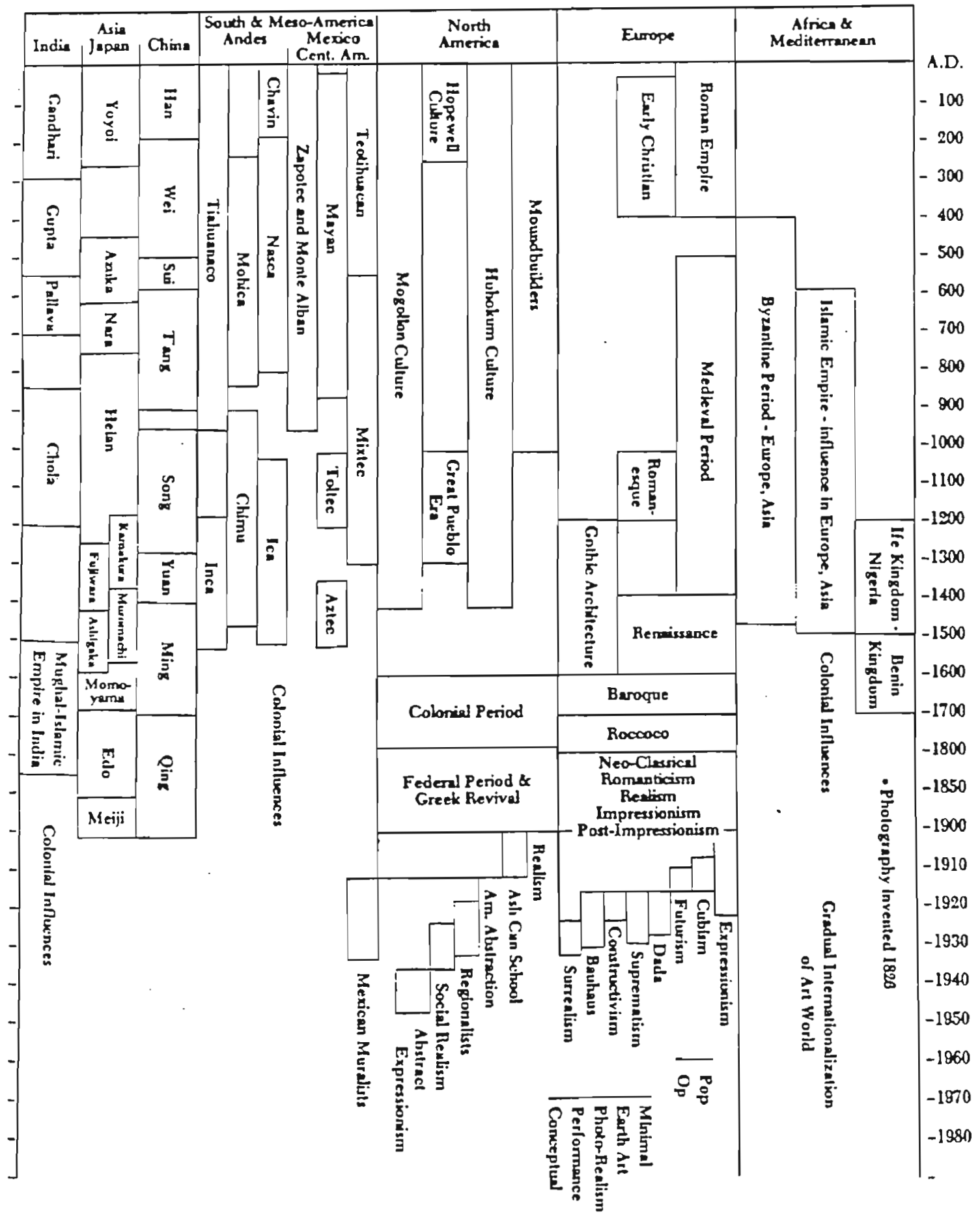

B2. Transparency master ${ }^{2}$.

${ }^{2}$ From A World of Images Teacher's Edition. By L. H. Chapman, 1992, Worcester: Davis Publications, Inc. Reprinted with permission. 


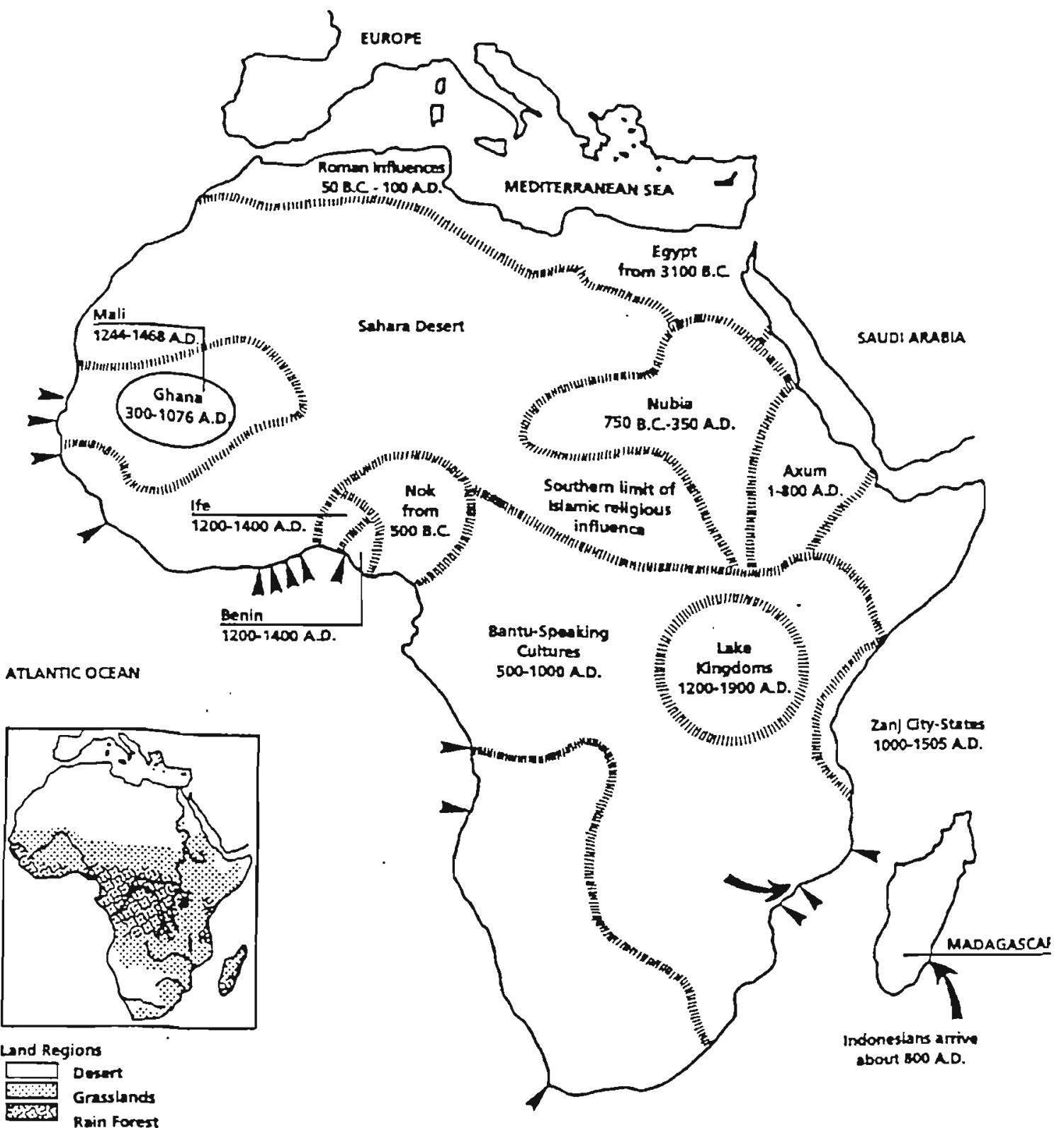

Art and Culture Map: African Art

WDLAN OCEAN

$2=$ Europen trading cemers atuer 1400

B3. Transparency master ${ }^{3}$.

${ }^{3}$ From A World of Images Teacher's Edition. by L. H. Chapman, 1992, Worcester: Davis Publications, Inc. Reprinted with permission. 


\section{Pre-Columbian and Native North American Art}

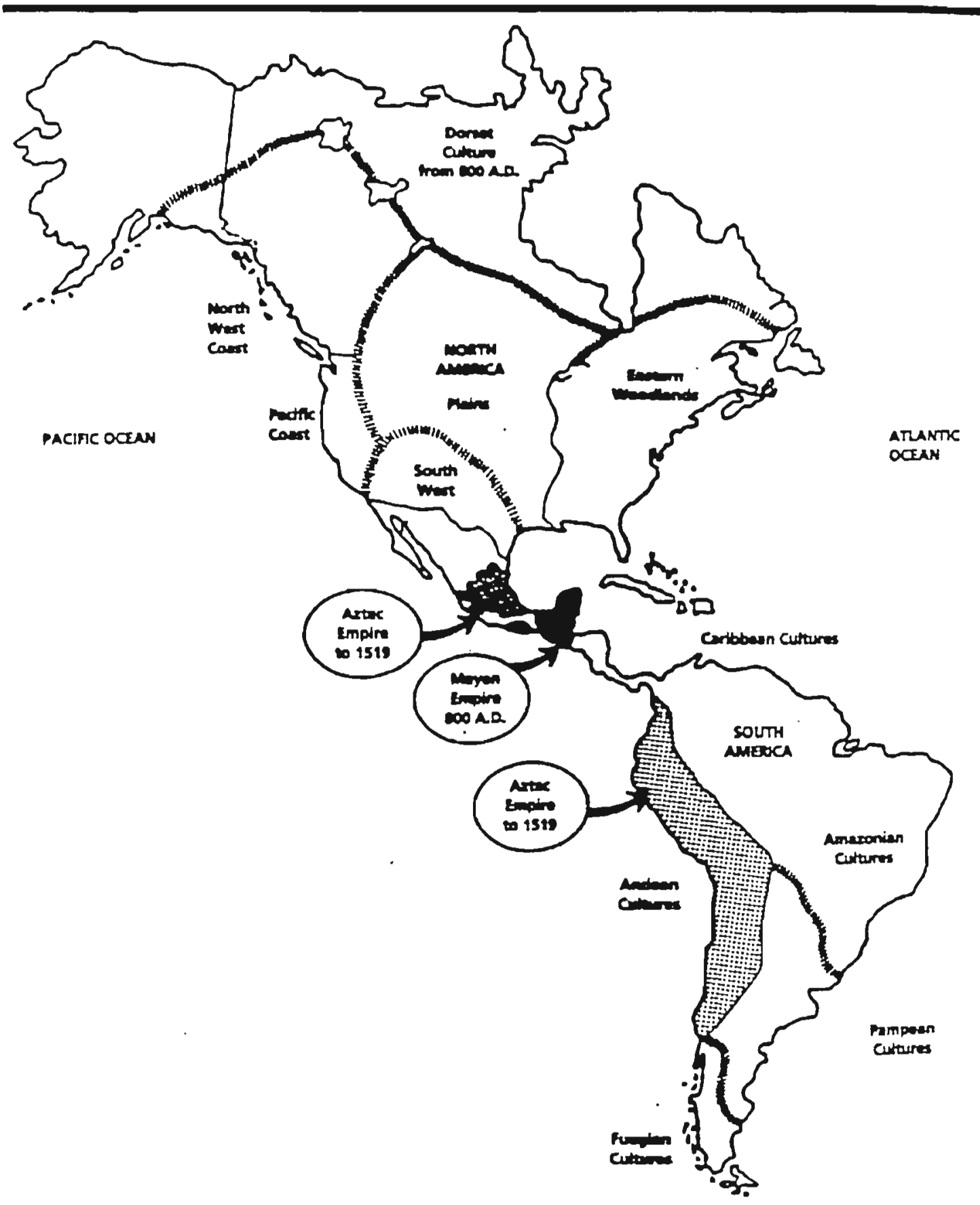

B4. Transparency master ${ }^{4}$.

${ }^{4}$ From A World of Images Teacher's Edition. By L. H. Chapman, 1992, Worcester: Davis Publications, Inc. Reprinted with permission. 


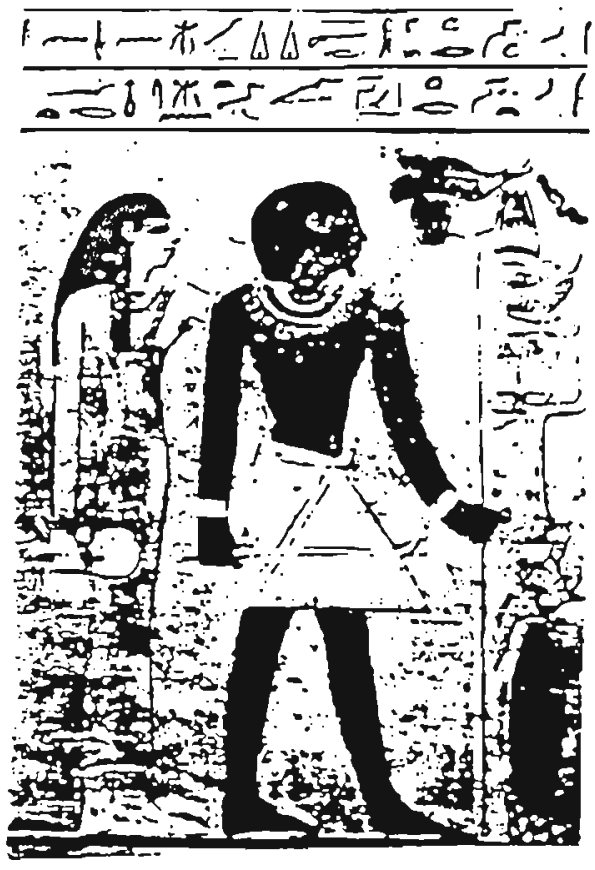

The art of the Egyptians begins in pre-history. It reflects the daily life, the beliefs, and the customs of the tribes who lived in the valley of the Nile and shared the common river life. At the beginning of the historic era, about 3100, when King Menes unired Upper and Lower Egypt and founded the I Dynasty, the Egrptians had already developed the picture writing of hierogiyph and the cursive form of these signs which we call "hieratic" Even from this eafly time, carvings in ivory show the keen observation of natural forms and a skill in reducing this to a scheme of decorative essentials which we associate with Egyptian art. The canons for figure drawing were laid down in these years and were dosely adhered 10 through succeeding centuries. In the time of the Middle Kingdom, which embraced, roughly, the XI-XII Dynasties and the years 2134-1786 B. C, a new naturalness and vigor appears. This "stela," a sepulchral slab commemorating Dedu and his wife, are from this period.

Dedu and Sit-Sobk are examples of the conventional figures which the Egyptian artists were trained to execute. The most characteristic aspects of the person are emphasized; the head in profile, but the eye from front view; the corso from the front, and the legs and feet again in profile. This causes the body to appear fiat, but to the Egyptian it expressed the power of the body better than the incomplete view of it which the eye nomally picks up. Nothing in this picture, or in any Egyptian painting is haphazard. A sense of order was so strong in the Egyp-

\section{DEDU AND HIS WIFE, SIT-SOBK (DAY dOo, ST so bik)}

(2134-1001 B.C.) Painted Limestone Stela AET07

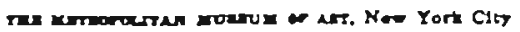

tian artist that amy reanangement would upset the painting entirely. The work was begum by drawing an outline and then engraving with fine incisions on quality limestone Painting was added to heighten the effect and add 2 realistic note.

Color was supposed to endow the figures with a magical life, for it was believed to be as vital to etemal, as it was to earthly, life. According to the canon, men's skin was painted a red-ochre, women's a light or pinkish yellow. The goddess Hathor was the exception to this, for according to law, her skin was as dark as a man's. Green was the symbol of death. The red and yellow colors were obtained from natural desert ochres; the white from chalk or lime Blues and greens were extracted from calcined mixtures; a cobalt base for blue and a copper base for green.

Egyptian art, as you know, was produced in honor of dead rulers and other imporant people of those far-distant times. The impressive legacy of pyramids, vast tombs and temples, of sculpture, paintings, and superbly craited objects are among the richest of our cultural heriuge. Most of what we have of Egyptian art comes from the grave, long the province of the archeologist. It is an interesting commentary of this remarkable people that none of it shows amy preoccupation with the morbid aspeces of death, but manifests the cheerful, industrious and plentiful life prized by these people and which they hoped to enjoy forever.

\section{B5. Handout created by the teachers in this study and regularly given to students at the site. This handout was used with lesson one.}




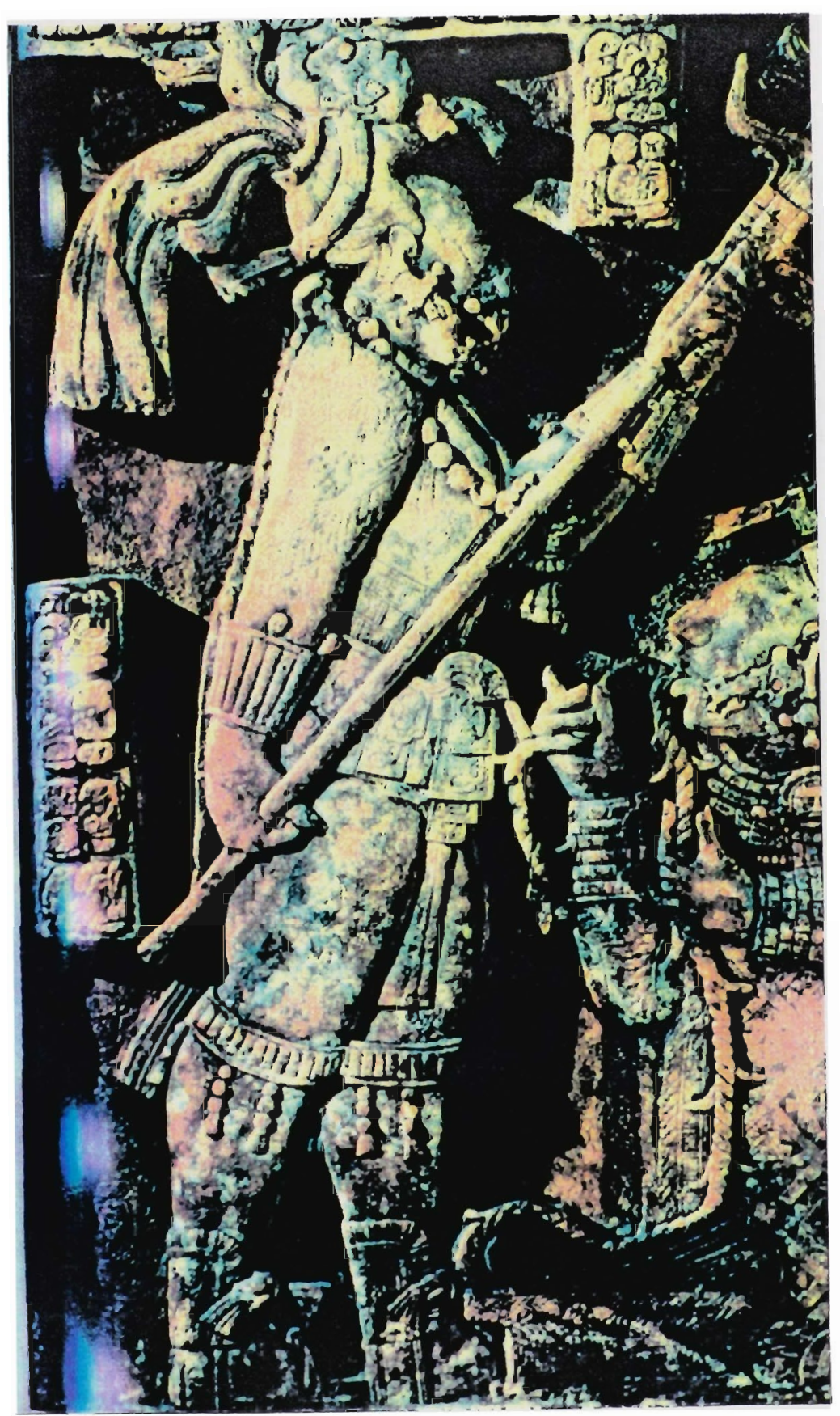

B6. Transparency created as a visual aid and depicting Maya art and glyphs. This visual aid was provided to the experimental classes for lesson one. 


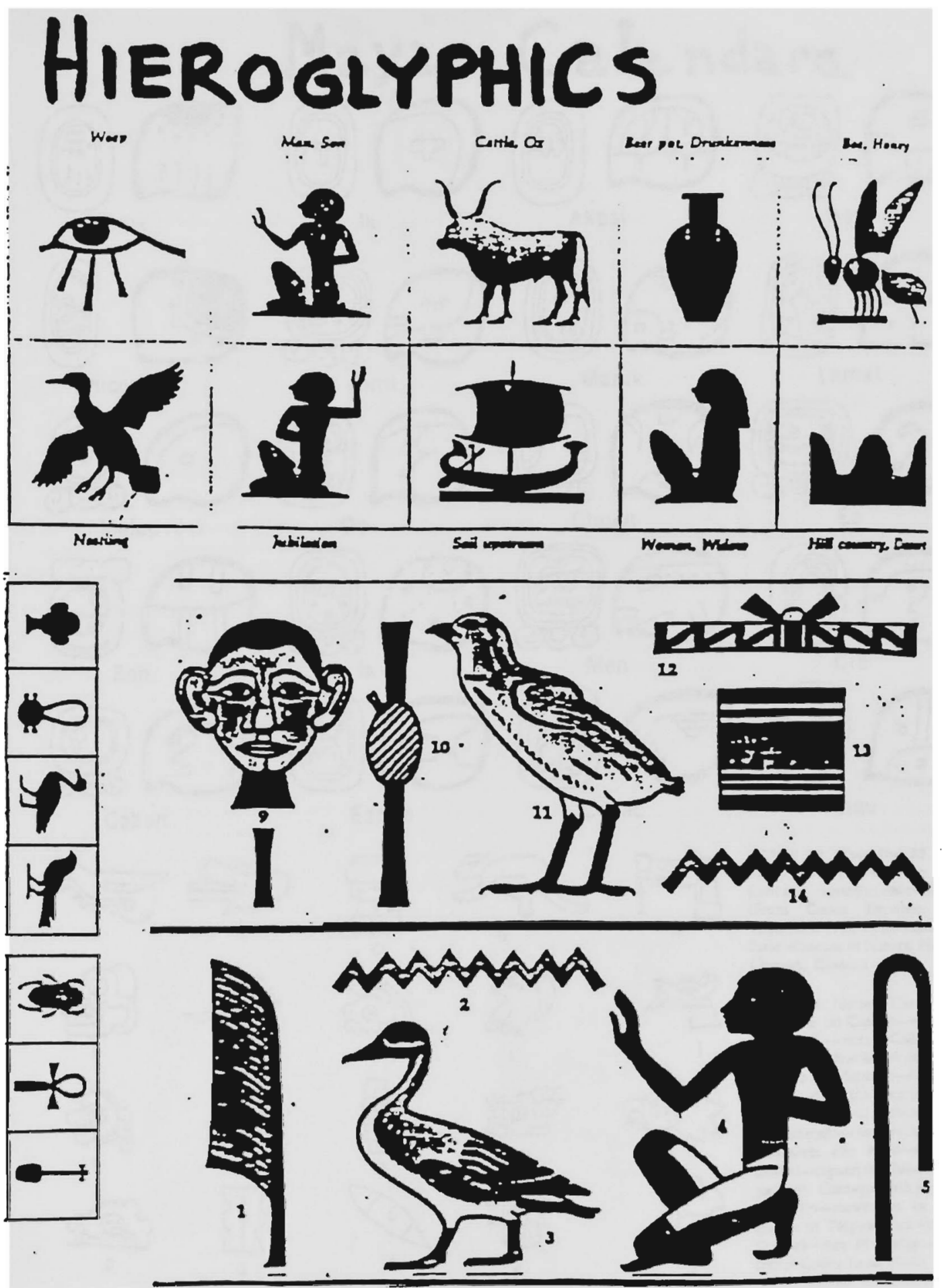

B7. Handout created by teachers at the site of this study and traditionally provided to students with lesson on hieroglyphics. 


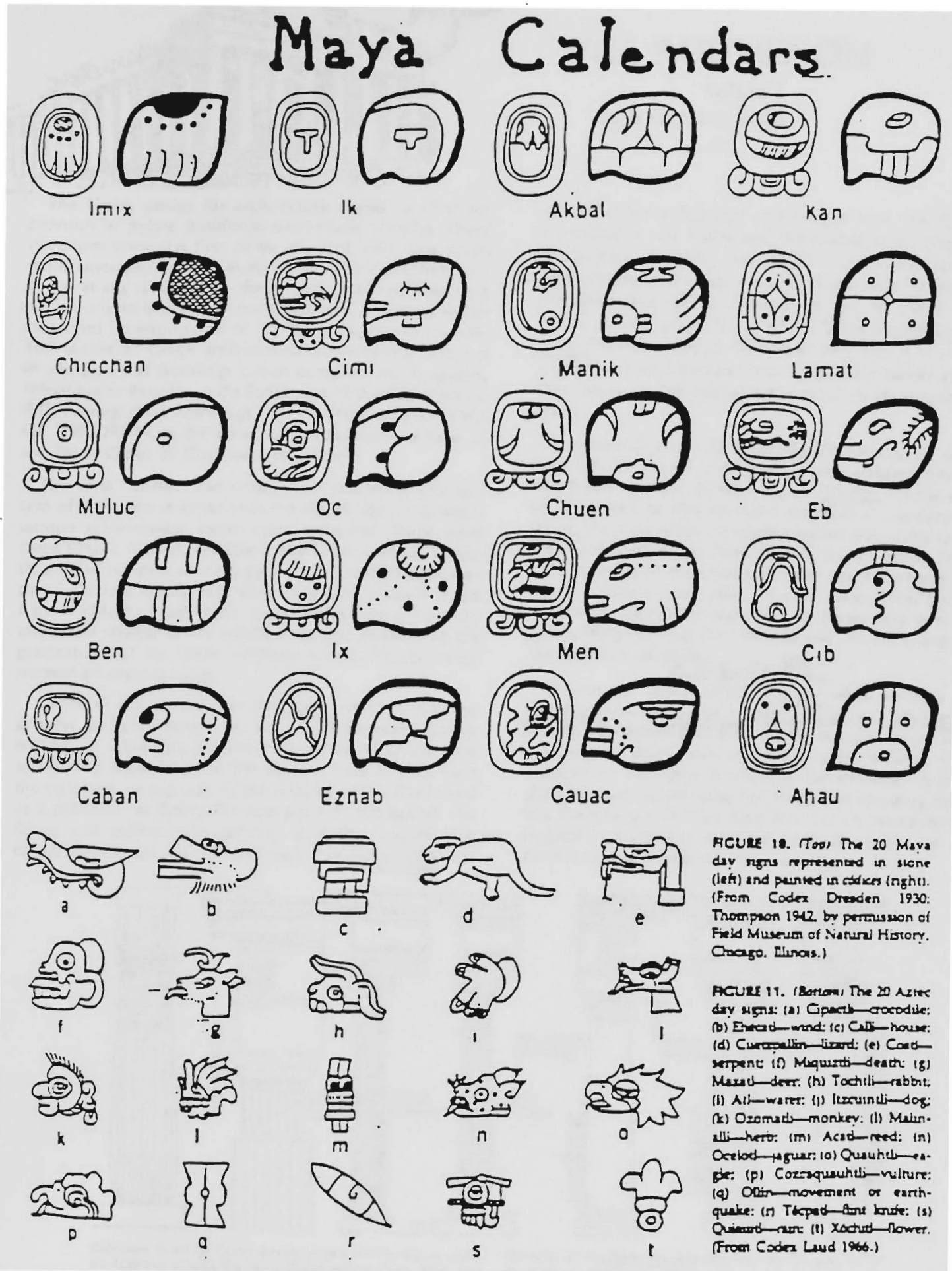

B8. Handout provided to students in the experimental group for lesson ones. sFrom Maya Hieroglyphic Writing. by J. K. Josserand and N. A. Hopkins, 1992, Tallahassee : Jaguar Tours. Adapted with permission. 


\section{THE PARTHENON}

GREECE

(5th Century B.C.)

The Creck genius for apchirecture iound its shrei ex. pression in public buildings. uarticularly temples. These structures were the first to be plunnod with their visual impurtance kepl dezily in mind. When viewed irom any angie. at any lime of day. these magnificent edifices wese cnciunting to behold: all purts balanced in a unity which conveyed an impression of susene strengsh and majesty. The climax of Creek archilcctural achievement is found in live group of buildings which comprise the Acropolis. rchult under Pericles in the lantip part of the Firith Century B.C. Among these buildings THE PARTHENON, or HALL OF THE VIRGIN, is the most periccl cxample we have of the Doric Order of Classical architecture.

The resm "Order" has never heen applied to any sys. tem of architecture other than the Crestx. for theirs was a unique achievement neyer agan sepealed. There were three Classic Orders. the Doric. the lonic, and the Corin. thisn. The temples of esch group were immediately recognizable as a lamily. and ivere so named because of the nipe or column used in the construction. The column. so intimately selated to the whole structure. detcrmined the proportions of the other clements so that logether they lormed an organic unity.

Oldest of the Orders was the Durer which was in the prucess oi derelopment un the Crectx mainland before i 00 8.C. It is the simplest and most poneriul of the three lums. The fluled shast oi the culumn sises directly Iram the stylobate. or top step of the rempie. which also served as a plation, of noor. The two pares of the capital, the iharcl and cushion-like echinus, and ite squared bla called the abacus, were unadorned. The lonic Onder ap- peared about a hundred years later than the Done, tlourshing in Asia Minor and the islands oi the Aegean. Its column was higher, more slender. and its gencral im. pression was more delicale and feminine than the mascu. line Doric. The capital of the lonic column ended in a carved double spiral. About 420 B.C. the elegant Corin. thian Orter deyeloped from the lonic but if was nol whoery used until Roman times. Exquisitely carved acanthus leaves on the capilal are one of its distinguishing maiks.

The sanctuary of THE PARTHENON housed an eight fol siatue in ivory and gold of the goddess Athena which was the work of the seviplor. Phidias Phidias and his studenis had also execuled some of the sculpiured friez- which ran along the upper exterior wall of the cella. wnicn depicied scenes from the Parathenic games. They are not visible in our picture because one must siand in. side the outer row of pillars to view them. Oiner sculp. ture pieces were finely executed in the metope loant of the building between the columns and the root?. and in the pediment. or gable.

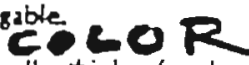

We do nos usustly think of color when we look at Greek lemples loday, bul orizmilv cring wse manidesed onte of me enemerts ol unily in the overall design. ine painting in which reds and blues predominaled. was conlined to the upper portions of the buildings so that the sculptures would stand out above the gleaming mar. ble. The beaciry of this building must indeed have seemed magical as it shone in splendor under the bright sun of Greece in that wanderiul ancient time.

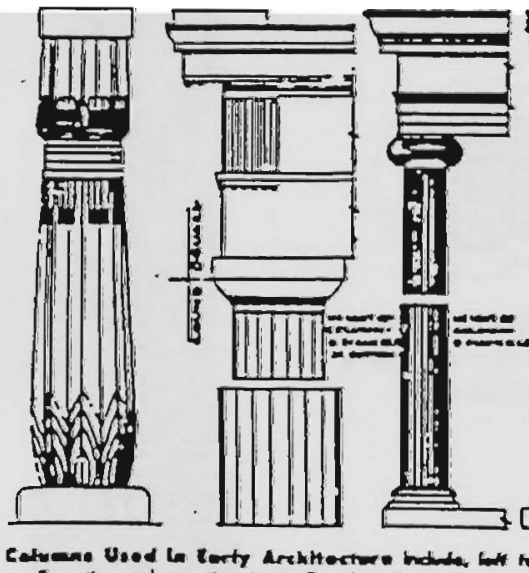

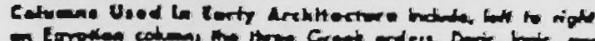

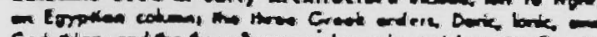

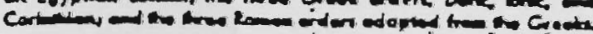

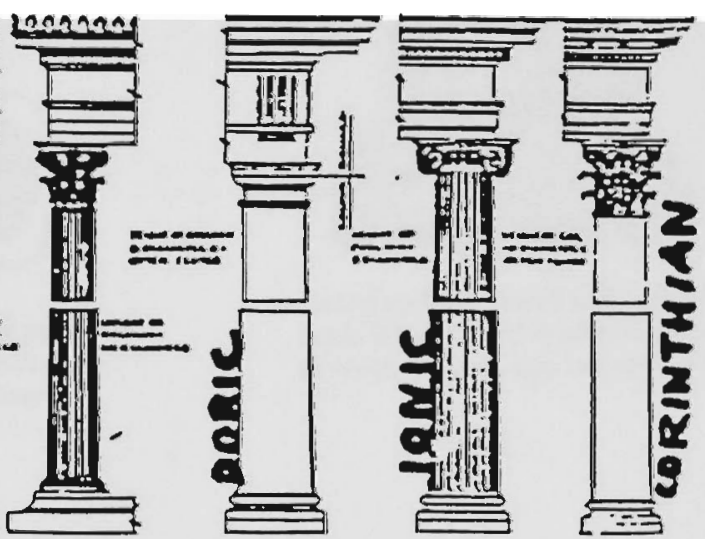

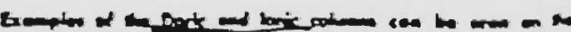

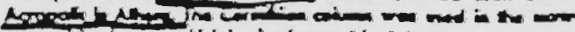

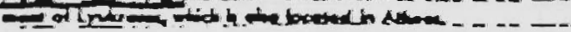

B9. Handout created by the teachers at the site and traditionally given to students with lesson two. 


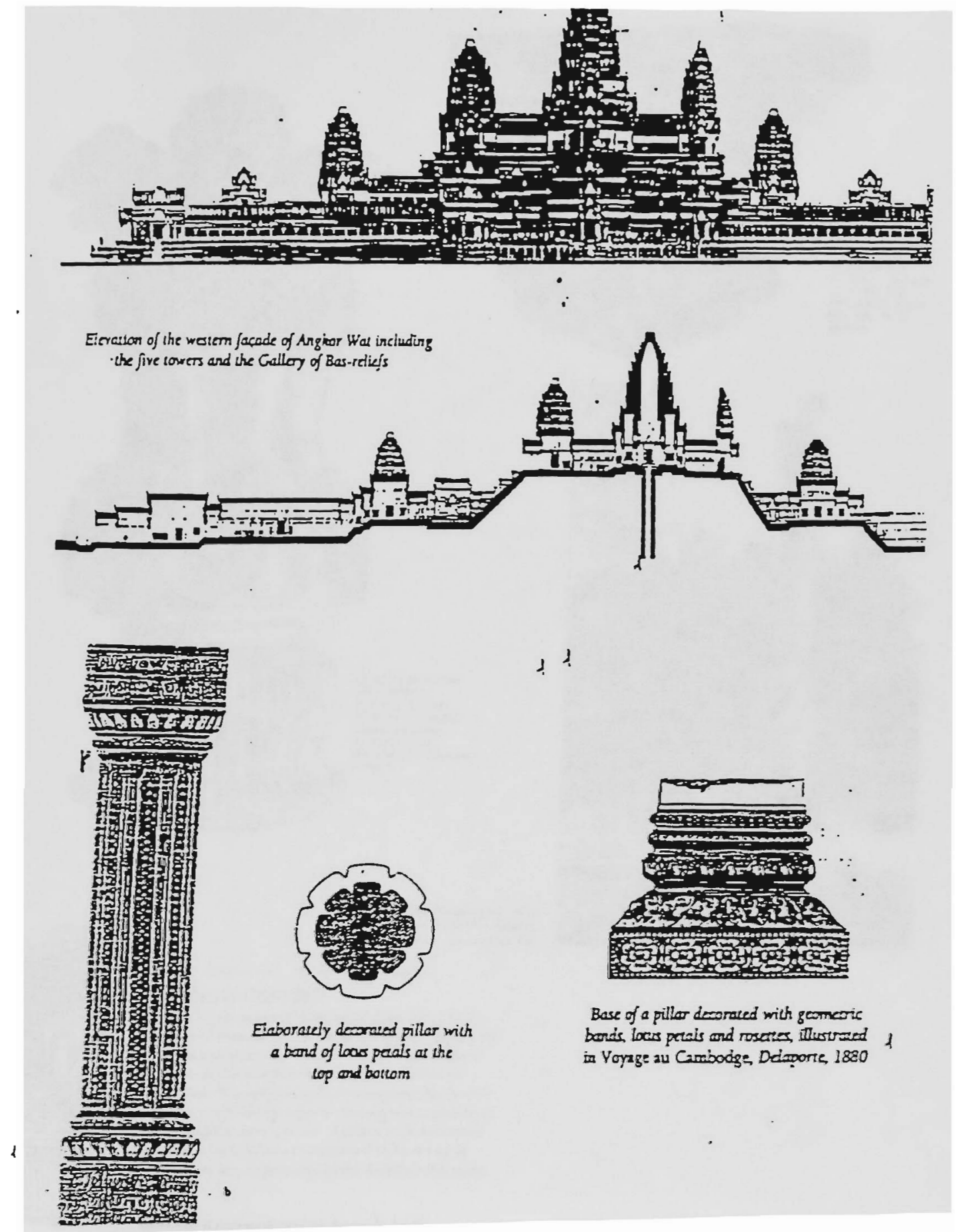

B10. Handout provided to students in the experimental class to go with lesson two. 


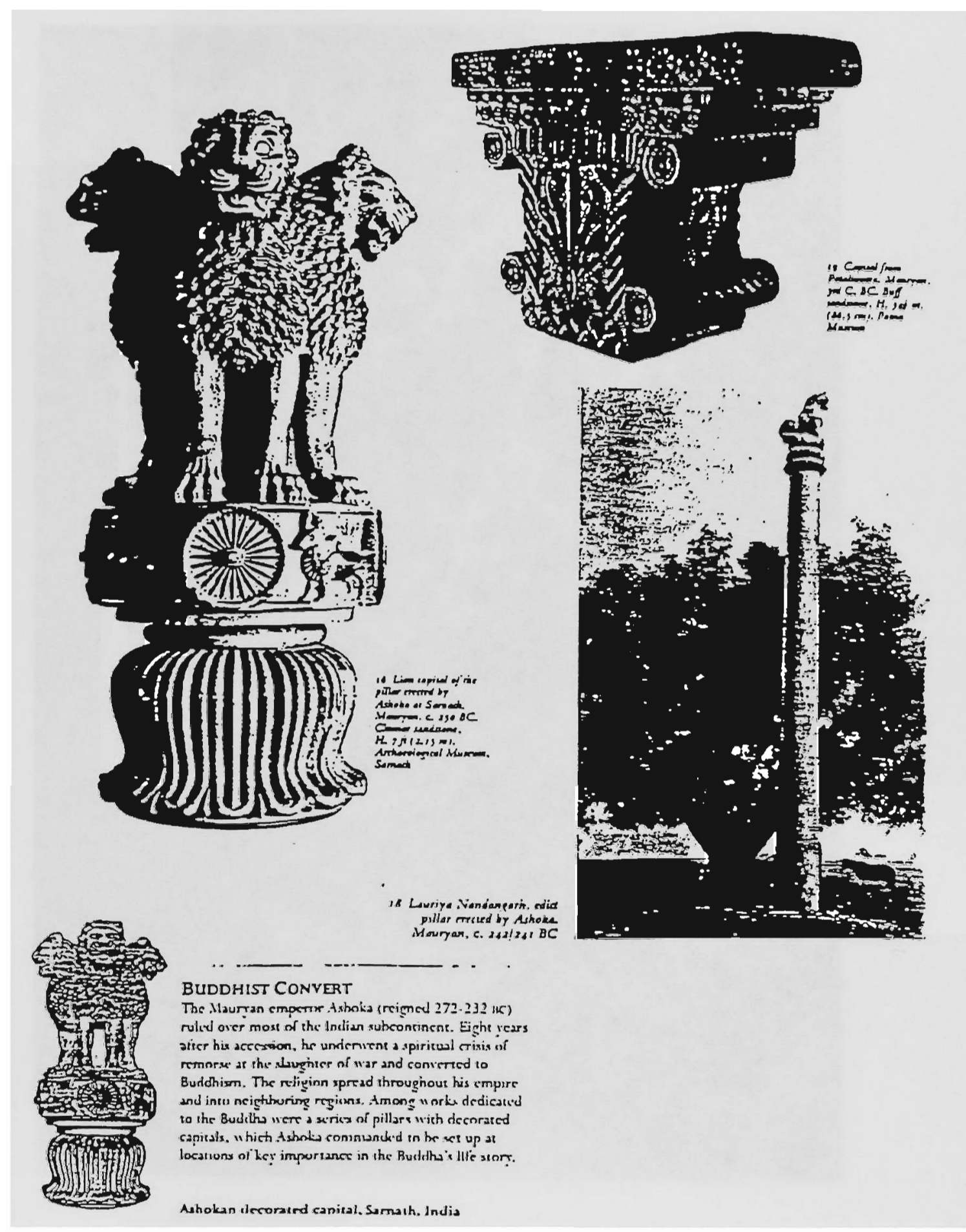

B11. Handout provided to students in the experimental class to go with lesson two. 


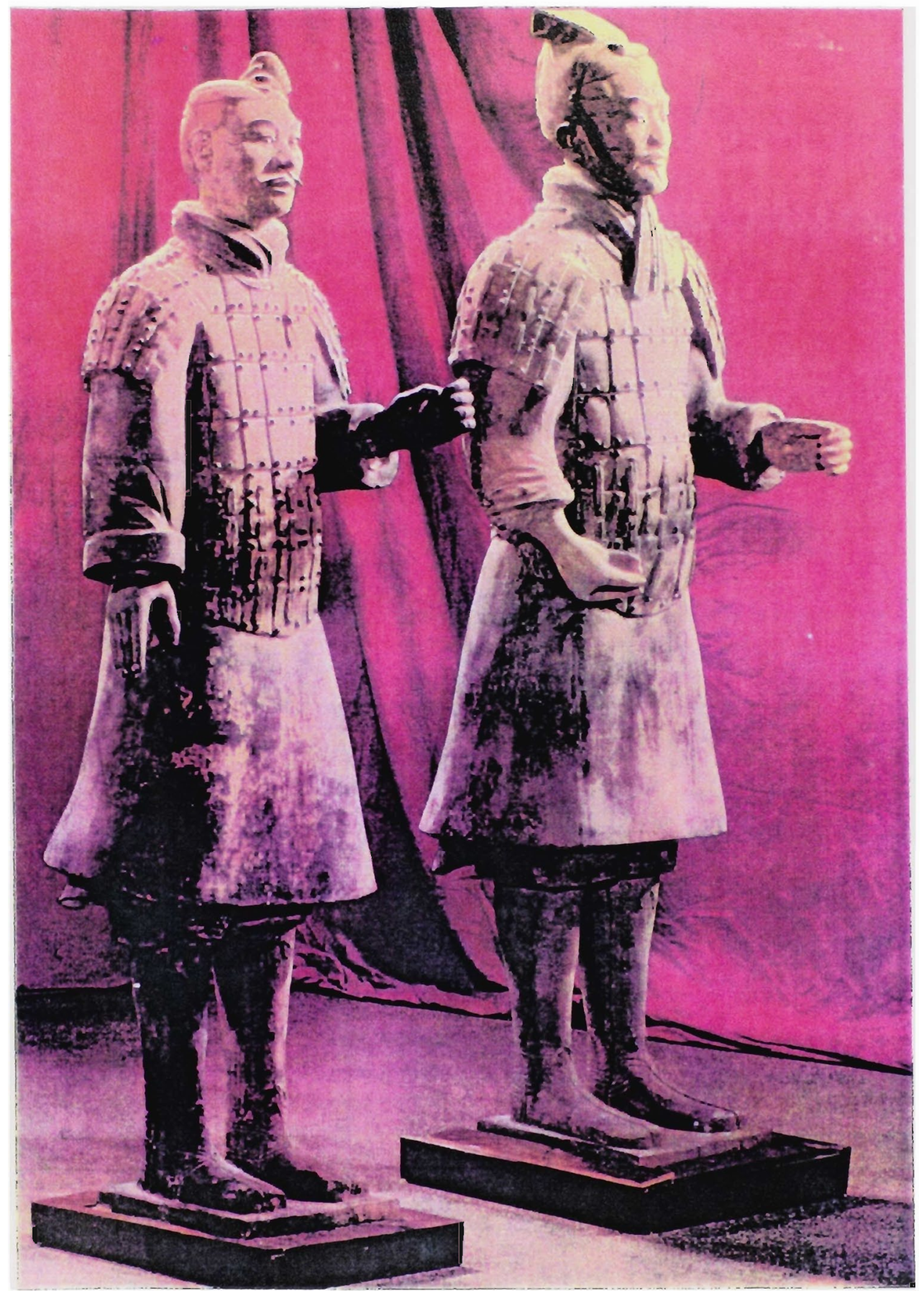

B12. Color transparency created as a visual aid for the experimental group classes depicting the terracotta warrior figures of the Qin emperor of China. This was to be contrasted with Winged Victory in lesson three. 


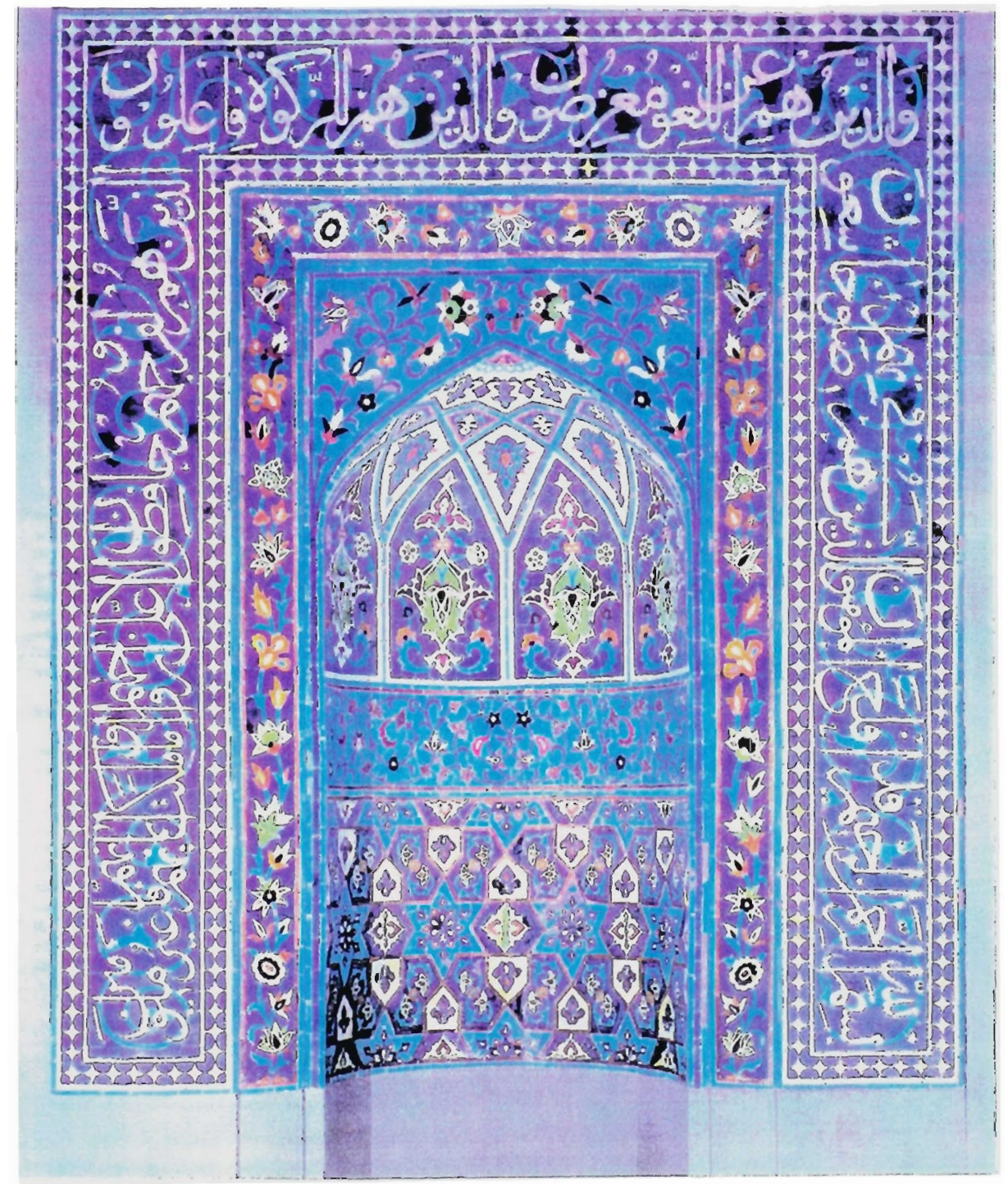

B13. Color transparency created for the experimental group classes depicting Islamic mosaic work. This was to be contrasted with the Byzantine mosaic work and used with lesson four. 


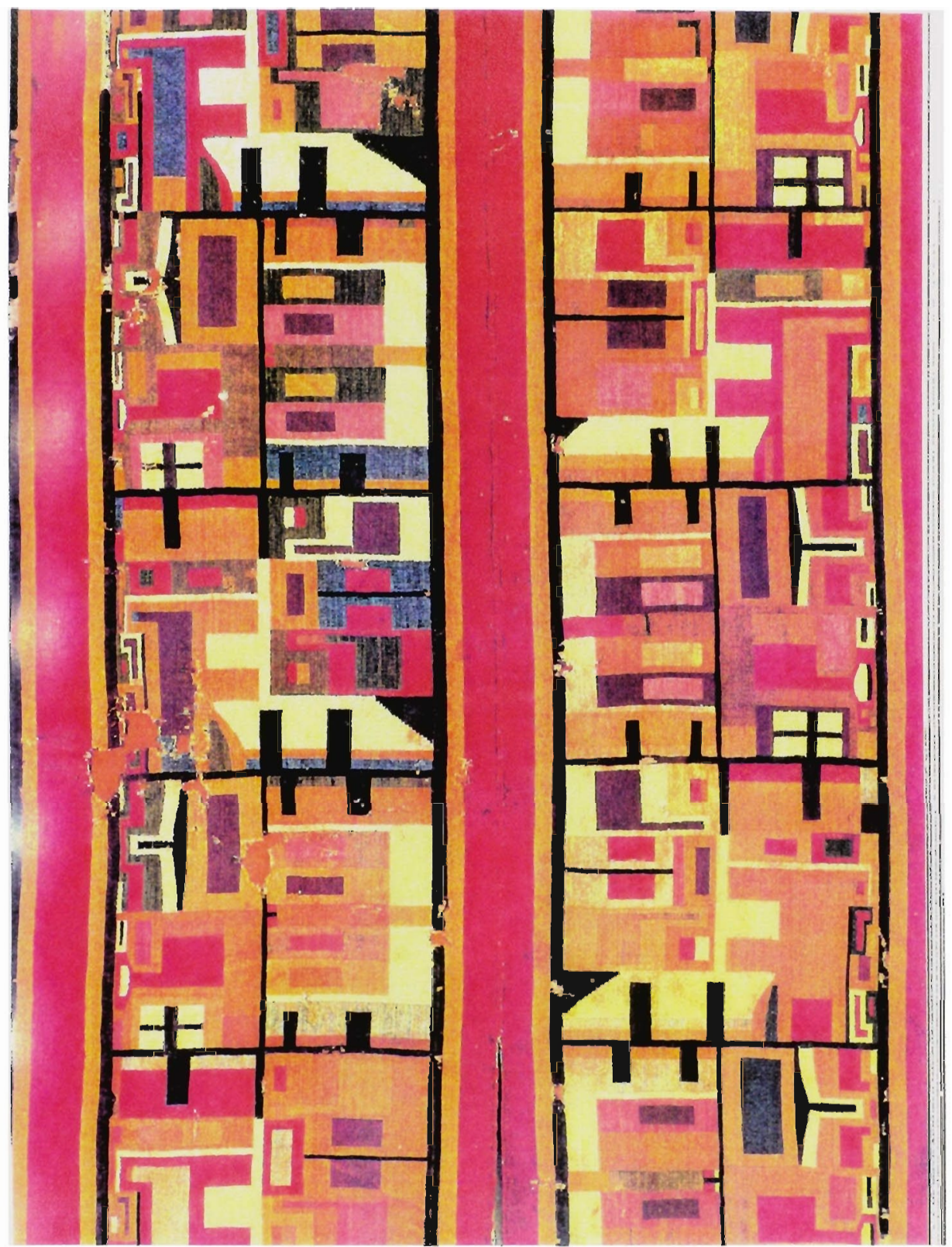

B14. Color transparency created for the experimental group classes depicting the geometry of Inca textile work. This was to be contrasted with the geometry in the work of Giotto and used with lesson six. 


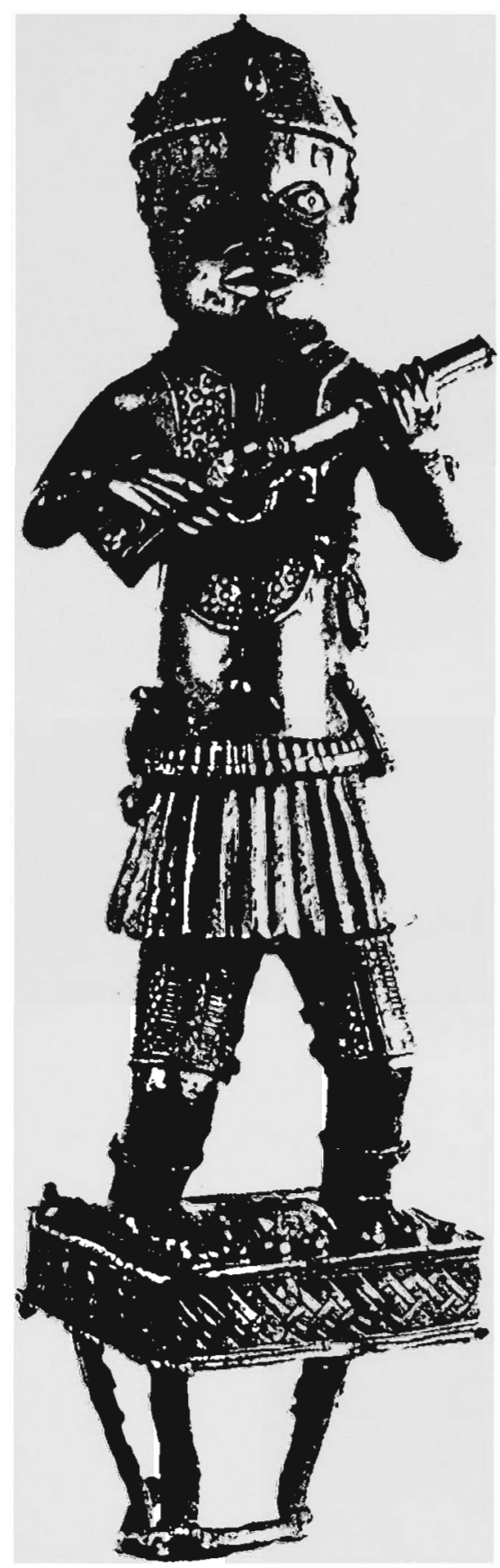

B15. Laminated visual aid created for the experimental group classes depicting a bronze of a Benin warrior. This is to be contrasted with the bronze of Verrocchio David and used for lesson nine. 


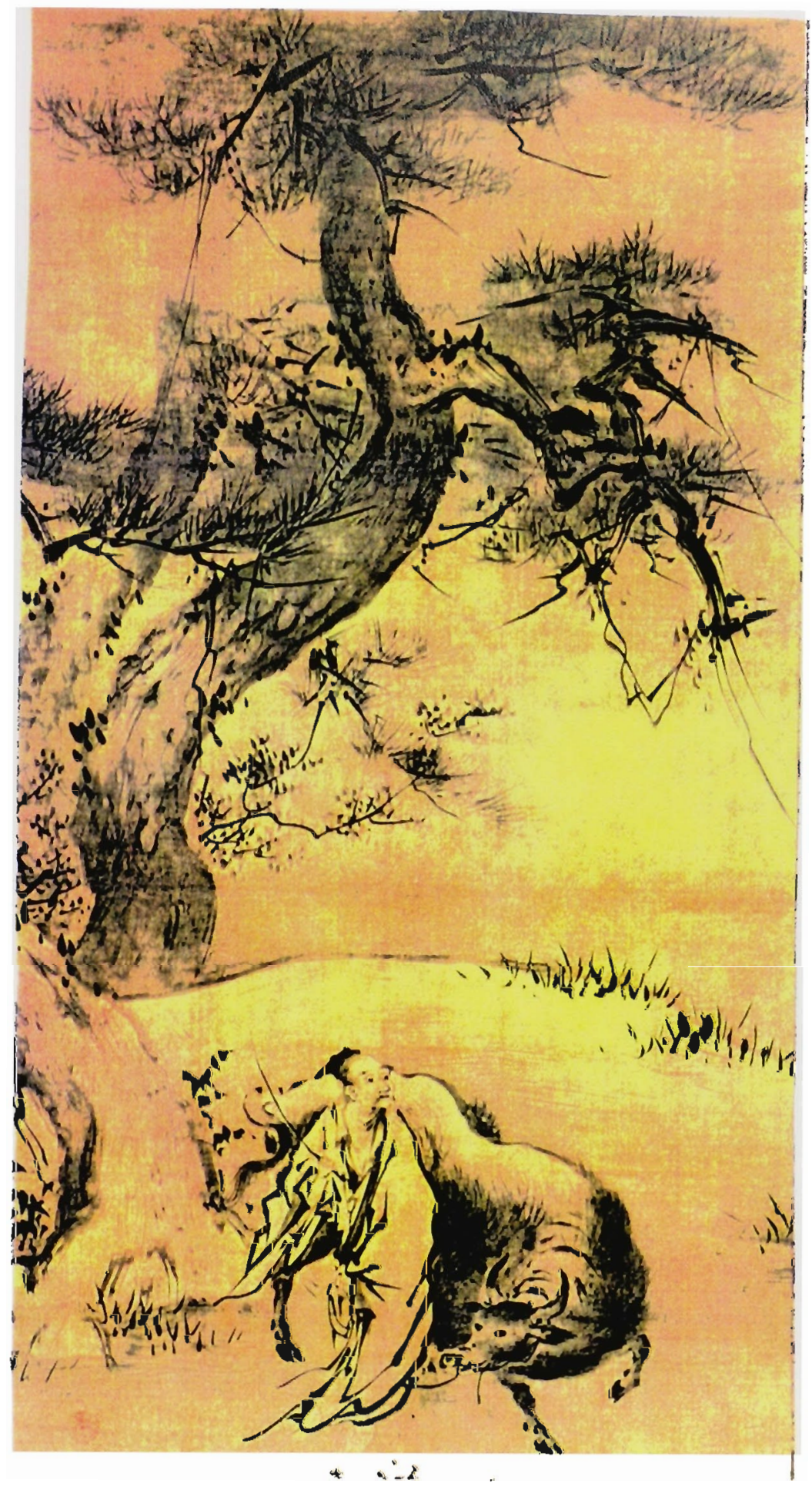

B16. Laminated visual aid created for the experimental group classes depicting a Chinese art rendition of a hermit on the mountain. This is to be contrasted with Dürer's St. Jerome and used with lesson ten. 


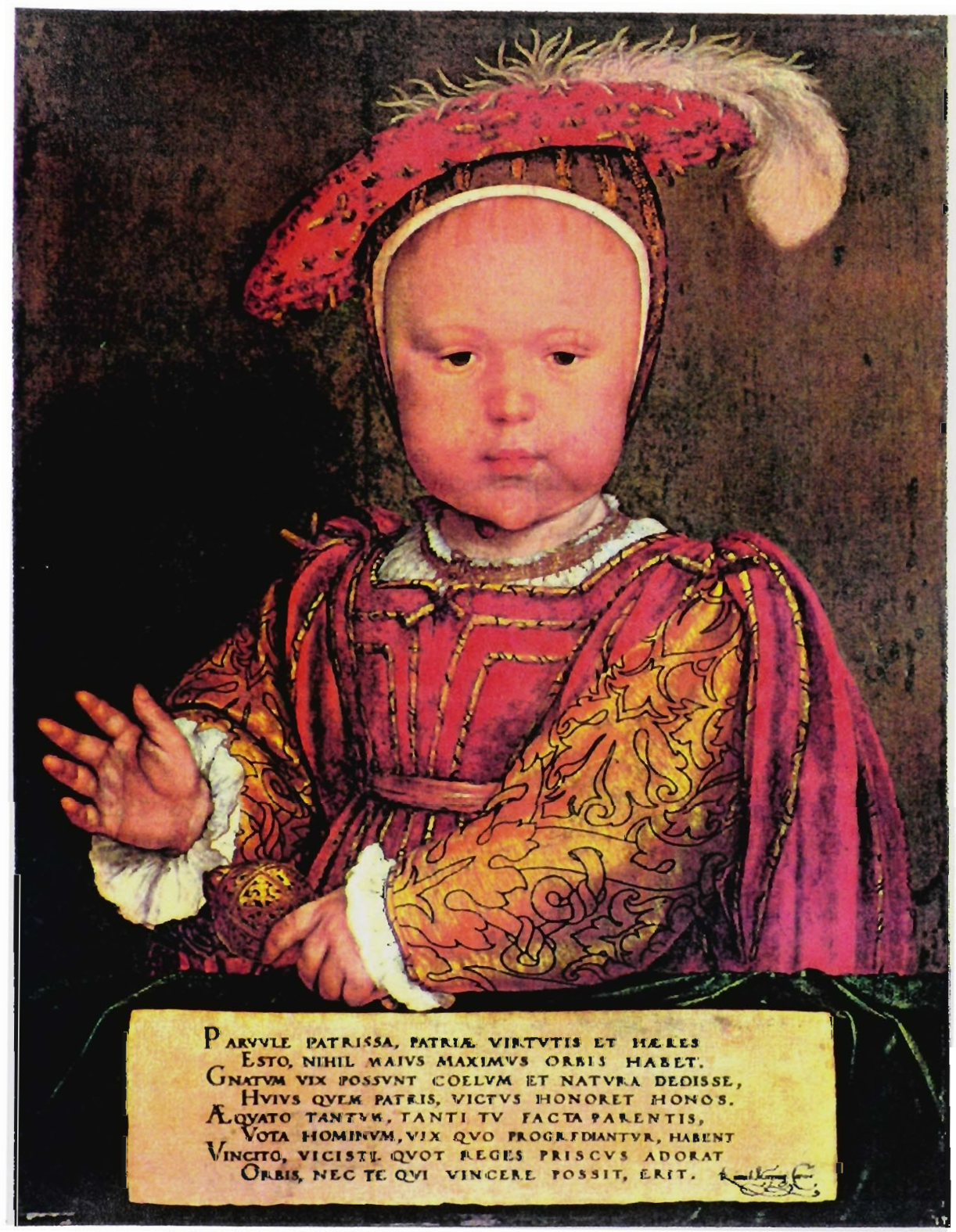

B17. Visual aid showing Edward VI as a child by Hans Holbein. This is an image provided by the teachers at the site and used with both experimental and control groups for lesson 11 . 


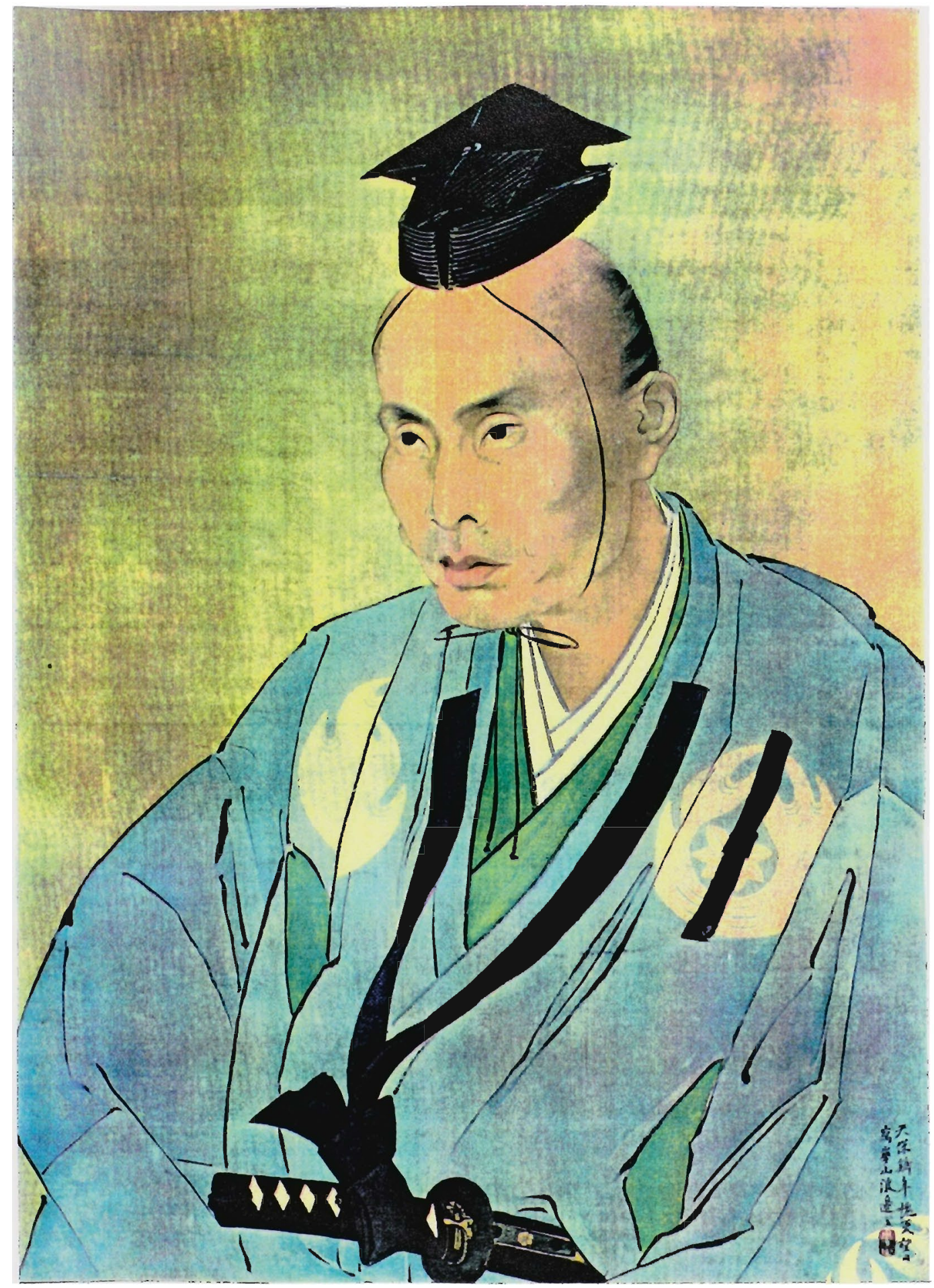

B18. Laminated visual aid created for the experimental group classes depicting a portrait of Takami Senseki by Japanese artist Watanabe Kazan. This is to be contrasted with the Holbein portrait and used with lesson 11. 


\section{APPENDIX C}

List of Cultures used to Augment the Art Curriculum and Sample Lessons for the Augmented Art Curriculum Classes 
Lesson one -- Hieroglyphics : Maya and Aztec cultures can be added to the Egyptian culture when studying hieroglyphics.

Lesson two -- Columns: Indian and Cambodian cultures can be added to the Greek culture when studying columns.

Lesson three -- Figures in the round: The culture of China can be added to that of Greece when studying figures in the round.

Lesson four -- Mosaics: Islamic cultures can be added to Byzantine culture.

Lesson five -- Sculpture based on Triangles: cultures of Japan, Java, Burma, and Thailand can be added to India when studying the Buddha.

Lesson six -- Geometry and art: The culture of the Inca in Peru can be added to Early European Renaissance when studying geometry in art.

Lesson seven -- Geometry and Symmetry: The Central American culture of The Cuna Indians can be added to European culture when studying the geometric concept of symmetry in art.

Lesson eight -- Perspective: The culture of the European Renaissance and that of China and Japan can be added to that of the Persians when studying the types of perspective used in art.

Lesson nine -- Image of the warrior: The culture of Benin in Africa can be added to western culture when studying warrior images.

Lesson ten -- Line: The culture of Japan can be added to western European culture when studying how line is used to build a picture.

Lesson eleven -- Portrait: The culture of Japan can be added to western European culture when studying the art of portraiture.

C1. List of Cultures used in augmenting the beginning art curriculum. 
Flipped Symmetrical Designs Based on Hierogtyphics

Art Historical Introduction: Show students the visual of Dedu and his wife. Give some background about Egyptian art and hieroglyphic writing. Explain to the students that other civilizations also built pyramids (theMayan and the Aztec) and also used hieroglyphics as a form of written language. You can show students the timeline to make the point about parallet developments in art by different cultures. Or, you can use the overhead transparencies of the Mayan and Aztec hieroglyphic symbols to compare and contrast with the Egyptian hierogtyphics.

Art Assignment: The student will develop a drawing that is basically a flipped symmeutcal design using a hieroglyphic symbol as the basic design unit. The student may choose from either Egyptian, Mayan, or Aztec hieroglyphic symbols for their basic design unit, which they will repeat, and flip to create a symmetrical design.

Art History Assignment: The student will complete the questions that go with the art history lecture and handout given by the teacher.

Assessment: The art assignment if done correctly, will generate a drawing that shows a repeated symmetrical design, with one hierogtyphic symbol used as the basic design unit. The drawings should look much like a wallpaper pattern. The art history assignment will be scored objectively on the number of correct answers to the questions given.

C2. Lesson plans. 


\title{
Colonnade Design
}

\begin{abstract}
Art Historical Introduction: Show students visuals of the Parthenon and discuss the three orders of Greek columns - Doric, Ionic, and Corinthian. Talk about the architectural elements of the Parthenon and what constitutes a colonnade. At the same time mention that in other parts of the world columns are also used as important architectural elements. Show visuals of the Indian column of Ashoka, and the Cambodian columns found at Angkor Wat.
\end{abstract}

Studio Assignment: The student will choose a column style from among the three Greek styles, or the Indian or Cambodian style and create a design that is based on the idea of a colonnade. After the design is drawn on the paper the student may either use color or shading on the negative space, or the columns themselves to accentuate the design.

Art History Assignment: The student will complete the questions that go with the handout they received on the Parthenon and the various column styles.

Assessment: The studio component will be evaluated to see that the student has created an all-over design based on a colonnade and using just one particular column style. The student's use of color or shading should add to the feeling of mythm and pattern created by the design. The art history component will be evaluated objectively based on giving the correct answers to the written questions according to the teacher's answer key.

C2. Lesson plans continued. 


\section{APPENDIX D}

Samples of Student Art Work 


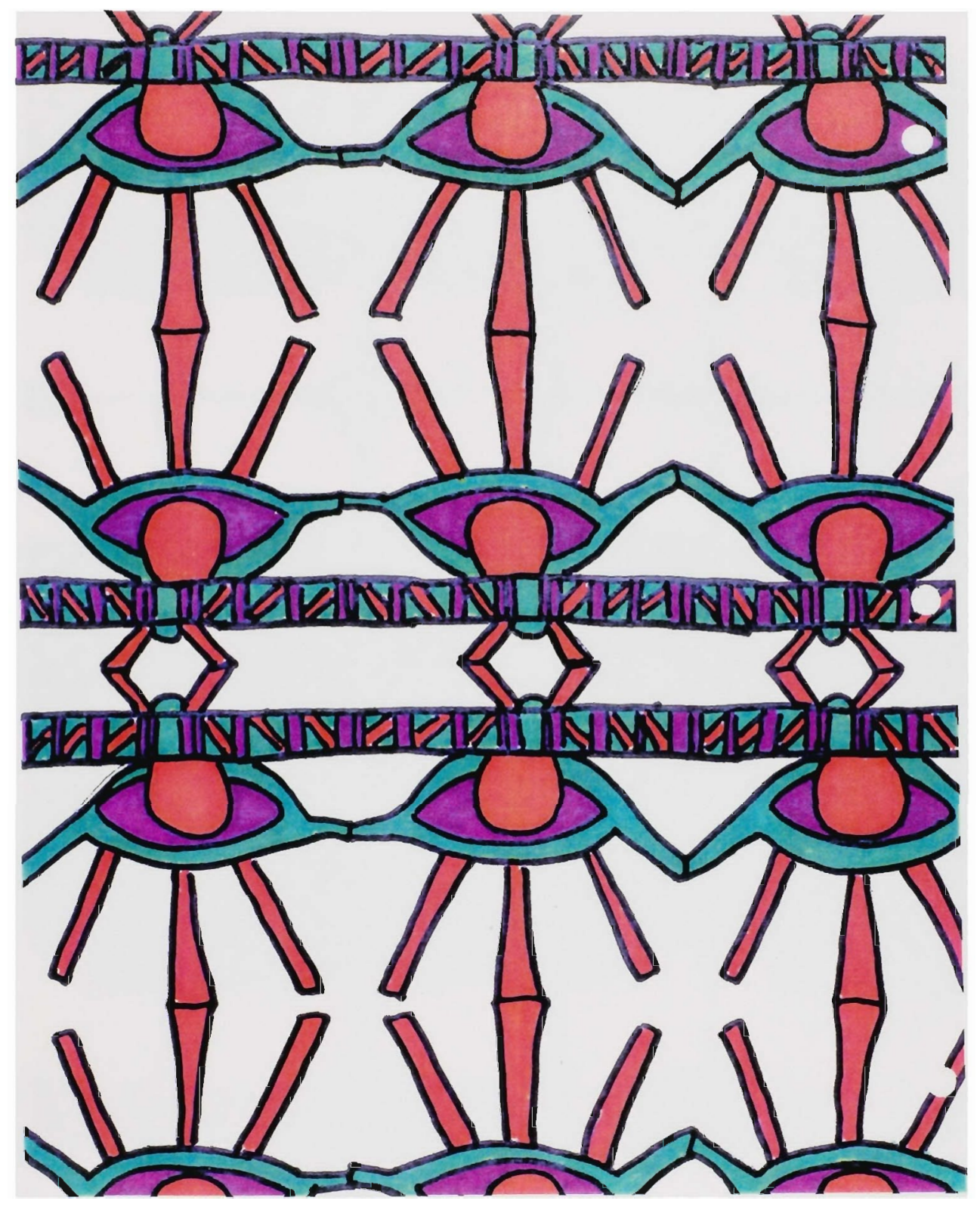

D1. Sample student art work from lesson one showing elements indicative of traditional art instruction. 


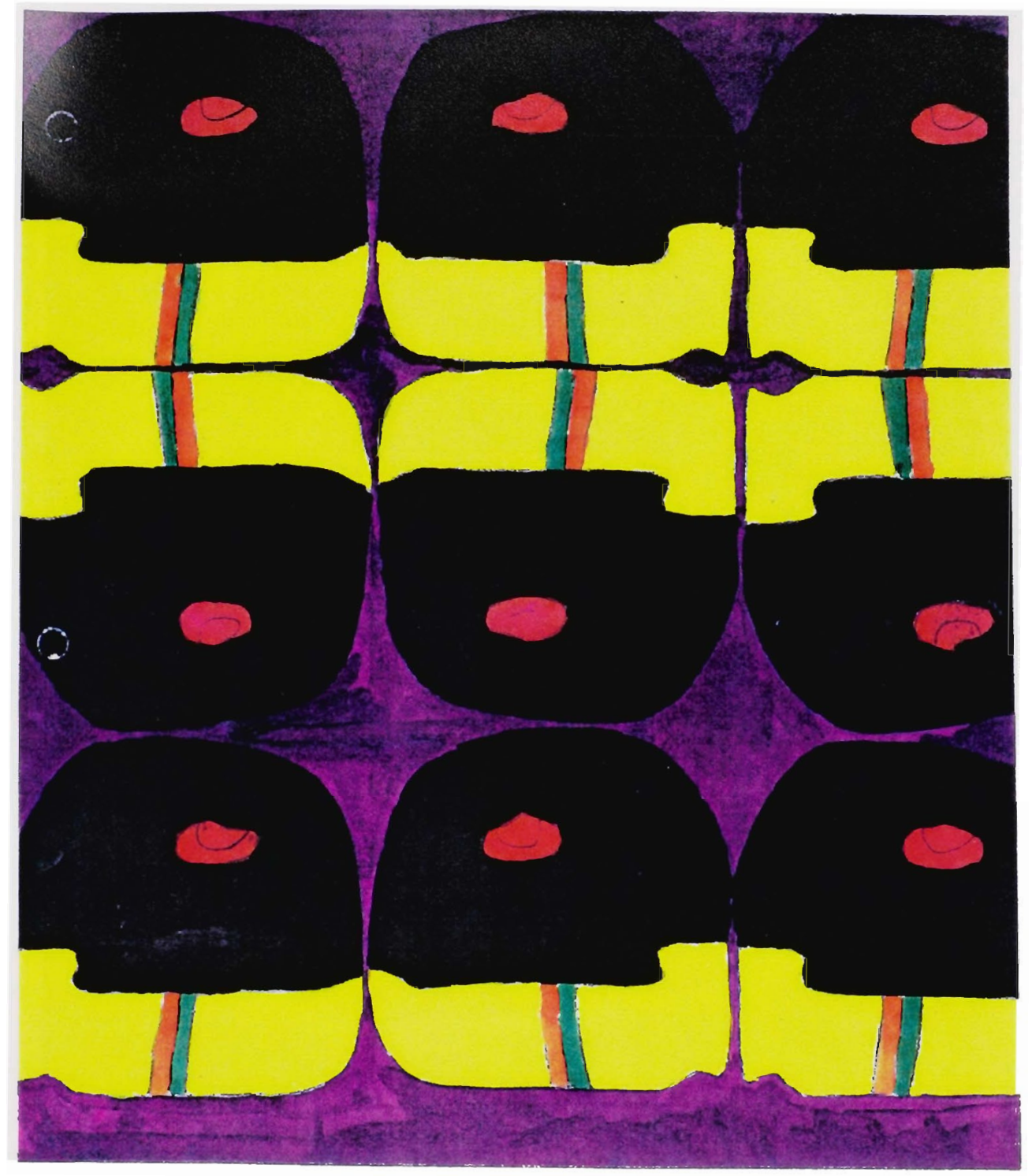

D2. Sample student art work from lesson one showing elements indicative of culturally augmented art instruction. 


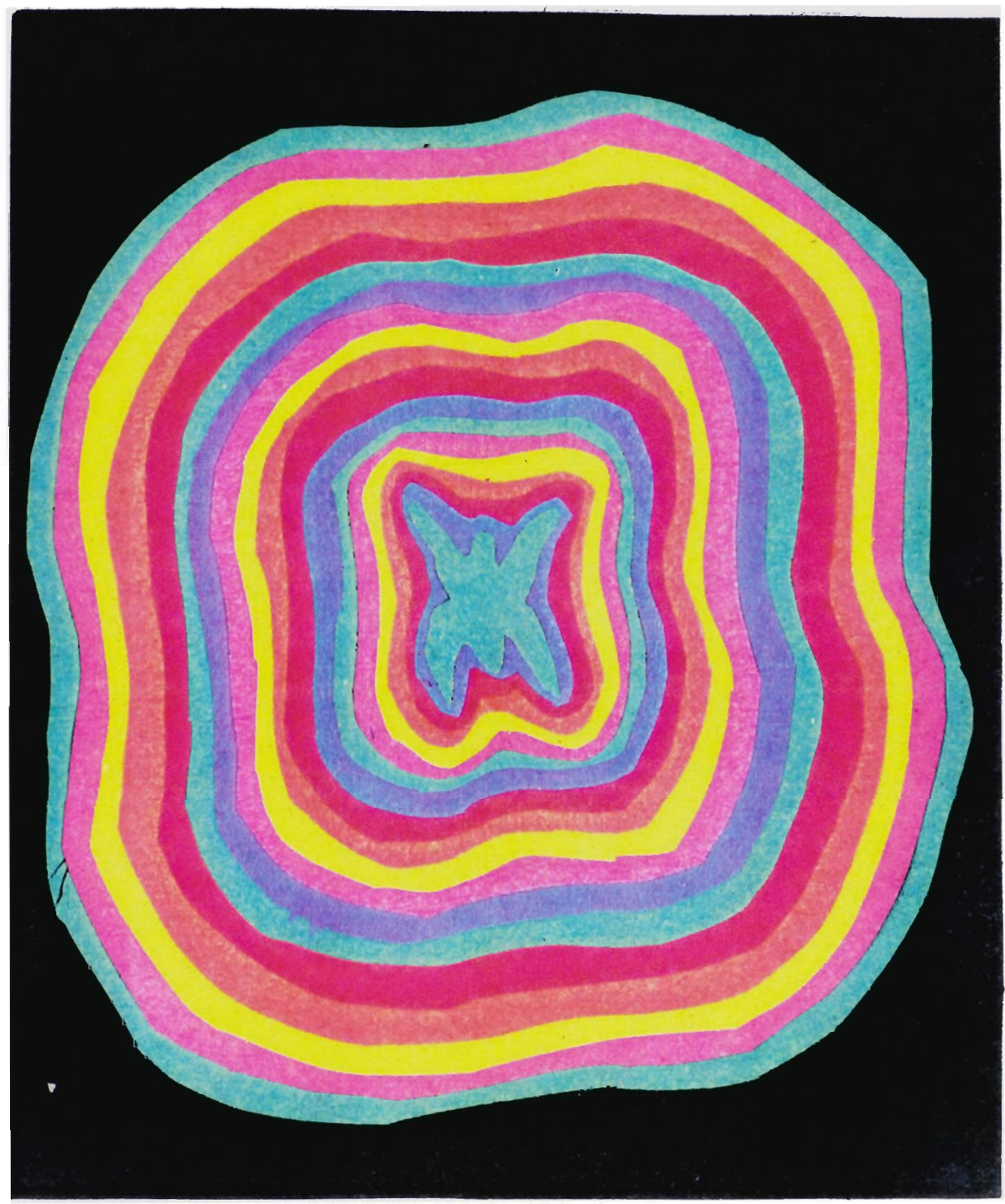

D3. Sample student art work from lesson seven showing elements indicative of culturally augmented art instruction. 


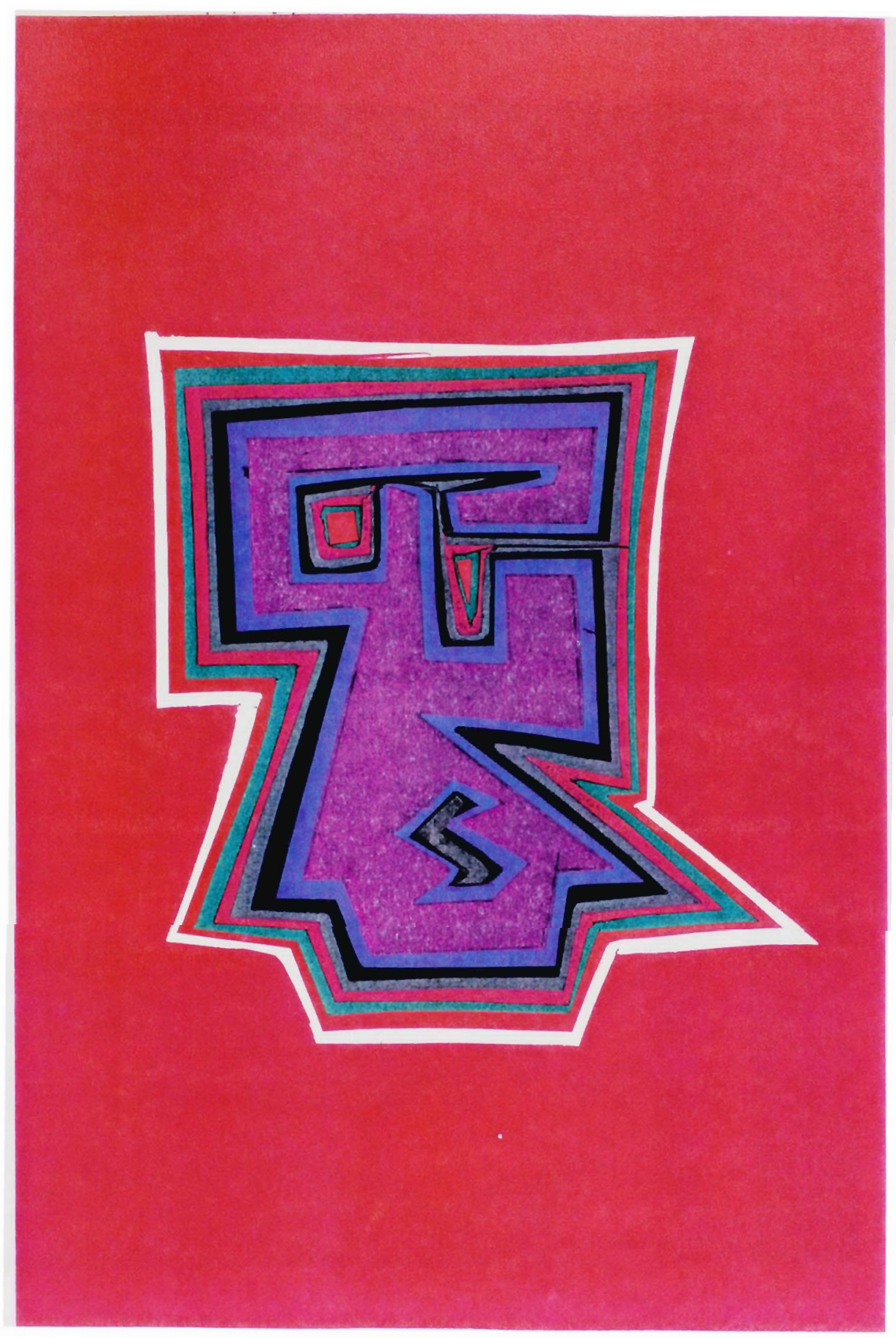

D4. Sample student art work from lesson seven showing elements indicative of culturally augmented art instruction. 


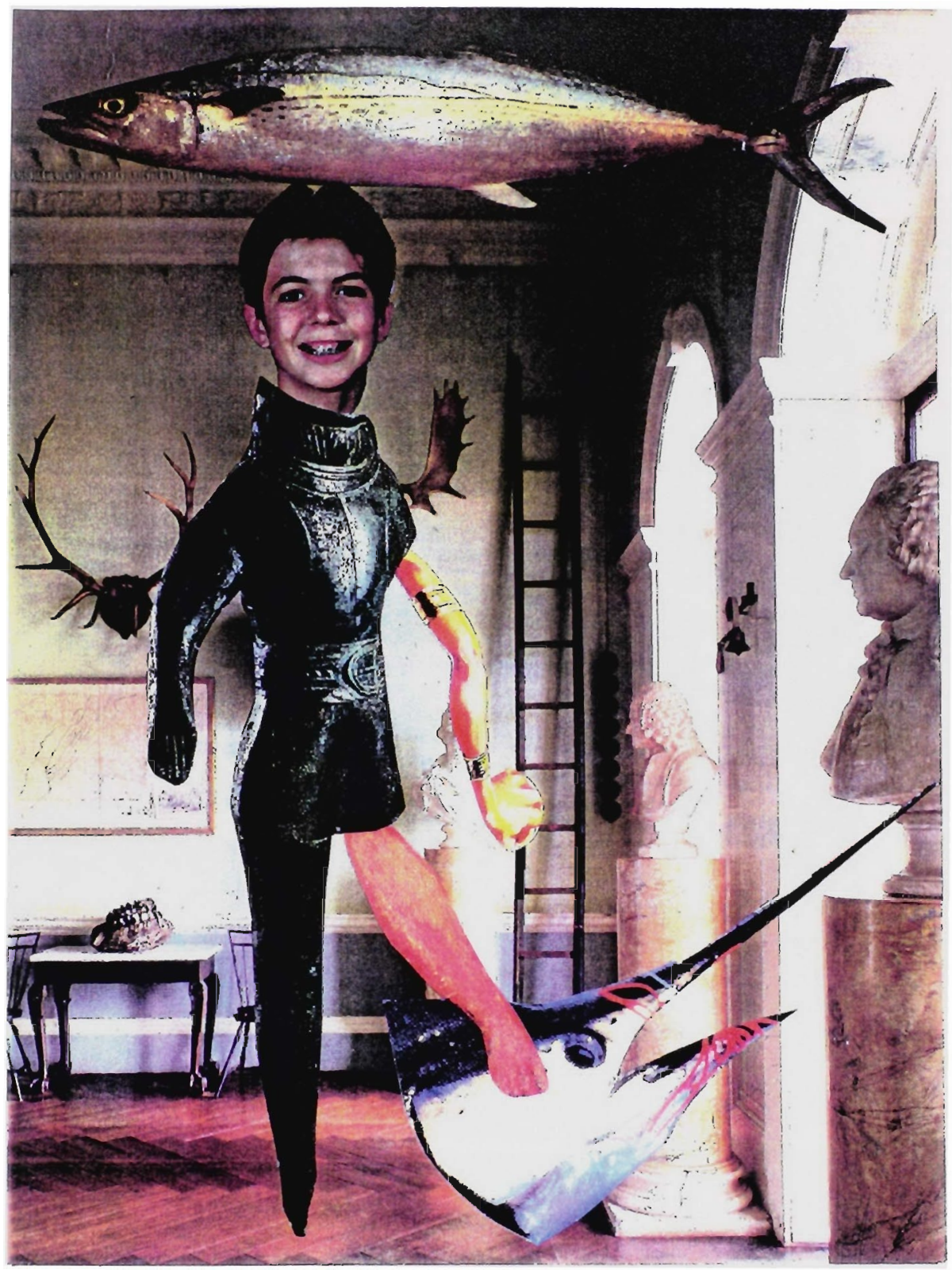

D5. Sample student art work from lesson nine showing a synthesis of traditional and culturally diverse art elements. 


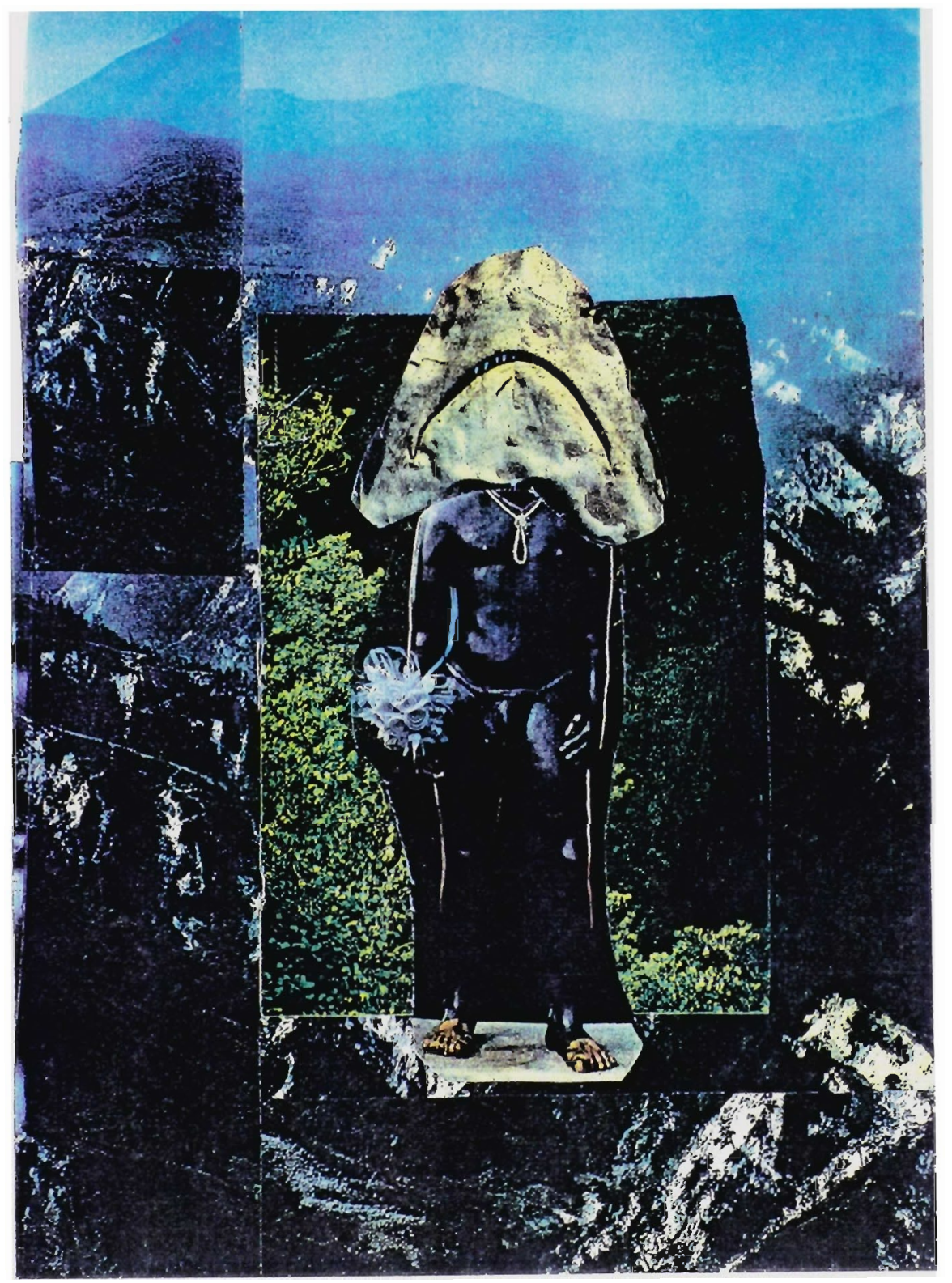

D6. Sample student art work from lesson nine showing a synthesis of traditional and culturally diverse art elements. 


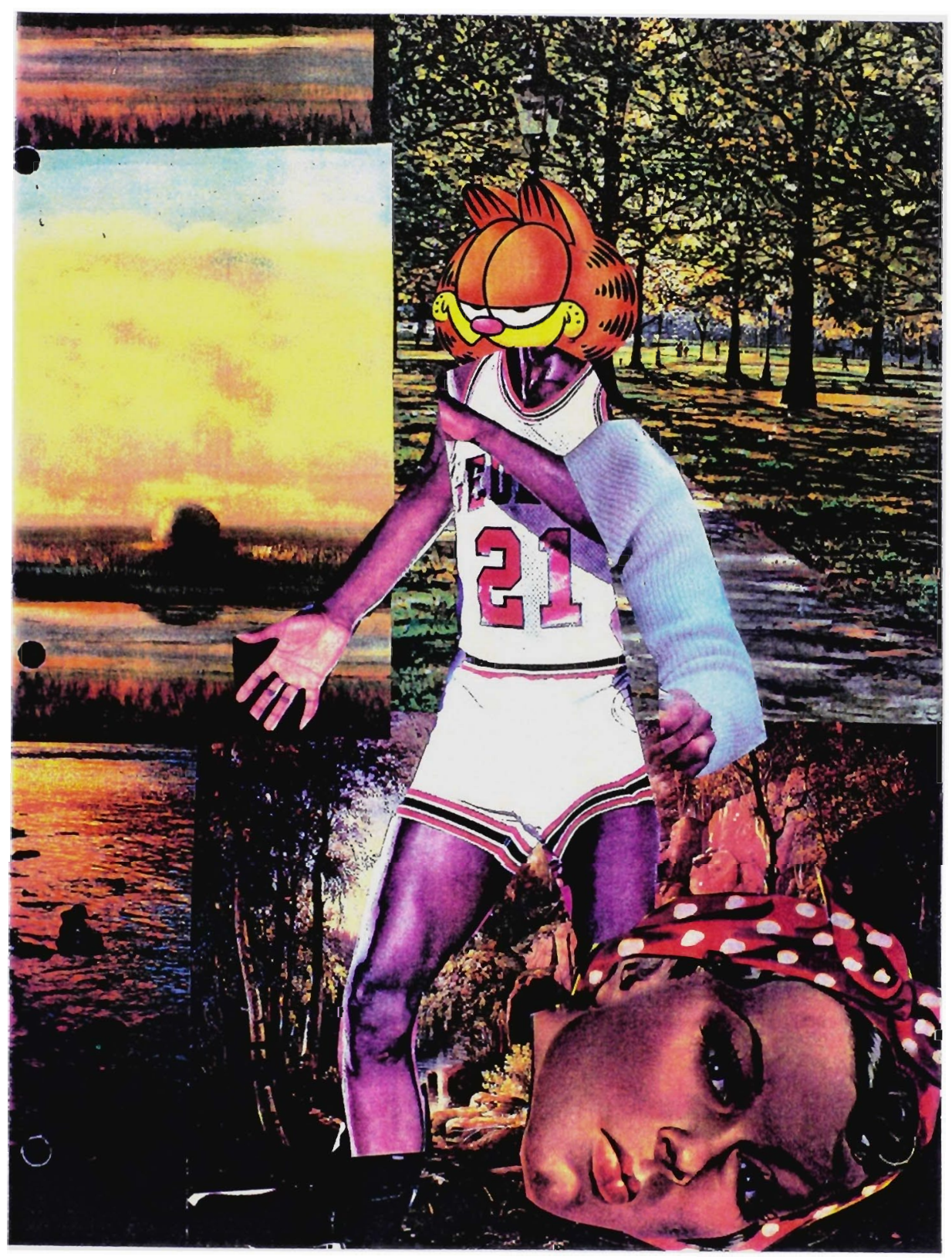

D7. Sample student art work from lesson nine showing a synthesis of traditional and culturally diverse art elements. 


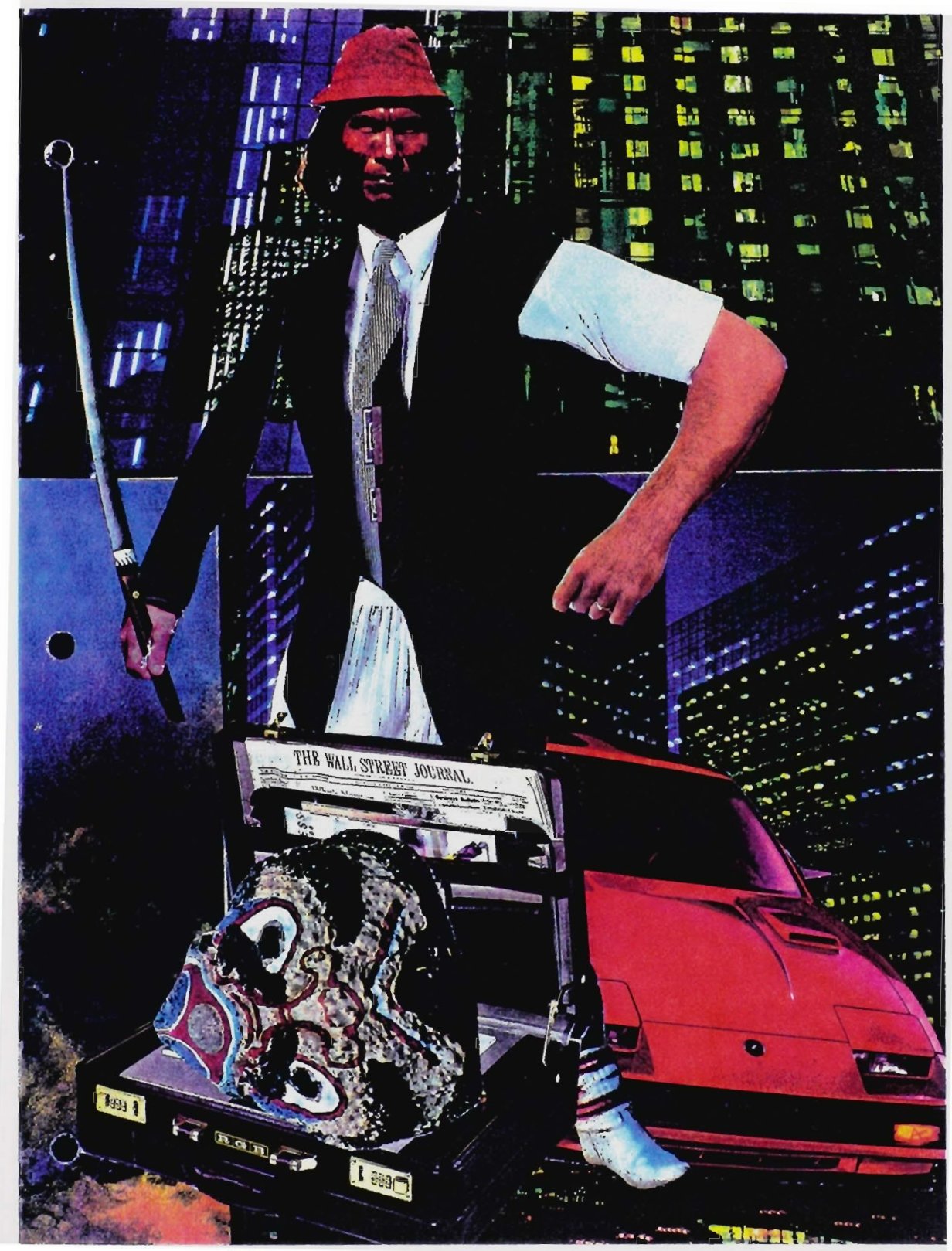

D8. Sample student art work from lesson nine showing a synthesis of traditional and culturally diverse art elements. 


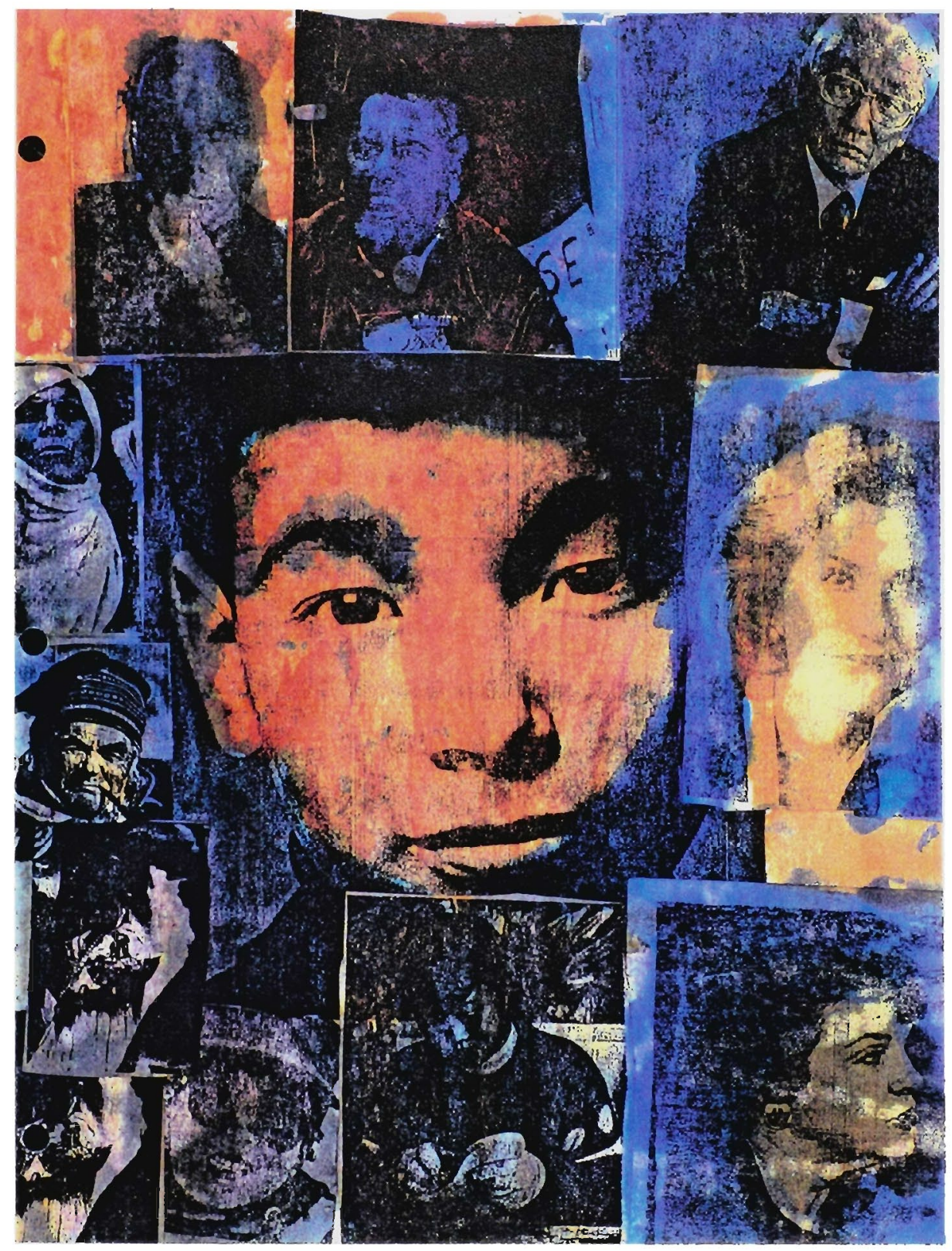

D9. Sample student art work from lesson 11 showing both traditional western and culturally diverse portrait images. 


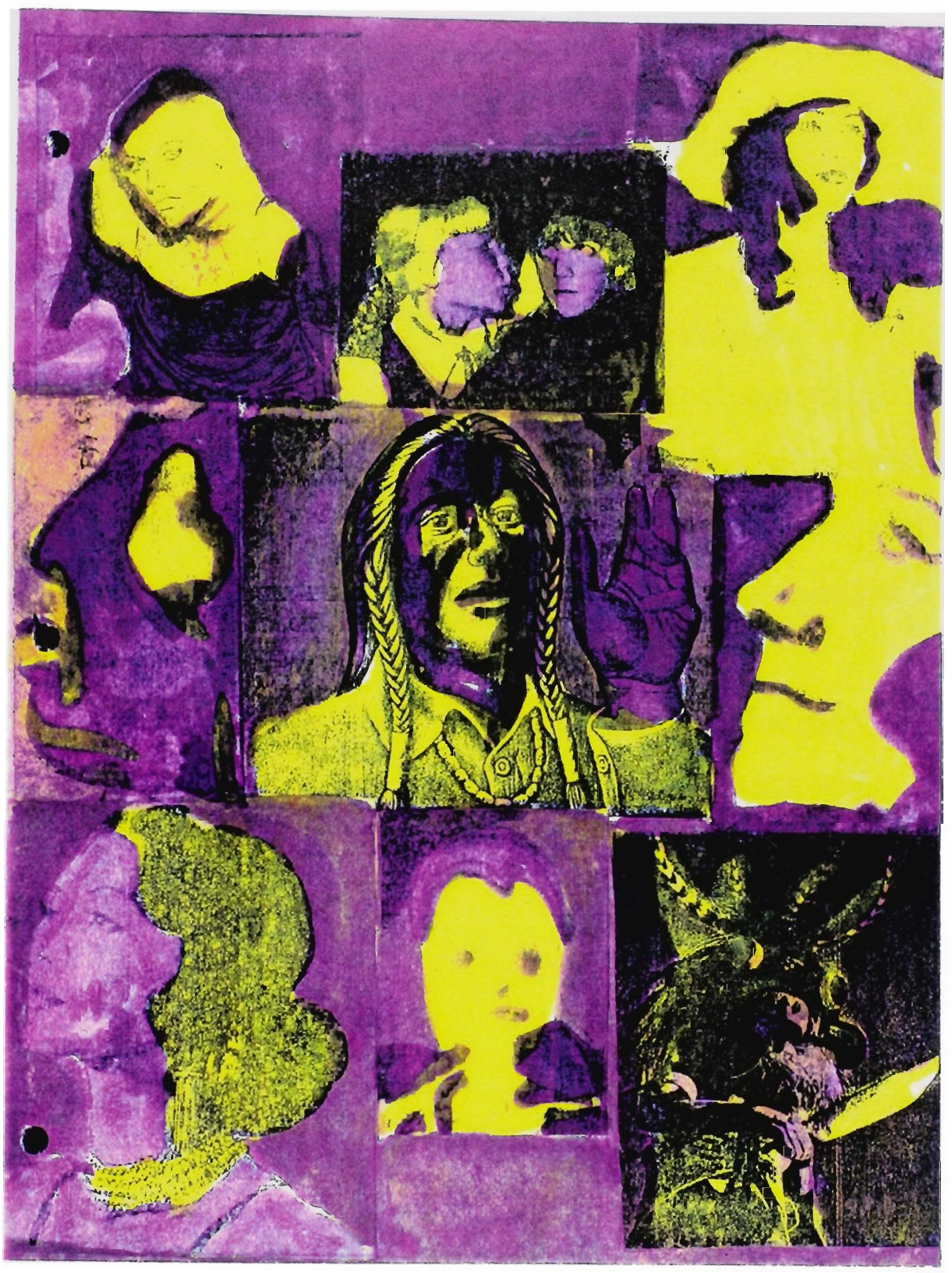

D10. Sample student art work from lesson eleven showing both traditional western and culturally diverse portrait images. 
January 19,1951

1972

$1979-1983$

1989

1991

1992
MS., Art Education

Florida International

University, Miami, Florida

Art Teacher

Hallandale High School

Hallandale, Florida 


\section{PRESENTATIONS}

Alvarez, A. A., \& Gambill, B. (Fall, 1990). A Multicultural Art Curriculum K-5. Paper presented at the meeting of the Florida Art Education Association, Miami, Florida.

Alvarez, A. A., \& Gambill, B., (Fall 1990). Kites and Kachinas. Art workshop presented at the meeting of the Florida Art Education Association, Miami, Florida.

Alvarez, A. A., (Spring 1991). Multiple Exposure: Multicultural or Global Art Education -- A Curriculum Guide for Grades 9 - 12. Paper presented at the meeting of the National Art Education Association, Atlanta, Georgia. 